\title{
Helechos y Licófitos de la Reserva de la Biosfera Los Tuxtlas, Veracruz, MÉXico
}

\author{
Amparo R. Acebey ${ }^{1,3}$, Thorsten Krömer ${ }^{1}$, Mario VÁzquez-Torres ${ }^{1}$ \\ y J. DANIEL Tejero-Díez ${ }^{2}$ \\ ${ }^{1}$ Centro de Investigaciones Tropicales, Universidad Veracruzana, Xalapa, Veracruz, México \\ ${ }^{2}$ Facultad de Estudios Superiores Iztacala, Universidad Nacional Autónoma de México, Los Reyes Iztacala, \\ Estado de México, México \\ ${ }^{3}$ Autor para la correspondencia: cacebey@gmx.net
}

\begin{abstract}
Resumen: Se presenta un listado actualizado de los helechos y licófitos de la Reserva de la Biosfera Los Tuxtlas, producto tanto de trabajo de campo como de la revisión de 1,380 ejemplares de herbario y literatura. Se registraron 246 taxones, distribuidos en 73 géneros y 24 familias, los cuales representan el 43 y $24 \%$ de la pteridoflora del estado de Veracruz y de México respectivamente. Se encontraron 35 nuevos registros para la Reserva, incluyendo dos para Veracruz (Elaphoglossum glabellum y E. pringlei). Las familias más numerosas fueron Polypodiaceae (39 especies), Dryopteridaceae (32) y Pteridaceae (31), mientras que los géneros más numerosos fueron Asplenium (22), Thelypteris (18), Trichomanes (13) y Elaphoglossum (12). Se registró un bajo porcentaje de especies de amplia distribución (7\%), el 58\% crecen de México hasta Sudámerica, el 23\% en México y Centroamérica y el 7\% son endémicas de México. La distribución altitudinal muestra una mayor riqueza entre 760 y 1,200 m; los tipos de vegetación con mayor número de especies fueron el bosque mesófilo de montaña (134) y la selva alta perennifolia (115); la alta riqueza de especies en esta última formación vegetal destaca su valor para la conservación. La Reserva presenta un alto nivel de epifitismo (37.4\%), particularmente en el bosque mesófilo de montaña. Se considera que el $65 \%$ de los taxones son raros o muy raros, probablemente por la especificidad de su hábitat.
\end{abstract}

Palabras clave: conservación, distribución, epífitas, pteridofitas, riqueza de especies

\begin{abstract}
We present an updated list of ferns and lycophytes from the Los Tuxtlas Biosphere Reserve, product of extensive field work and review of 1,380 herbarium specimens and literature. We recorded 246 taxa, distributed in 73 genera and 24 families, representing 43 and 24\% of the pteridophytes of Veracruz State and Mexico, respectively. We found 35 new records for the Reserve, including two for Veracruz (Elaphoglossum glabellum y E. pringlei). Polypodiaceae (39 species), Dryopteridaceae (32), and Pteridaceae (31) were the largest families, whereas Asplenium (22), Thelypteris (18), Trichomanes (13) and Elaphoglossum (12) were the most species-rich genera. A low percentage of widespread species (7\%) was recorded, 58\% occur in tropical America mainly from Mexico to South America including the West Indies, 23\% in Mexico and Central America, and 7\% are endemic to Mexico. The altitudinal distribution shows the highest species-richness between 760 and 1,200 m elevation; the most species-rich vegetation types were the humid montane forest (134) and tropical lowland rainforest (115), the latter contains a high number of species, which highlighs its value for conservation. Furthermore, a high level of epiphytism (37.4\%) stands out, particularly among humid montane forest species. We consider $65 \%$ of the taxa as rare or very rare, probably due to their habitat specificity.
\end{abstract}

Key words: conservation, distribution, epiphytes, pteridophytes, species-richness

S e estima que la diversidad de helechos y licófitos a nivel mundial oscila entre 11,000 y 15,000 especies (Smith et al., 2006; Kreft et al., 2010; Mehltreter, 2010), de los cuales 1,030 especies han sido registrados para México hasta el momento (Mickel y Smith, 2004; Tejero-Díez et al., 2014). Esto representa el $4.4 \%$ de la flora vascular de México, cal- culada en 23,359 especies (Villaseñor, 2003; Ramírez-Cruz et al., 2009). La mayor riqueza de helechos y licófitos en el Neotrópico tiende a concentrarse en las regiones húmedasmontañosas (Watkins et al., 2006; Salazar et al., 2015) y su aporte a nivel de las floras locales puede alcanzar entre el 13-22\% (Kelly et al., 1994; Kessler, 2010). En México, 
de acuerdo a Tejero-Díez et al. (2014), la pteridoflora del bosque mesófilo de montaña (BMM; 630 especies) llega a representar poco más del $10 \%$ de la flora vascular de este tipo de vegetación (Villaseñor y Gual-Díaz, 2014), aunque indican que oscila entre el diez hasta el $32 \%$ dependiendo del tipo de asociación de BMM.

El estado de Veracruz cuenta con 566 especies de helechos y licófitos, por lo cual ocupa el tercer lugar en términos de riqueza después de Oaxaca y Chiapas (Krömer et al., 2007a; Acebey y Krömer, 2010; Tejero-Díez et al., 2011; Krömer et al., 2013a). Esta alta riqueza es el producto de una amplia variedad de ambientes propiciados principalmente por una compleja topografía, una alta gama de climas y suelos (Soto-Esparza y Geissert, 2011), donde destaca la franja húmeda de la sierra Madre Oriental-Faja Transvolcánica, la cual contiene el $61 \%$ de la pteridoflora de este estado (Tejero-Díez et al., 2011). Sin embargo, al ser un área con alta presión antropogénica presenta un fuerte deterioro ecológico (CONABIO, 2010).

La sierra de Los Tuxtlas a pesar de los continuos procesos de deforestación y cambio del uso del suelo todavía conserva una parte considerable de sus paisajes naturales (Guevara et al., 2004). Esta región se caracteriza por poseer una notable diversidad de especies de plantas (3,356 taxones) y un alto endemismo de árboles (Rzedowski, 1991; Wendt, 1993; Castillo-Campos y Laborde, 2004). Se le considera el límite boreal extremo de la selva tropical en el continente americano (Dirzo y Miranda, 1991), y tiene una gran importancia biogeográfica debido a la presencia de elementos de fauna y flora muy peculiares con afinidad austral, boreal y endémica (Andrle, 1964). Para salvaguardar las particularidades de esta región y contrarrestar el deterioro ecológico, una gran parte de la misma fué declarada en 1998 como Reserva de la Biosfera y forma parte del Sistema Nacional de Áreas Naturales Protegidas (SINAP). Actualmente también es considerada una región terrestre prioritaria (RTP) para la conservación en México por la Comisión Nacional para el Conocimiento y Uso de la Biodiversidad (CONABIO) (Arriaga et al., 2000; Laborde, 2004).

Desde el punto de vista florístico, sólo la selva alta perennifolia de la Estación de Biología Tropical Los Tuxtlas (EBT) (Ibarra-Manriquez y Sinaca-Colín, 1995, 1996a, b) y la sierra de Santa Marta (Ramírez, 1999) han sido estudiadas en más detalle. Los trabajos específicamente sobre helechos y licófitos en la zona son escasos; en el listado de la EBT se incluyen 80 especies (Riba y Pérez-García, 1997), que representan poco más del $8 \%$ del número total de especies de plantas registradas para esta área. Por otro lado, Lira y Riba (1984) registraron 148 especies en diferentes tipos de vegetación de la sierra de Santa Marta. Sin embargo, estos trabajos en general fueron muy localizados y todavía no existe un listado florístico que integre, complemente y actualice la información acerca de la pteridoflora para la región de Los Tuxtlas.
El objetivo de este estudio fue revisar, complementar y actualizar el conocimiento de la riqueza, composición florística y taxonomía de los helechos y licófitos de la Reserva de la Biosfera de Los Tuxtlas y presentar información relevante sobre su distribución, hábitat y formas de crecimiento, así como de su estado de conservación.

\section{Materiales y métodos}

Área de estudio. La Reserva de la Biosfera Los Tuxtlas (RBLT) se encuentra ubicada en la región de la sierra de Los Tuxtlas, un macizo volcánico aislado que emerge de la llanura costera del Golfo de México, ubicado al sureste del estado de Veracruz entre los $18^{\circ} 30^{\prime}$ y $18^{\circ} 40^{\prime}$ latitud Norte y los $95^{\circ} 03^{\prime}$ y $95^{\circ} 10^{\prime}$ longitud Oeste (Figura 1). La RBLT tiene una superficie de 155,122 ha, de las cuales 125,403 ha representan la zona de amortiguamiento que envuelve a las tres zonas núcleo que constituyen las partes altas de los volcanes más grandes: (1) San Martín Tuxtla (1,680 m) con 9,805 ha, (2) sierra de Santa Marta (1,680 m) con 18,031 ha y (3) San Martín Pajapan (1,180 m) con 1,883 ha (Laborde, 2004). El relieve es variado, con un gradiente de altitud que abarca desde el nivel del mar hasta los 1,680 m. Los suelos son de origen volcánico y, al estar en un ambiente tropical, los horizontes se encuentran poco desarrollados y el contenido de materia orgánica es variable. Campos (2004) reconoce 18 tipos de suelo distribuidos en nueve grupos principales: Andosol, Feozem, Luvisol, Acrisol, Vertisol, Cambisol, Nitosol, Regosol y Litosol.

El clima de la región de Los Tuxtlas está fuertemente influenciado por el pronunciado gradiente altitudinal, su topografía compleja, y la proximidad al Golfo de México. La sierra es una barrera climática entre el mar y el interior del continente, situación que genera diferencias climáticas entre la vertiente noreste hacia el Golfo y la vertiente suroeste que

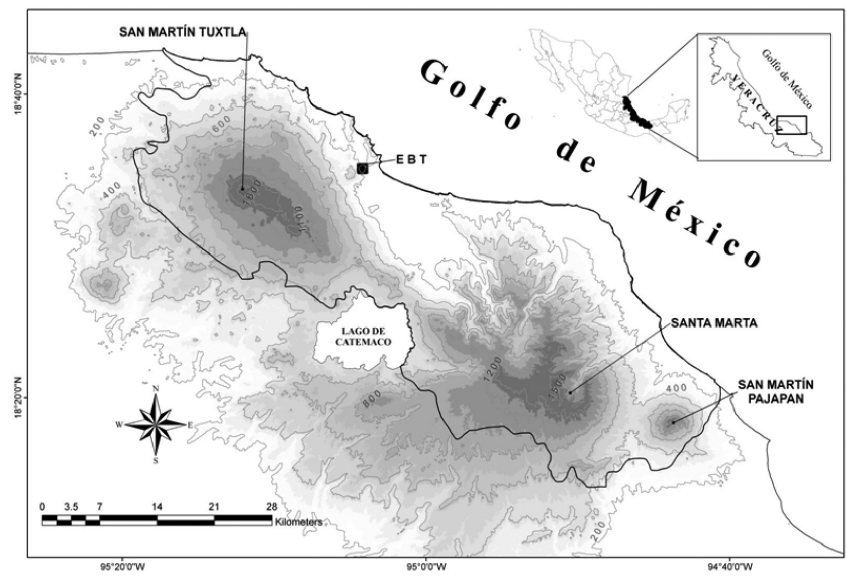

Figura 1. Mapa de la región de Los Tuxtlas, ubicado en el sureste del estado de Veracruz, México, resaltando la delimitación de la Reserva de la Biosfera (línea negra), los tres principales volcanes y la Estación de Biología Tropical Los Tuxtlas (EBT). 
da al interior del continente. Por lo tanto, la precipitación es de 3,000 a 4,500 $(7,000) \mathrm{mm} / \mathrm{año}$ en la vertiente noreste, mientras que en la vertiente suroeste con sombra de lluvia es de 1,500 a 3,500 mm/año (Soto, 2004; Gutiérrez-García y Ricker, 2011). A pesar de que llueve durante casi todo el año, el régimen lluvioso es marcadamente estacional, con una época húmeda de junio a febrero y una seca entre marzo y mayo. En la RBLT las temperaturas medias anuales más altas oscilan entre los $27-36^{\circ} \mathrm{C}$, y las más bajas de $8-18^{\circ} \mathrm{C}$. En general se identifican tres zonas térmicas: cálida en las partes bajas de la región con cinco subtipos, semicálida en la zona intermedia entre 600 y $1,000 \mathrm{~m}$ dependiendo de la orientación de la vertiente y templada en las partes altas de la sierra entre 1,600 y 1,700 m (Soto y Gama, 1997).

Castillo-Campos y Laborde (2004) caracterizaron nueve tipos de vegetación para la región entre los que destacan: selva alta perennifolia, selva mediana perennifolia, bosque mesófilo de montaña, bosque de encino cálido (Quercus spp.), bosque de pino (Pinus oocarpa) y manglar, donde los tres primeros abarcan la mayor superficie. Tanto el bosque mesófilo como la selva mediana perennifolia son los más conservados por encontrarse en sitios menos accesibles en las laderas de los volcanes (Castillo-Campos y Laborde, 2004), mientras que la selva alta perennifolia ha sido fuertemente fragmentada por la deforestación y cambios de uso del suelo (Dirzo y García, 1992). Para una descripción detallada de Los Tuxtlas, ver González-Soriano et al. (1997) y Guevara et al. (2004).

Trabajo de campo y herbario. Entre 2005 y 2006 se realizó el trabajo de campo, se dispusieron 91 parcelas de $20 \times$ $20 \mathrm{~m}$, en diferentes pisos altitudinales sobre las laderas de los volcanes Santa Marta y San MartínTuxtla, así como en la EBT de acuerdo a los métodos propuestos por Kessler y Bach (1999) y Gradstein et al. (2003), para obtener un inventario exhaustivo de helechos y licófitos terrestres y epífitos. Estas parcelas estuvieron representadas en las siguientes formaciones vegetales según Castillo-Campos y Laborde (2004): selva alta y mediana perennifolia, bosque mesófilo de montaña, bosque de pino, bosque de encino, y se incluyeron acahuales (bosques secundarios en recuperación derivados de selva alta perennifolia) de 15-20 años y plantaciones de cítricos semi-abandonados en los alrededores de la EBT. Además, un total de 23 árboles grandes ubicados dentro de parcelas en los principales tipos de vegetación se muestrearon desde la base a la copa mediante técnicas de alpinismo (Single Rope Technique; Perry, 1978), para contribuir al conocimiento del componente epifítico, el cuál fue considerado sólo de manera fragmentaria en la región. Debido a que la pteridoflora epifítica en el sotobosque es diferente a la de los árboles del dosel (Krömer et al., 2007b), se muestrearon también las especies presentes sobre los arbustos y árboles jóvenes, usando garrocha y binoculares. Entre 2005 y 2013 se realizaron recolectas adicionales durante salidas a diferentes áreas como: San Martín Pajapan, Parque de la Flora y Fauna Silvestre Tropical-UV, y la reserva privada "La Jungla" a orillas del lago Catemaco.

Una segunda fuente de información proviene del trabajo de herbario efectuado entre 2005 y 2013, en el cual se revisaron las colecciones de herbarios nacionales e internacionales: Escuela Nacional de Ciencias Biológicas, Instituto Politécnico Nacional (ENCB), Herbario Nacional de México, Universidad Nacional Autónoma de México (MEXU), División de Ciencias Biológicas y de la Salud, Universidad Autónoma Metropolitana Iztapalapa (UAMIZ), Instituto de Ecología, A.C., Xalapa (XAL), University Herbarium, University of California (UC) en Berkeley, E.U.A. y otros locales: Instituto de Investigaciones Biológicas, Universidad Veracruzana (CIB), Facultad de Biología, Universidad Veracruzana Campus Córdoba (CORU) y Estación de Biología Tropical "Los Tuxtlas", Universidad Nacional Autónoma de México (EBT; herbario local no incluido en el Index Herbariorum), donde se encontraron colecciones importantes del grupo para la región de estudio.

Se revisó además la literatura relevante, que incluía capítulos de libros y artículos científicos (Lira y Riba, 1984; Ibarra-Manríquez y Sinaca-Colín, 1995; Riba y Pérez-García, 1997; Mickel y Smith, 2004; Tejero-Díez et al., 2011), y tesis de licenciatura y maestría (Palacios-Ríos, 1992; Ramírez, 1999). Además se consultaron en línea las bases de datos importantes como La Red Mundial de Información sobre Biodiversidad (REMIB) de la CONABIO y Tropicos. org del Missouri Botanical Garden, St. Louis, EEUU. Con esta información se elaboró una base de datos de todas las especies registradas y confirmadas hasta el presente para la RBLT, que constituían un total de 1,380 ejemplares de herbario (incluyendo 463 recolectas propias depositadas en los herbarios EBT, MEXU, SEL, UC y/o XAL), cuyas determinaciones fueron confirmadas mediante cotejo con ejemplares tipo y ciertos problemas taxonómicos se resolvieron con la consulta de especialistas. La nomenclatura científica se uniformizó según el tratamiento de la Pteridoflora de México (Mickel y Smith, 2004) y de Smith et al. (2006), con algunas actualizaciones taxonómicas (Ebihara et al., 2006; Moran et al., 2010; Moran y Prado 2010; Regalado y Prada 2011; Lehnert, 2012; Øllgaard 2012; Krömer et al., 2013a; Jørgensen et al., 2014; Smith y Tejero-Díez, 2014).

Análisis de datos. Con la información registrada en la base de datos se contabilizaron las especies para obtener los valores de riqueza total. Además se calculó el índice de biodiversidad taxonómica (IB), definido por el número de especies dividido entre el logaritmo natural del área en $\mathrm{km}^{2}$ (IB $=\mathrm{S} / \mathrm{ln} \mathrm{A}$, donde $\mathrm{S}$ es el número de especies registradas y A el tamaño del área; Squeo et al., 1998). Este índice fue utilizado para comparar la riqueza a nivel regional de las especies de helechos y licófitos de la RBLT con la de dos áreas protegidas mexicanas (Cerro El Quetzal, El Triunfo 
y Cañon del Sumidero, ambas del estado de Chiapas), tres áreas protegidas de Centro- y Sudamérica (La Selva, Costa Rica, Barro Colorado, Panamá y Parque Amboró, Bolivia) y tres municipios mexicanos (Tenango Doria, Tlanchinol, ambos del estado de Hidalgo y Tlatlauquitepec, Puebla) que en su mayoría contaban con una metodología similar.

Se presenta la distribución geográfica de las especies registradas, en el contexto global y a nivel estatal dentro de México. Además se analizó la distribución del número de especies, géneros y familias en relación al gradiente altitudinal presente en Los Tuxtlas (0-1,680 m), para lo cual se utilizaron 11 intervalos altitudinales de $150 \mathrm{~m}$ (para fines prácticos el último fue de $180 \mathrm{~m}$ ). Se analizó la presencia de los helechos y licófitos en los diferentes tipos de vegetación natural de la RBLT, siguiendo la clasificación de CastilloCampos y Laborde (2004): Selva alta perennifolia (SAP; 0-700 m), selva mediana perennifolia (SMP; 650-1,000 m), bosque mesófilo de montaña (BMM; 1,000-1,680 m), bosque de encino cálido (BQ; 100-600 m), bosque de pino (BP; 500-900 m), manglar (MGL; nivel del mar), dunas costeras (DNC; 0-50 m). Además, fue necesario considerar en este estudio como unidades de vegetación el bosque de transición ó ecotono entre la selva alta y mediana perennifolia con el bosque mesófilo (ECO; (750-) 800-1,000 m) y el bosque de pino y encino (BP-BQ; 400-900 m), debido a que varios especímenes de herbario consignaban esta información, la cual no puede ser modificada ó eliminada. También se consideró las formas de crecimiento en relación al sustrato de acuerdo a Grayum y Churchill (1987) en: terrestre (T), epífita (E), hemiepífita (HE), rupícola (R) e hidrófita (Hi) para todas las especies y por tipo de vegetación.
Para obtener información acerca del estado de conservación de la pteridoflora en la RBLT se realizó el conteo del número de especímenes registrados en la base de datos para cada especie, utilizando dos categorías de acuerdo a Grayum y Churchill (1987): muy rara $=1-2$ y rara $=3-5$ colecciones. Además, se revisó información acerca del estado de conservación de las especies registradas para Los Tuxtlas en la NOM-059-ECOL-2010 (SEMARNAT, 2010) y el trabajo de (Tejero-Díez et al., 2011).

\section{Resultados}

Riqueza de especies. De un total de 1,380 especímenes que conforman la base de datos elaborada, se obtuvieron 246 taxones repartidos en 18 especies, tres géneros y dos familias de Lycopodiophyta y 228 especies, 70 géneros y 22 familias de Polypodiophyta en la RBLT (Apéndice 1). Las familias más numerosas fueron Polypodiaceae, Dryopteridaceae y Pteridaceae, con más de 30 especies cada una, mientras que los géneros con mayor número de especies fueron: Asplenium (22; 8.9\%), Thelypteris (18; 7.3\%), Trichomanes (13; 5.2\%), Elaphoglossum (12; 4.9\%), Polypodium (12; 4.9\%) y Selaginella (11; 4.5\%; Cuadro 1). En diferentes estudios referentes a la RBLT (Lira y Riba, 1984; Riba y Pérez-García, 1997, Ramírez, 1999, Tejero-Diéz et al. 2011), se consigna la existencia de un total de 308 taxones; sin embargo, en este estudio se confirma la presencia de 210 taxones, ya que 52 resultaron ser sinónimos o tenían determinaciones previas erróneas (ver Apéndice 2 y 3). Además, algunos nombres asignados (21) pertenecen a taxones de localidades ubicados fuera de los límites de la RBLT y otros 25 no

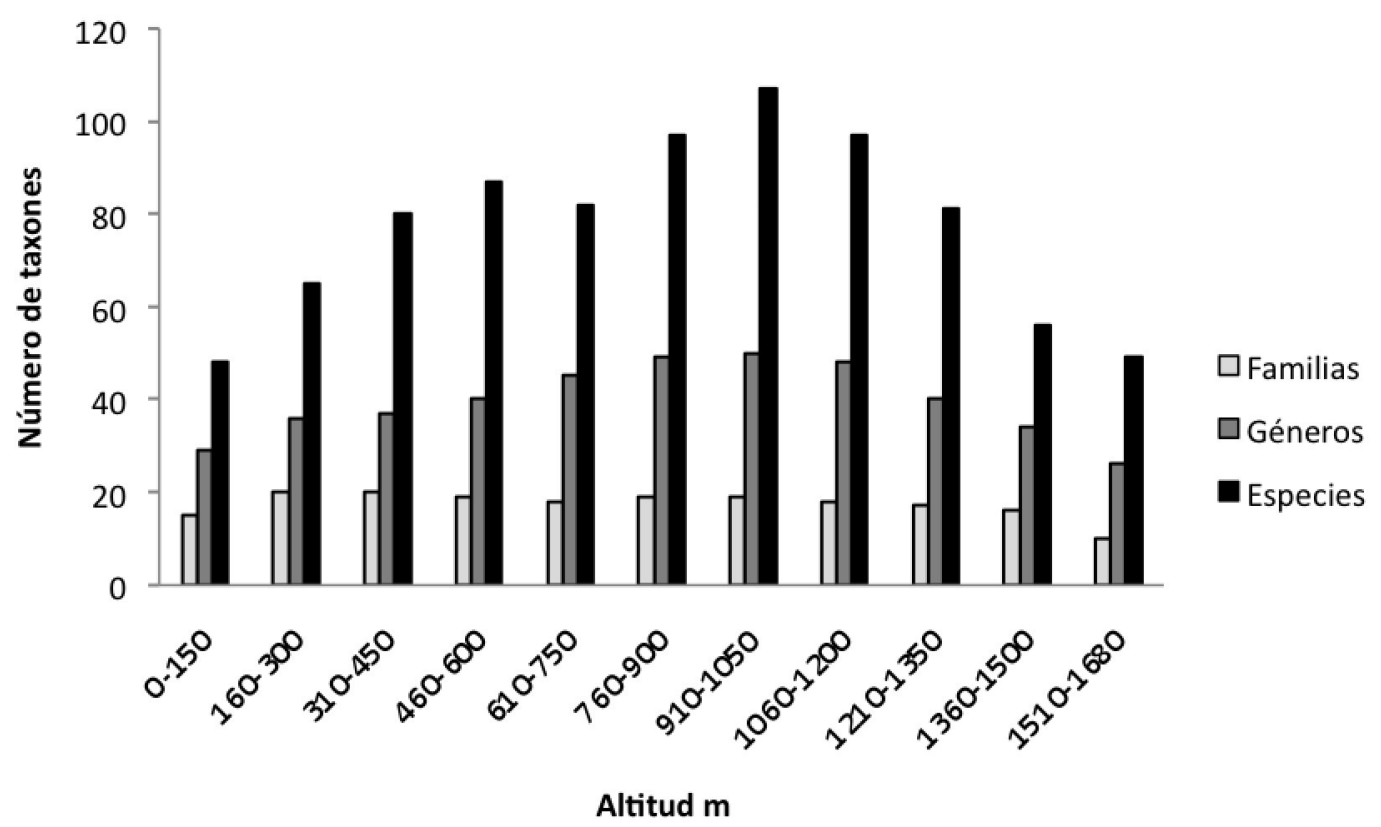

Figura 2. Número de familias, géneros y especies de helechos y licófitos por intervalos altitudinales de 150 m en la Reserva de la Biosfera de Los Tuxtlas. 
Cuadro 1. Familias y géneros de helechos y licófitos con mayor riqueza de especies (> 10) en la Reserva de la Biosfera Los Tuxtlas.

\begin{tabular}{lcc}
\hline Familia/Género & $\begin{array}{c}\text { Número de } \\
\text { especies }\end{array}$ & $\begin{array}{c}\text { \% del total } \\
\text { de especies }\end{array}$ \\
\hline Polypodiaceae & 39 & 15.8 \\
Polypodium & 12 & 4.8 \\
Dryopteridaceae & 32 & 13.4 \\
Elaphoglossum & 12 & 5 \\
Pteridaceae & 31 & 12.6 \\
Aspleniaceae & 22 & 8.9 \\
Asplenium & 22 & 8.9 \\
Hymenophyllaceae & 22 & 8.9 \\
Trichomanes & 13 & 5.3 \\
Thelypteridaceae & 19 & 7.9 \\
Thelypteris & 18 & 7.5 \\
Selaginellaceae & 11 & 4.6 \\
Selaginella & 11 & 4.6 \\
\hline
\end{tabular}

pudieron ser confirmados al no encontrarse el material de referencia (Apéndice 2). Por lo tanto, se considera que 35 taxones son nuevos registros para la Reserva, de los cuales Elaphoglossum glabellum y E. pringlei también fueron nuevos para el estado de Veracruz (Apéndice 1).

Distribución. En relación a su distribución geográfica solo un 7\% (18 spp.) de las especies son de amplia distribución mundial ó cosmopolitas, el 58\% (142) tienen una amplia distribución en América tropical principalmente desde México hasta Sudámerica incluyendo las Antillas, un 23\% (57) se distribuyen en México y Centroamérica, un 5\% se restringen de México hasta Honduras, aunque la mayoría de estas últimas se comparten entre México y Guatemala, y ca. 7\% (17) tienen una distribución restringida a México (Apéndice 1).

$\mathrm{Al}$ analizar la distribución de las especies y géneros en relación a la altitud, se observa la mayor riqueza ( $\geq 95$ especies por intervalo) entre los 750-1,200 m con un máximo (107 especies; 50 géneros) entre los 900-1,050 m (Figura 2). Este último intervalo coincide en gran parte con el bosque de transición entre selva mediana perennifolia y bosque mesófilo de montaña. A nivel de familia los valores son similares a lo largo del gradiente altitudinal que abarca la RBLT con una ligera disminución hacia los límites extremos.

Riqueza por tipo de vegetación. Los tipos de vegetación natural donde se registraron mayor número de especies fueron el BMM (134 especies), la SAP (115), el bosque de transición ECO (95), el BP-BQ (23) y la SMP (23) (Figura 3). En vegetación secundaria incluyendo acahuales y vegetación antropogénica (cultivos, pastizales) se registraron 65 y 34 especies respectivamente, mientras que en las otras formaciones vegetales, los helechos están representados por menos de diez especies cada uno (Apéndice 1). Los taxones reportados exclusivamente para el BMM y SAP fueron $47 \mathrm{y}$ 34 respectivamente. En el BMM se observa que las familias de helechos y licófitos más representativas son Polypodia-

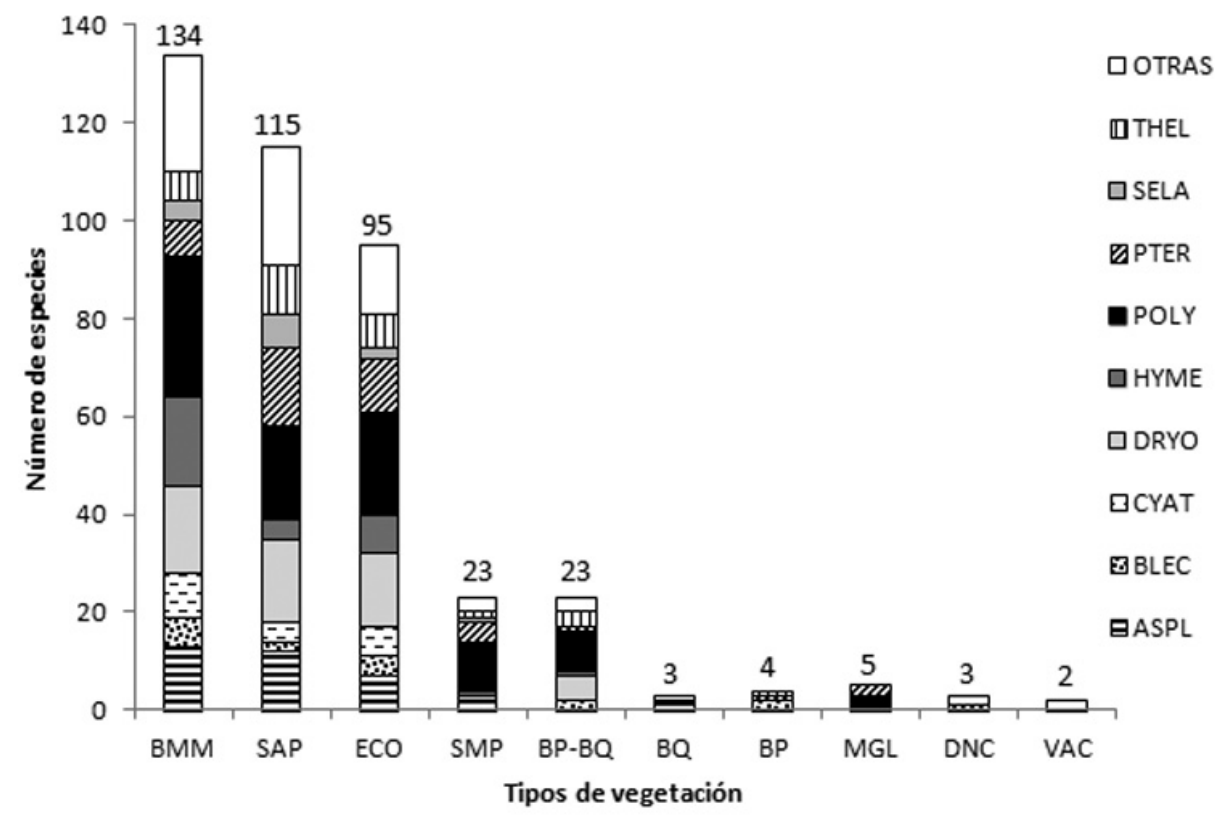

Figura 3. Número de las familias de helechos y licófitos (ASPL: Aspleniaceae; BLEC: Blechnaceae; CYAT: Cyathaceae; DRYO: Dryopteridaceae; HYME: Hymenophyllaceae; POLY: Polypodiaceae; PTER: Pteridaceae; SELA: Selaginellaceae; THEL: Thelypteridaceae), así como su riqueza de especies (cifras arriba) por tipo de vegetación (BMM: Bosque mesófilo de montaña; SAP: Selva alta perennifolia; ECO: Bosque de transición SAP-BMM; SMP: Selva mediana perennifolia; BP-BQ: Bosque pino-encino; BP: Bosque de pino; BQ: Bosque de encino; DNC: Dunas costeras, MGL: Manglar, VAC: Vegetación acuática). 


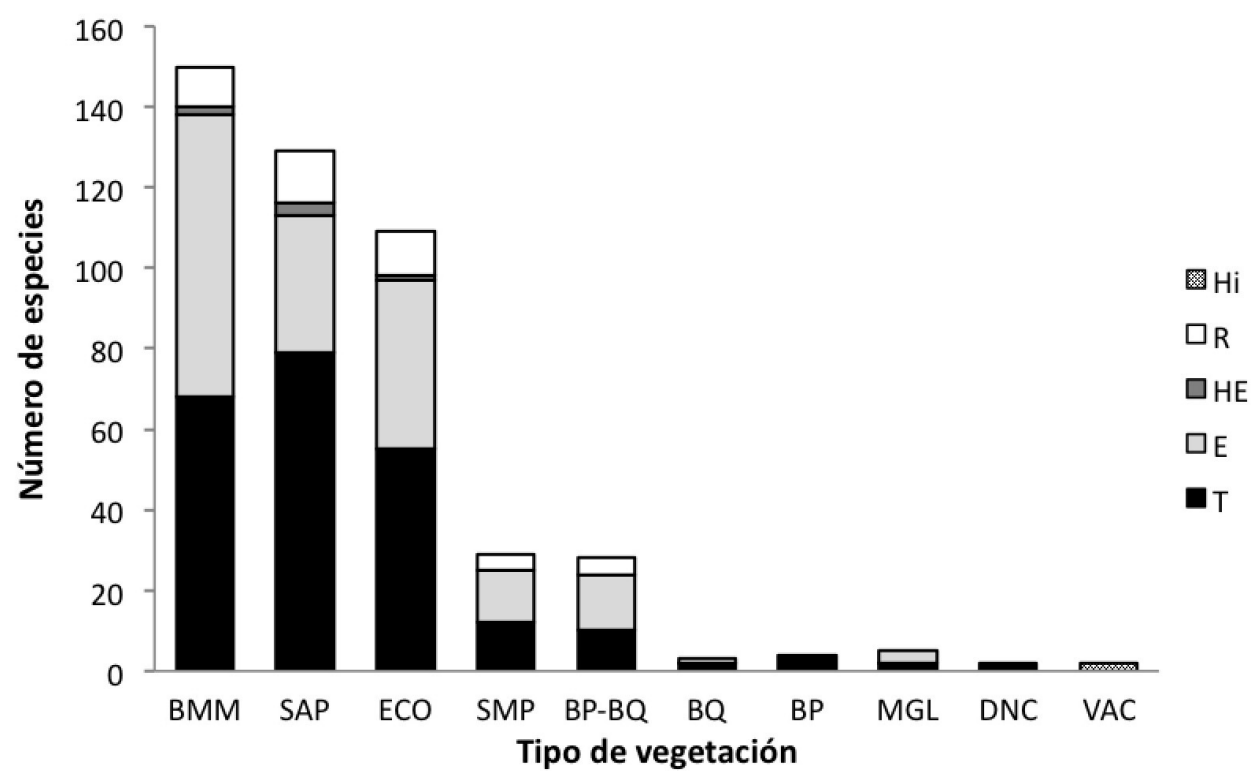

Figura 4. Formas de crecimiento (en relación al sustrato) de los helechos y licófitos (T: terrestres; E: epífitas; HE: hemiepífitas; R: rupícolas; Hi: hidrófitas) de la Reserva de la Biosfera de Los Tuxtlas por tipo de vegetación (SAP: Selva alta perennifolia; BMM: Bosque mesófilo de montaña; ECO: Bosque de transición; SMP: Selva mediana perennifolia; BP-BQ-: Bosque de pino-encino; BP: Bosque de pino; BQ: Bosque de encino; MGL: Manglar; DNC: Dunas costeras; VAC: vegetación acuática).

ceae (29 especies), Dryopteridaceae e Hymenophyllaceae (18 cada una), Aspleniaceae (13) y Cyatheaceae (9), mientras que en la SAP son Polypodiaceae (19), Dryopteridaceae (17), Pteridaceae (16), Aspleniaceae (12) y Thelypteridaceae (10). Los bosques de transición muestran una combinación entre ambos, y en los otros tipos de vegetación se destacan principalmente Polypodiaceae y Pteridaceae.

Microambientes y formas de crecimiento. Según los registros realizados, el $62.2 \%$ (153 especies) de las especies son terrestres, 37.4\% (92) epífitas, 8.9\% (22) rupícolas, 2\% (5) hemiepífitas, y el 0.8\% (2) hidrófitas flotantes (Apéndice 1); sin embargo, estos valores no son exclusivos debido a que algunas especies pueden presentarse en una o más de estas categorías. Si se analiza la forma de crecimiento con relación a los tipos de vegetación se puede observar que en la SAP las especies son mayormente terrestres (79 especies) y sólo 34 especies son epífitas, mientras que en el BMM y la SMP las epífitas son ligeramente más numerosas que las terrestres 70 contra 68 y 13 contra 12 . El bosque de transición ECO tiene un mayor número de terrestres que epífitas (55 contra 42), mientras que en el BP-BQ (10 contra 14) al igual que en el MGL (2 contra 3 ) las epífitas son ligeramente predominantes. El BP y las DNC tienen esencialmente helechos terrestres y sólo se registran dos especies hidrófitas flotantes para la región (Figura 4).

Estado de conservación. Del total de las especies analizadas de la RBLT, el 39\% (96 especies) se pueden considerar como muy raras (con 1-2 especímenes) y el 26\% (65 especies) son raras (con 3-5); ambas representan el $65 \%$ del total de las especies. De todas las especies reportadas para la RBLT en el presente estudio solo 13 se encuentran incluídas en la NOM-059-ECOL-2010 (SEMARNAT, 2010), una en peligro, cuatro amenazadas y ocho bajo protección especial (Apéndice 1), en su mayoría se trata de helechos arborescentes.

\section{Discusión}

En este estudio se registraron 246 especies, dos de las cuales (Elaphoglossum glabellum y E. pringlei) se pueden considerar nuevos registros para Veracruz, mientras que otras 33 son nuevos para la RBLT, debido a que no fueron incluidos con anterioridad en la literatura pertinente. Así, el número total de taxones conocidos se incrementa a 568 para el estado y en un $14 \%$ para la Reserva. La riqueza de especies de la RBLT se puede considerar alta para el país ya que equivalen al $43 \%$ de los helechos y licófitos del estado de Veracruz (Tejero-Díez et al., 2011; Krömer et al., 2013a) y al 23.8\% de los reportados para México (1,030 según Tejero-Díez et al., 2014).

A su vez, el área de estudio tiene el mayor índice de biodiversidad taxonómica a nivel regional en México (ver Cuadro 2), debido a que en la RBLT confluyen una combinación de factores ambientales a lo largo del gradiente altitudinal que tienen una fuerte correlación con la alta riqueza de la pteridoflora, especialmente la elevada precipitación de 4,000 a 7,000 mm (Kreft et al., 2010, Krömer et al., 2013b), las neblinas frecuentes en la media montaña de la vertiente oceánica de la sierra (Mickel y Smith, 2004) y una alta heterogeneidad topográfica (Geissert, 2004; Moran, 2008, Kreft 
Cuadro 2. Comparación de los números de especies de helechos y licófitos y el índice de biodiversidad taxonómica (IB) de la Reserva de la Biosfera Los Tuxtlas (RBLT) y otras regiones mexicanas y neotropicales. * CONAGUA estaciones metereológicas municipio Tlatlauquitepec: Tlatlauquitepec (Comisión Federal de Electricidad), La Pagoda (Comisión Federal de Electricidad) y Oyameles (Comisión Federal de Electricidad).

\begin{tabular}{|c|c|c|c|c|c|c|}
\hline Regiones & $\begin{array}{l}\text { Intervalo } \\
\text { altitudinal (m) }\end{array}$ & $\begin{array}{l}\mathrm{Pp} \\
(\mathrm{mm})\end{array}$ & $\begin{array}{l}\text { Área } \\
\left(\mathbf{k m}^{2}\right)\end{array}$ & $\begin{array}{c}\text { Número } \\
\text { de taxones }\end{array}$ & IB & Referencia \\
\hline Estación Biológica La Selva, Costa Rica & $35-135$ & 4,000 & 15 & 150 & 55.4 & Grayum y Churchill, 1987 \\
\hline Parque Nacional Amboró, Bolivia & $235-3,100$ & $500-4,000$ & 6,376 & 431 & 49.2 & Sundue, 2010 \\
\hline Barro Colorado, Panamá & $25-165$ & 2,750 & 15.6 & 104 & 37.9 & Grayum y Churchill, 1987 \\
\hline Guavio, Colombia & $400-3,875$ & $800-7,000$ & 3,666 & 278 & 33.9 & Murillo-A. et al., 2008 \\
\hline RBLT, Veracruz, México & $100-1,680$ & $1,500-4,500$ & 1,551 & 246 & 33.5 & Presente estudio \\
\hline $\begin{array}{l}\text { Cerro El Quetzal, Reserva } \\
\text { El Triunfo, Chiapas }\end{array}$ & $1,200-2,300$ & 1,263 & 120 & 109 & 22.8 & Pérez-Farrera et al., 2012 \\
\hline Tenango de Doria, Hidalgo, México & $630-2,250$ & 1,930 & 211 & 111 & 20.7 & Zúñiga-Salvatierra, 2009 \\
\hline $\begin{array}{l}\text { Parque Nacional Cañon del Sumidero, } \\
\text { Chiapas, México }\end{array}$ & $360-1,720$ & 957 & 218 & 83 & 15.4 & Espinosa-Jiménez et al., 2011 \\
\hline Tlatlauquitepec, Puebla, México & $800-2,000$ & $1570-2,650 *$ & 246 & 66 & 11.9 & Cerón-Carpio et al., 2006 \\
\hline Mun. Tlanchinol, Hidalgo & $1,107-1900$ & $2,156.2$ & 380 & 130 & 21.9 & Álvarez-Zúñiga et al., 2012 \\
\hline Zimatán, Oaxaca & $0-2,580$ & - & 713.39 & 49 & 7.45 & Salas-Morales et al., 2003 \\
\hline
\end{tabular}

et al., 2010). Se sabe que los helechos y licófitos tienen un bajo control del potencial evaporativo durante la mayor parte de su ciclo de vida y por ello son más dependientes de la disponibilidad del agua y una alta humedad relativa (Page, 2002; Hietz, 2010). Por esta razón, en regiones donde la precipitación y la humedad ambiental son menores y/o la estación invernal es marcadamente seca, la riqueza de especies, sobre todo de las epífitas, está reducida (Kreft et al., 2004), así como en el Parque Nacional Cañon del Sumidero y El Cerro Quetzal, El Triunfo, ambos ubicados en el estado de Chiapas (Cuadro 2). En climas preponderantemente cálidos y semihúmedos la riqueza disminuye aun más y las epífitas están escasamente representadas como en el pacífico mexicano (Sálas-Moreno et al., 2003), lo que demuestra la alta dependencia de este grupo de plantas a la disponibilidad de agua. Además, la alta heterogeneidad topográfica en las partes altas de la sierra favorece el establecimiento de un mayor número de helechos y licófitos (Moran, 2008; Kreft et al., 2010), debido a que está condiciona la distribución de los tipos de suelo y la variabilidad de sus propiedades (Nichols et al., 1998). Por otro lado, el índice de biodiversidad de la RBLT se encuentra ligeramente por debajo de lo calculado para otras localidades más cercanas al ecuador (Cuadro 2), lo que coincide con el patrón de diversidad latitudinal, por el cual el número de especies de helechos y licófitos por unidad de área aumenta al acercarse al ecuador continental (Kreft et al., 2010; Salazar et al., 2015).

La pérdida de hábitat, impulsada por las actividades humanas como la fragmentación y el cambio de uso del suelo, es considerada la principal causa de la disminución de la diversidad de helechos y licófitos (Walker y Sharpe, 2010). La deforestación afecta particularmente la disponibilidad de hábitats y sustratos adecuados para estas plantas (Paciencia y Prado, 2005; Mehltreter, 2010; Carvajal-Hernández et al., 2014), además de causar cambios microclimáticos hacia condiciones más secas (Barthlott et al., 2001; Krömer y Gradstein, 2003; Werner et al., 2005; Larrea y Werner, 2010). En el área de estudio, el cambio del uso de suelo afecta a aproximadamente 110 mil ha (CONANP, 2006), lo que repercute en la riqueza de la pteridoflora debido a que muy pocas especies son favorecidas por estos cambios (Walker y Sharpe, 2010); en vegetación secundaria y acahuales se registraron el $26 \%$ de las especies, en su mayoría especies de amplia distribución y colonizadoras de ambientes perturbados (p. ej. Dennstaedtia bipinnata, Lygodium venustum, Nephrolepis brownii, Tectaria heracleifolia), mientras que en la vegetación antropogénica sólo se encontró el 14\% de las especies, algunas de las cuales (Blechnum appendiculatum, Macrothelypteris torresiana, Pteridium caudatum) son malezas ampliamente reconocidas de este ambiente (Robinson et al., 2010). En estos ambientes secundarios, las especies epífitas son las más afectadas por la desaparición de los forófitos de preferencia, sobre todo las especies higrófilas (vulnerables a sequía) y umbrófilas (susceptibles a la alta incidencia de luz), por ej: Scoliosorus ensiformis y Hymenophyllaceae. Estas últimas son especialmente sensibles a cambios en la humedad relativa y niveles de luz (Foster, 2001), por lo cual tienden a desaparecer y/o son reemplazadas por especies generalistas tolerantes a la sequía (Werner et al., 2005; Larrea y Werner, 2010; Carvajal-Hernández et al., 2014).

La pteridoflora de la RBLT esta representada en su mayoría por especies de amplia distribución en América tropical, más del 50\% se distribuyen en México y Centroámerica y 
un bajo porcentaje son especies cosmopolitas y endémicas. Estos mismos patrones fueron encontrados por Lira y Riba (1984) para la sierra de Santa Marta, lo que demuestra según estos autores una fuerte relación florística de las zona montañosas del centro y sur de México con la región andina en Sudamérica.

La riqueza de especies de la pteridoflora en el área de estudio forma una curva de campana en relación con la altitud (Figura 2), donde la mayor riqueza se encuentra en el bosque de transición ECO y el BMM. Este comportamiento está correlacionado con los parámetros físicos (disminución de la temperatura, mayor precipitación y humedad atmosférica) en gradientes altitudinales ya ampliamente documentado (Gentry y Dodson, 1987; Kessler et al., 2001; Küper et al., 2004; Krömer et al., 2005; Cardelús et al., 2006; Krömer et al., 2013b; Salazar et al., 2015), dando como resultado una combinación óptima de humedad y temperatura que favorece el crecimiento de estas plantas (Kessler, 2010; Tejero-Díez et al., 2014). Lomolino (2001) sugirió que los patrones de riqueza altitudinal de especies se ven influenciados por la superposición de las comunidades adyacentes, creando máximos de riqueza en las zonas de transición, es decir, en zonas de co-presencia de los límites extremos de distribución superior e inferior de las especies. En el gradiente altitudinal estudiado se registró una mayor riqueza de especies entre 900 y 1,050 m justamente en el bosque de transición (TRA) constatándose esta predicción.

El componente epifítico de los helechos y licófitos en la RBLT es relativamente alto (37.4\%), en comparación con el patrón global de esta forma de crecimiento, el cual oscila entre un 25-29\% (Kress, 1986; Zotz, 2013). Este valor elevado demuestra la influencia de un clima marcadamente húmedo en la RBLT (Page, 1979), ya que la disponibilidad de agua juega un papel muy importante en la distribución de las epífitas a macro- y microescala (Zotz y Andrade, 2002; Kreft et al., 2004). Sin embargo, el grado de epifitismo en la RBLT no es uniforme, se incrementa con la altitud y es mayor en el bosque mesófilo. Esto coincide con lo mencionado por Lira y Riba (1984) y Tejero-Díez et al. (2014), donde la pteridoflora epifítica de la región de Los Tuxtlas y de la Sierra Madre Oriental oscila entre 20 y 60\%, mientras que en las regiones del Pacífico desciende a menos del $15 \%$.

El bosque mesófilo es el tipo de vegetación más rico en helechos y licófitos de la RBLT, debido al gran aporte de las especies epífitas, las cuales son favorecidas no sólo por la lluvia sino también por la "precipitación horizontal" o niebla (Kessler et al., 2012). Se ha comprobado que ésta contribuye con un 20\% más al aporte hídrico total (Hölscher et al., 2004; Thies et al., 2008) y así mitiga los períodos secos, los cuales en tipos de vegetación de tierras bajas como la selva alta perennifolia reducen la abundancia y diversidad de las epífitas (Kessler et al., 2012).

La selva alta perennifolia en la RBLT contiene un elevado número de especies (115) comparada con otras regiones del estado de Veracruz tales como el valle del río Uxpanapa y Las Choapas (Rancho el Milagro) con 69 y 56 especies respectivamente (Riba y Pérez-García, 1979; F.G. Lorea-Hernández y colaboradores, datos no publicados). Lo anterior, se relaciona a que en la RBLT esta formación vegetal tiene la particularidad de distribuirse desde el nivel del mar hasta los $700 \mathrm{~m}$ de altitud (Castillo-Campos y Laborde, 2004) con un incremento de humedad y sobre una topografía accidentada hacia el límite superior. Contrariamente a lo que ocurre en los dos sitios mencionados, donde la topográfia es más homogénea y el clima menos idóneo para este grupo de plantas (Riba y Pérez-García, 1979).

La alta proporción de especies raras y muy raras (65\%) en la RBLT coincide con lo mencionado para la Estación Biológica La Selva, Costa Rica, donde el $45 \%$ pertenecían a estas dos categorías (Grayum y Churchill, 1987) y podría relacionarse a una alta distribución localizada de las especies. Helechos y licófitos terrestres han mostrado una alta especialización edáfica a escala local (Tuomisto y Ruokolainen, 1994; Tuomisto y Dalberg, 1996; Tuomisto et al., 1998, 2002; Jones et al., 2007, 2008), mientras que las epífitas dependen de las particularidades de sus forófitos (Moran et al., 2003; Mehltreter et al., 2005) o de condiciones microclimáticas (Gardette, 1996). No obstante, debido a que estos datos están dependientes de la intensidad de estudio de la región, el elevado porcentaje de especies raras podría estar reflejando una falta de exploración botánica.

De las 156 especies que entran en las categorías de raras (65) y muy raras (96) en el presente estudio, sólo tres (Asplenium serratum, Marattia weinmanniifolia y Schizaea elegans) se mencionan en la NOM-059-ECOL-2010 (SEMARNAT, 2010).

Por otro lado, tomando como referencia el análisis del estado de conservación para la pteridoflora del estado de Veracruz (Tejero-Díez et al., 2011), 66 especies vulnerables, 59 amenazadas y seis protegidas coinciden con especies raras y muy raras en la RBLT, mientras que el resto son consideradas sin problemas de acuerdo a estos autores. Igualmente, en los estudios del estado de conservación de las especies de helechos grammitidoides y del género Phlegmariurus de Veracruz (Krömer et al., 2013a; Armenta-Montero et al., 2015) de las 11 y seis especies respectivamente que ocurren en Los Tuxtlas, seis de cada uno estan clasificadas bajo alguna categoría de amenaza de acuerdo a los criterios de la Unión Internacional para la Conservación de la Naturaleza a nivel regional (IUCN, 2003), sin embargo solo P. dichotomus esta mencionada como amenazada en la NOM-059-ECOL-2010.

\section{Conclusiones}

La Reserva de la Biosfera "Los Tuxtlas" alberga una elevada riqueza de helechos y licófitos y por la alta incidencia de registros nuevos aportados por la presente contribución, es muy probable que tal cifra aún se incremente mediante 
estudios florísticos en áreas poco exploradas y enfocados a este grupo de plantas en la región. Sin duda, en la RBLT el bosque mesófilo de montaña es el tipo de vegetación más rico en especies y actualmente se encuentra en mejor estado de conservación que otros por su menor accesibilidad. En contraste, la selva alta perennifolia que también contiene una alta riqueza de helechos y licófitos es el tipo de vegetación más amenazado por la deforestación. Las especies consideradas como raras (de distribución localizada y con alta especificidad de hábitat) serían las primeras en ser afectadas por estos cambios (Arcand y Ranker, 2008). Este estudio es el primero, que no solamente ofrece un listado actualizado de los helechos y licófitos de la RBLT, sino que analiza distintos aspectos básicos acerca de la riqueza y distribución de las especies, formas de crecimiento y del conocimiento actual sobre el estado de conservación, lo que será relevante para ser consideradas en los planes de manejo y tomar medidas para la conservación general de la RBLT.

\section{Agradecimientos}

Queremos agradecer a E. Otto, A. Perez-Peña y E. Velásquez-Sinaca, así como la gente del Ejido Plan Agrario y los miembros del Grupo Ecoturístico "Los Clarines" en Ruíz Cortínez por su apoyo en el trabajo de campo. A J.T. Mickel, A.R. Smith y R.C. Moran por su apoyo con la identificación y búsqueda de ejemplares, C.I. Carvajal-Hernández y J.C. López-Acosta por la revisión del manuscrito y sus valiosos comentarios, B. Holst por la revisión del "abstract", y S. Armenta-Montero por la elaboración del mapa. A. R. Coates y M. Ricker por el apoyo logístico en la EBT-UNAM. La investigación fue financiada con una beca del CONACyT (No. 249766) otorgada a A. R. Acebey, así como una beca posdoctoral de la UNAM y fondos de PROMEP (PROMEP/103.5/07/2753) otorgados a T. Krömer.

\section{Literatura citada}

Acebey A. y Krömer K. 2010. Asplenium peruvianum Desv. En: Gómez-Pompa A., Krömer T. y Castro-Cortés R. Coords. Atlas de la Flora de Veracruz: Un Patrimonio Natural en Peligro, pp. 399-400, Comisión del Estado de Veracruz para la Conmemoración de la Independencia Nacional y la Revolución Mexicana.

Álvarez-Zuñiga E., Sánchez-González A., López-Mata L. y TejeroDíez J.D. 2012. Composición y abundancia de las pteridofitas en el bosque mesófilo de montaña del municipio de Tlanchinol, Hidalgo, México. Botanical Sciences 90:163-177.

Andrle R.F. 1964. A biogeographical investigation of the sierra de Tuxtlas in Veracruz. Tesis Doctoral, Louisiana State University, Baton Rouge. 247 pp.

Arcand N.N. y Ranker T.A. 2008. Conservation biology. En: Ranker T.A. y Haufler C.H. Eds. Biology and Evolution of Fer$n s$ and Lycophytes, pp. 257-283, Cambridge University Press, Cambridge.

Armenta-Montero S., Carvajal-Hernández C.I., Ellis E.A. y Krömer T. 2015. Distribution and conservation status of Phlegma- riurus (Lycopodiaceae) in the state of Veracruz, Mexico. Tropical Conservation Science 8:114-137.

Arriaga L., Espinoza J.M., Aguilar C., Martínez E., Gómez L. y Loa E. (coords.). 2000. Regiones Terrestres Prioritarias de México. Comisión Nacional para el Conocimiento y uso de la Biodiversidad, México, D.F. http://www.conabio.gob.mx/conocimiento/regionalizacion/doctos/terrestres.html (consultado 14 de febrero de 2014).

Barthlott W., Schmitt-Neuerburg V., Nieder, J. y Engwald S. 2001. Diversity and abundance of vascular epiphytes: a comparison of secondary vegetation and primary montane rain forest in the Venezuelan Andes. Plant Ecology 152:145-156.

Campos A. 2004. El suelo. En: Guevara S., Laborde J. y Sánchez G. Eds. Los Tuxtlas. El Paisaje de la Sierra, pp. 181-192, Instituto de Ecología, A.C., Xalapa.

Cardelús C.L., Colwell R.K. y Watkins J.E. Jr. 2006. Vascular epiphyte distribution patterns: explaining the mid-elevation richness peak. Journal of Ecology 94:144-156.

Carvajal-Hernández C., Krömer T. y Vázquez-Torres M. 2014. Riqueza y composición florística de pteridobiontes en bosque mesófilo de montaña y ambientes asociados, en el centro de Veracruz, México. Revista Mexicana de Biodiversidad 85:491-501.

Castillo-Campos G. y Laborde. J. 2004. La vegetación. En: Guevara S., Laborde J. y Sánchez-Ríos G. Eds. Los Tuxtlas. El Paisaje de la Sierra, pp. 231-265, Instituto de Ecología, A.C., Unión Europea, Xalapa.

Cerón-Carpio A.B., Arreguín-Sánchez M.L. y Fernández-Nava R. 2006. Listado con anotaciones de las pteridofitas del municipio de Tlatlauquitepec, Puebla, México y distribución de las especies en los diferentes tipos de vegetación. Polibotánica 21:4560 .

CONABIO. Comisión Nacional para el Conocimiento y Uso de la Biodiversidad. 2010. El Bosque Mesófilo de Montaña en México: Amenazas y Oportunidades para su Conservación y Manejo Sostenible. Comisión Nacional para el Conocimiento y Uso de la Biodiversidad, México, D.F.

CONANP. Comisión Nacional de Áreas Naturales Protegidas. 2006. Programa de Conservación y Manejo, Reserva de la Biosfera Los Tuxtlas. Comisión Nacional de Áreas Naturales Protegidas. Secretaría del Medio Ambiente y RecursosNaturales. México, D. F.

Dirzo R. y Miranda A. 1991. El límite boreal de la selva húmeda en el continente americano: contracción de la vegetación y solución de una controversia. Interciencia 16:240-247.

Dirzo R. y García M.C. 1992. Rates of deforestation in Los Tuxtlas, Veracruz, México. Conservation Biology 6:84-90.

Ebihara A., Dubuisson J.Y., Iwatsuki K., Hennequin S. e Ito M. 2006. A taxonomic revision of Hymenophyllaceae. Blumea 51:221-280.

Espinosa-Jiménez J.A., Pérez-Farrera M.A. y Martínez-Camilo R. 2011. Inventario florístico del parque nacional Cañón del Sumidero, Chiapas, México. Boletín de la Sociedad Botánica de México 89:37-82.

Foster P. 2001. The potential negative impacts of global climate change on tropical montane cloud forests. Earth-Science Reviews 55:73-106.

Gardette E. 1996. Microhabitats of epiphytic fern communities in large lowland rain forest plots in Sumatra. En: Camus J.M., Gibby M.y Johns R.J. Eds. Pteridology in Perspective, pp. 655658, Royal Botanic Gardens, Kew, Londres. 
Geissert D. 2004. La geomorfología. En: Guevara S., Laborde J. y Sánchez G. Eds. Los Tuxtlas. El Paisaje de la Sierra, pp. 159178, Instituto de Ecología, A.C., Unión Europea, Xalapa.

Gentry A.H. y Dodson C.H. 1987. Diversity and biogeography of Neotropical vascular epiphytes. Annals of the Missouri Botanical Garden 74:205-233.

González-Soriano E., Dirzo R. y Vogt R. (Eds). 1997. Historia Natural de Los Tuxtlas. Universidad Nacional Autónoma de México-Comisión Nacional para el Conocimiento y Uso de la Biodiversidad, México D.F.

Gradstein S.R., Nadkarni N.M., Krömer T., Holz I. y Nöske N. 2003. A protocol for rapid and representative sampling of vascular and non-vascular epiphyte diversity of tropical rain forests. Selbyana 24:105-111.

Grayum M.H. y Churchill H.W. 1987. An introduction to the Pteridophyte Flora of Finca La Selva, Costa Rica. American Fern Journal 77:73-89.

Guevara S., Laborde J. y Sánchez-Ríos G. Eds. 2004. Los Tuxtlas. El Paisaje de la Sierra. Instituto de Ecología, A.C., Unión Europea, Xalapa.

Gutiérrez-García G. y Ricker M. 2011. Climate and climate change in the region of Los Tuxtlas (Veracruz, Mexico): A statistical analysis. Atmósfera 24:347-373.

Hietz P. 2010. Fern adaptations to xeric environments. En: Mehltreter K., Walker L.R. y Sharpe J.M. Eds. Fern Ecology, pp. 140-176, Cambridge University Press, Cambridge.

Hölscher D., Köhler L., van Dijk A.I.J.M. y Bruijnzeel L.A. 2004. The importance of epiphytes to total rainfall interception by a tropical montane rain forest in Costa Rica. Journal of Hydrology 292:308-322.

Ibarra-Manríquez G. y Sinaca-Colín S. 1995. Lista florística comentada de la Estación de Biología Tropical "Los Tuxtlas", Veracruz, México. Revista de Biología Tropical 43:75-115.

Ibarra-Manríquez G. y Sinaca-Colín S. 1996a. Lista florística comentada de la estación de Biología Tropical Los Tuxtlas, Veracruz. México. Mimosaceae a Verbenaceae. Revista de Biología Tropical 44:41-60.

Ibarra-Manríquez G. y Sinaca-Colín S. 1996b. Lista comentada de plantas de la Estación de Biología Tropical Los Tuxtlas, Veracruz,México: (Violaceae-Zingiberaceae). Revista de Biología Tropical 44:427-447.

IUCN. International Union for Conservation of Nature. 2003. Guidelines for Application of IUCN Red List Criteria at Regional Levels: Version 3.0. IUCN Species Survival Commission. International Union for Conservation of Nature, Gland y Cambridge.

Jones M.M., Rojas P.O., Tuomisto H. y Clark D.B. 2007. Environmental and neighbourhood effects on tree fern distributions in a Neotropical lowland rain forest. Journal of Vegetation Science 18:13-24.

Jones M.M., Tuomisto H., Borcard D., Legendre P., Clark D.B. y Olivas P.C. 2008. Explaining variation in tropical plant community composition: influence of environmental and spatial data quality. Oecologia 155:593-604.

Jørgensen P.M., Nee M.H. y Beck S.G. Eds. 2014. Catálogo de las Plantas Vasculares de Bolivia. Monographs in Systematic Botany from the Missouri Botanical Garden, St. Louis.

Kelly D.L., Tanner E.V.J., Nic Lughadha E.M. y Kapos V. 1994. Floristics and biogeography of a rain forest in the Venezuelan Andes. Journal of Biogeography 21:421-440.
Kessler M., Parris B.S. y Kessler E. 2001. A comparison of the tropical montane pteridophyte floras of mount Kinabalu, Bormeo, and Parque Nacional Carrasco, Bolivia. Journal of Biogeography 28:611-622.

Kessler M. 2010. Biogeography of ferns. En: Mehltreter K., Walker L.R. y Sharpe J.M. Eds. Fern Ecology, pp. 22-60, Cambridge University Press, Cambridge.

Kessler M., Grytnes J.A., Halloy S.R.P., Kluge J., Krömer T., León B., Macía M.J. y Young K.R. 2012. Gradientes de diversidad vegetal: Patrones y procesos locales. En: Herzog S.K., Martínez R., Jørgensen P.M. y Tiessen H. Eds. Cambio Climático y la Biodiversidad en los Andes Tropicales, pp. 235-253, Instituto Interamericano para la Investigación del Cambio Global (IAI), São José dos Campos, Comité Científico sobre Problemas del Medio Ambiente (SCOPE), Paris.

Kessler M. y Bach K. 1999. Using indicator families for vegetation classification in species-rich Neotropical forests. Phytocoenologia 29:485-502.

Kreft H., Köster N., Küper W., Nieder J. y Barthlott W. 2004. Diversity and biogeography of vascular epiphytes in Western Amazonia, Yasuní, Ecuador. Journal of Biogeography 31:14631476.

Kreft H., Jetz W., Mutke J. y Barthlott W. 2010. Contrasting environmental and regional effects on global pteridophyte and seed plant diversity. Ecography 33:408-419.

Kress W.J. 1986. The systematic distribution of vascular epiphytes: an update. Selbyana 9:2-22.

Krömer T. y Gradstein S.R. 2003. Species richness of vascular epiphytes in two primary forests and fallows in the Bolivian Andes. Selbyana 24:190-195.

Krömer T., Kessler M., Gradstein S.R. y Acebey A. 2005. Diversity patterns of vascular epiphytes along an elevational gradient in the Andes. Journal of Biogeography 32:1799-1809.

Krömer T., Acebey A. y Smith A.R. 2007a. Thelypteris tuxtlensis (Thelypteridaceae), a new species in subgenus Goniopteris from Los Tuxtlas, Veracruz, Mexico. American Fern Journal 97:136-139.

Krömer T., Kessler M. y Gradstein S.R. 2007b. Vertical stratification of vascular epiphytes in submontane and montane forest of the Bolivian Andes: the importance of the understory. Plant Ecology 189:261-278.

Krömer T., Acebey A.R. y Smith A.R. 2013a. Taxonomic update, distribution and conservation status of grammitid ferns (Polypodiaceae, Polypodiopsida) in Veracruz State, Mexico. Phytotaxa 82:29-44.

Krömer T., Acebey A.R., Kluge J. y Kessler M. 2013b. Effects of altitude and climate in determining elevational plant species richness patterns: a case study from Los Tuxtlas, Mexico. Flora 208: 197-210.

Küper W., Kreft H., Nieder J., Köster N. y Barthlott W. 2004. Large-scale diversity patterns of vascular epiphytes in Neotropical montane rain forests. Journal of Biogeography 31:1477-1487.

Laborde J. 2004. La Reserva de la Biosfera. En: Guevara S., Laborde J. y Sánchez-Ríos G. Eds. Los Tuxtlas. El paisaje de la sierra, pp. 271-279, Instituto de Ecología, A.C., Unión Europea, Xalapa.

Larrea M.L. y Werner F. 2010. Response of vascular epiphyte diversity to different land-use intensities in a Neotropical montane wet forest. Forest Ecology and Management 260:1950-1955.

Lehnert M. 2012. A synopsis of the species of Cyathea (Cyathea- 
ceae-Polypodiopsida) with pinnate to pinnate-pinnatifid fronds. Phytotaxa 61:17-36.

Lira R. y Riba R. 1984. Aspectos fitogeográficos y ecológicos de la flora pteridofita de la sierra de Santa Marta, Veracruz, México. Biótica 9:451-467.

Lomolino M.V. 2001. Elevation gradients of species-density: historical and prospective views. Global Ecology and Biogeography 10:3-13.

Mehltreter K., Flores-Palacios A. y García-Franco J.G. 2005. Host preferences of low-trunk vascular epiphytes in a cloud forest of Veracruz, Mexico. Journal of Tropical Ecology 21:651-660.

Mehltreter K. 2010. Fern conservation. En: Mehltreter K., Walker L.R. y Sharpe J.M. Eds. Fern Ecology, pp. 323-359, Cambridge University Press, Cambridge.

Mickel J.T. y Smith A.R. 2004. The Pteridophytes of Mexico. Memoirs of the New York Botanical Garden 88:1-1054.

Moran R.C., Klimas S. y Carlsen M. 2003. Low-trunk epiphytic ferns on tree ferns versus angiosperms in Costa Rica. Biotropica 35:48-56.

Moran R.C. 2008. Biogeography of ferns and lycophytes. En: Ranker T.A. y Haufler C. Eds. The Biology and Evolution of Ferns and Lycophytes, pp. 369-396, Cambridge University Press, Cambridge.

Moran R.C., Labiak P.H. y Sundue M. 2010. Synopsis of Mickelia, a newly recognized genus of bolbitidoid ferns (Dryopteridaceae). Brittonia 62:337-356.

Moran R.C. y Prado J. 2010. Megalastrum (Dryopteridaceae) in Central America. Kew Bulletin. 65: 137-188.

Murillo-A.J., Polanía-S.C. y León-P.A. 2008. Los helechos y licófitos de la región del Guavio. Biota Colombiana 9:63-76.

Nichols W.F., Killingbeck K. T. y August P. V. 1998. The influence of geomorphological heterogeneity on biodiversity. II. A landscape perspective. Conservation Biology 12:371-379.

Øllgaard B. 2012. New combinations in neotropical Lycopodiaceae. Phytotaxa 57:10-22.

Paciencia M.L.B. y Prado J. 2005. Effects of forest fragmentation on pteridophyte diversity in a tropical rain forest in Brazil. Plant Ecology 180:87-104.

Page C.N. 1979. The diversity of ferns: An ecological perspective. En: Dyer A.F. Ed. The Experimental Biology of Ferns, pp. 1056, Academic Press, Londres.

Page C.N. 2002. Ecological strategies in fern evolution, a neopteridological overview. Review of Palaeobotany and Palynology 119:1-33.

Palacios-Ríos M. 1992. Las Pteridofitas del estado de Veracruz. Tesis de Maestría, Facultad de Ciencias, Universidad Autónoma de México, México D.F. 364 pp

Pérez-Farrera M.A., Martínez-Camilo R., Martínez-Meléndez N., Farrera-Sarmiento O. y Maza-Villalobos S. 2012. Listado florístico del Cerro Quetzal (polígono III) de la reserva de la biosfera El Triunfo, Chiapas, México. Botanical Sciences 90:113-142.

Perry D.R. 1978. A method of access into the crowns of emergent and canopy trees. Biotropica 10:155-157.

Ramírez-Cruz S., Sánchez-González A. y Tejero-Díez J.D. 2009. La Pteridoflora del parque nacional Los Mármoles, Hidalgo, México. Taxonomía y florística. Boletín de la Sociedad Botánica de México 84:35-44.

Ramírez R.F. 1999. Flora y vegetación de la Sierra de Santa Marta, Veracruz. Tesis de Licenciatura, Facultad de Ciencias, Universidad Autónoma de México. 409 pp.
Regalado G.L. y Prada C. 2011. The genus Hymenasplenium (Aspleniaceae) in Cuba, including new combinations for the neotropical species. American Fern Journal 101:265-281.

Riba R. y Pérez-García, B. 1979. Estudio botánico y ecológico de la región del río Uxpanapa, Veracruz. $N^{\circ} 8$ Pteridofitas. Biótica 4:135-139.

Riba R. y Pérez-García B. 1997. Pteridofitas. En: González-Soriano E., Dirzo R. y Vogt R.C. Eds. Historia Natural de Los Tuxtlas, pp. 175-181, Universidad Nacional Autónoma de México, Comisión Nacional para el Conocimiento y Uso de la Biodiversidad, México D.F.

Robinson R.C. Sheffield E. y Sharpe J.M. Problem ferns: their impact and management. En: Mehltreter K., Walker L.R. y Sharpe J.M. Eds. Fern Ecology, pp. 255-322, Cambridge University Press, Cambridge.

Rzedowski J. 1991. El endemismo de la flora fanerogámica mexicana: una apreciación analítica preliminar. Acta Botanica Mexicana 15:47-64.

Salazar L., Homeier J., Kessler M., Abrahamczyk S., Lehnert M., Krömer T. y Kluge J. 2015. Diversity patterns of ferns along elevation in Andean tropical forests. Plant Ecology and Diversity 8:13-24.

SEMARNAT. Secretaría del Medio Ambiente y Recursos Naturales. 2010. Norma Oficial Mexicana NOM-059-SEMARNAT-2010. Protección ambiental-Especies nativas de México de flora y fauna silvestres-Categorías de Riesgo y especificaciones para su inclusión, exclusión o cambio-Lista de especies en riesgo. Diario Oficial de la Federación 30 de Diciembre de 2010, México D.F. Disponible en: http://www.semarnat.gob. $\mathrm{mx} /$ temas/gestionambiental/vidasilvestre/Documents/NOM_ 059_SEMARNAT_2010.pdf (revisada: 01 enero 2014).

Smith A.R., Pryer K.M., Schuettpelz E., Korall P., Schneider H. y Wolf P.G. 2006. A classification for extant ferns. Taxon 55:705731.

Smith A.R. y Tejero-Díez J.D. 2014. Pleopeltis (Polypodiaceae), a redefinition of the genus and nomenclatural novelties. Botanical Sciences 92:43-58.

Soto M. 2004. El clima. En: Guevara S., Laborde J. y SánchezRíos G. Eds. Los Tuxtlas. El Paisaje de la Sierra, pp. 195-198, Instituto de Ecología, A.C., Unión Europea, Xalapa.

Soto M. y Gama L. 1997. Climas. En: González-Soriano E., Dirzo R. y Vogt R. Eds. Historia Natural de Los Tuxtlas, pp. 7-23, Universidad Nacional Autónoma de México-Comisión Nacional para el Conocimiento y Uso de la Biodiversidad, México D.F.

Soto-Esparza M. y Geissert D. 2011. Geografía. En: Comisión Nacional para el Conocimiento y Uso de la Biodiversidad. Ed. La Biodiversidad en Veracruz: Estudio de Estado Vol.1, pp. 31-34, Comisión Nacional para el Conocimiento y Uso de la Biodiversidad, México D.F. y Gobierno del Estado de Veracruz, Universidad Veracruzana, Instituto de Ecología, A.C., Xalapa.

Squeo F.A., Caviers L.A., Arancio G., Novoa J.E., Matthei O., Marticorena C., Rodríguez R., Arroyo M.T.K. y Muñoz M. 1998. Biodiversidad vegetal de Antofagasta. Revista Chilena de Historia Natural 71:571-591.

Sundue M. 2010. Licófitas, helechos. En: Nee M.H. Ed. Flora de la Región del Parque Nacional Amboró, Bolivia. Parte 1. Licofitas, Helechos y Gimnospermas, pp. 50-383, Editorial FAN, Santa Cruz de la Sierra.

Tejero-Díez J.D., Torres-Díaz A., Mickel J.T., Mehltreter K. y 
Krömer T. 2011. Pteridoflora de Veracruz. En: Lorea Hernández F.G., Hernández Ortiz V., Morales mavil. J.E. Eds. La diversidad en veracruz: Estudio de Estado. pp. 97-115, Comisión Nacional para el Conocimiento y Uso de la Biodiversidad, Instituto de Ecología, A.C., Universidad Veracruzana, Xalapa.

Tejero-Díez J.D., Torres-Díaz, A.N. y M. Gual-Díaz. 2014. Licopodios y helechos en el bosque mesófilo de montaña de México. En: Gual-Díaz, M. y A. Rendón-Correa (comps.). 2014. Bosques Mesófilos de Montaña de México: Diversidad, Ecología y Manejo, pp. 197-220, Comisión Nacional para el Conocimiento y Uso de la Biodiversidad. México, D. F.

Thies B., Nauss T. y Bendix J. 2008. Discriminating raining from non-raining clouds at mid-latitudes using meteosat second generation daytime data. Atmospheric and Chemical Physics 8:2341-2349.

Tuomisto H. y Ruokolainen K. 1994. Distribution of pteridophyta and Melastomataceae along an edaphic gradient in an Amazonian rain forest. Journal of Vegetation Science 5:25-34.

Tuomisto H. y Poulsen A.D. 1996. Influence of edaphic specialization on pteridophyte distributions in Neotropical rain forests. Journal of Biogeography 23:283-293.

Tuomisto H., Poulsen A.D. y Moran R.C. 1998. Edaphic distribution of some species of the fern genus Adiantum in Western Amazonia. Biotropica 30:392-399.

Tuomisto H., Ruokolainen K., Poulsen A.D., Moran R.C., Quintana C., Cañas G. y Celi J. 2002. Distribution and diversity of pteridophytes and Melastomataceae along edaphic gradients in Yasuni National Park, Ecuadorian Amazonia. Biotropica 34:516-533.

Villaseñor J.L. 2003. Diversidad y distribución de las Magnoliophyta de México. Interciencia 28:160-167.

Villaseñor J.L. y M. Gual-Díaz. 2014. El bosque mesófilo de mon- taña en México y sus plantas con flores. En: Gual-Díaz, M. y Rendón-Correa A. (comps.). Bosques Mesófilos de Montaña de México: Diversidad, Ecología y Manejo. p.p. 221- 235. Comisión Nacional para el Conocimiento y Uso de la Biodiversidad. México, D.F.

Walker L. y Sharpe J. 2010. Ferns, disturbance and succession. En: Mehltreter K., Walker L.R. y Sharpe J.M. Eds. Fern Ecology, pp. 177-219, Cambridge University Press, Cambridge.

Watkins J.E. Jr., Cardelús C.L., Colwell R.K. y Moran R.C. 2006. Species richness and distribution of ferns along an elevational gradient in Costa Rica. American Journal of Botany 93:73-83

Wendt T. 1993. Composition floristic affinities and origins of the canopy tree flora of the Mexican Atlantic slope rain forest. En: Ramamoorthy T.P., Bye R., Lot A. y Fa J. Eds. Biological Diversity of Mexico: Origins and Distribution, pp. 595-680, Oxford University Press, Nueva York.

Werner F.A., Homeier, J. y Gradstein, S.R. 2005. Diversity of vascular epiphytes on isolated remnant trees in the montane forest belt of southern Ecuador. Ecotropica 11:21-40.

Zotz G. 2013. The systematic distribution of vascular epiphytesa critical update. Botanical Journal of the Linnean Society 171:453-481.

Zotz G. y Andrade J.L. 2002. La ecología y la fisiología de las epífitas y las hemiepífitas. En Guariguata M.R. y Kattan G.H. Eds. Ecología y Conservación de Bosques Neotropicales, pp. 271296, Libro Universitario Regional del Instituto Tecnológico de Costa Rica, San José, Costa Rica.

Zúñiga-Salvatierra J.R. 2009. Los helechos y licopodios del municipio de Tenango de Doria, estado de Hidalgo, México. Tesis de Licenciatura, Universidad Autónoma del estado de Hidalgo, Hidalgo. 79 pp.

Recibido: 2 de mayo de 2014

Aceptado: 30 de junio de 2014 
Apéndice 1. Listado florístico de los helechos y licófitos de la Reserva de la Biosfera Los Tuxtlas, incluyendo rango altitudinal. TV = Tipos de vegetación según Castillo y Laborde (2004): selva alta perennifolia (SAP), bosque mesófilo de montaña (BMM), selva mediana perennifolia (SMP), bosque de pino (Pinus oocarpa) (BP), bosque de encino (Quercus spp.) (BQ), manglar (MGL), dunas costeras (DNC), bosque de pino-encino (BP-BQ), bosque de transición selva alta perennifolia y bosque mesófilo de montaña (ECO), vegetación secundaria (VS), vegetación riparia (VR), vegetación acuática (VAC), vegetación antropogénica (cultivos, plantaciones, cercas vivas, vegetación ruderal, pastizal) (VA); FC = Formas de crecimiento según Grayum y Churchill (1987): E = Epífita (crecen sobre árboles del dosel o sotobosque), T = terrestre, $\mathrm{R}=$ rupícola (crecen sobre rocas), He = hemiepífita (crecen inicialmente en el suelo, o muy cerca de él, y en la madurez son trepadoras adpresas en las bases de los troncos (comúnmente la conexión con el suelo se pierde), Hi = Hidrófita; EC NOM=Estado de conservación según la NOM-059-ECOL-2010: A = amenazada, $\mathrm{P}$ = en Peligro, $\mathrm{Pr}=$ bajo protección especial; ECV: Estado de conservación según Tejero et al. (2011); distribución geográfica y estatal en México según Mickel y Smith (2004): Cos= Cosmopolita, A= América, USA: Estados Unidos de América $(\mathrm{s}=$ sur, sw = suroeste), Fla = Florida, $\mathrm{M}=$ México, $\mathrm{AN}=$ Antillas, $\mathrm{CA}=$ Centroamérica, $\mathrm{SA}=\mathrm{Sudamérica}(\mathrm{n}=\mathrm{norte}), \mathrm{Ags}=$ Aguascalientes, BCN = Baja California Norte, BCS = Baja California Sur, Camp = Campeche, Chih = Chihuahua, Chis $=$ Chiapas, Coah $=$ Coahuila, Col = Colima, DF = Distrito Federal, Dgo = Durango, Gro = Guerrero, Gto = Guanajuato, Hgo $=$ Hidalgo, Jal $=$ Jalisco, Méx = México, Mich = Michoacán, Mor = Morelos, Nay = Nayarit, NL = Nuevo León, Oax = Oaxaca, Pue = Puebla, Qro = Quintana Roo, Qro = Querétaro, Rev = Islas Revillagigedo, SLP = San Luis Potosí, Sin = Sinaloa, Son = Sonora, Tab = Tabasco, Tam = Tamaulipas, Tlax = Tlaxcala, Ver = Veracruz, Yuc = Yucatán y Zac = Zacatecas; Observ.=Observaciones: NT = nuevos registros para Los Tuxtlas, NV = nuevos registros para Veracruz, $r=$ rara hasta 3-5 colectas, mr = muy rara 1-2 colectas; y un ejemplar de herbario de referencia revisado. * Las colecciones de R. Lira 128 y 173 (MEXU) identificados como Campyloneurum serpentinum corresponden a C. xalapense confirmado por A.R. Smith y M. Palacios-Ríos en 1998.

\begin{tabular}{|c|c|c|c|c|c|c|c|c|c|}
\hline Familia/Especie & $\begin{array}{l}\text { Altitud } \\
(\mathrm{m})\end{array}$ & TV & FC & $\begin{array}{l}\text { EC } \\
\text { NOM }\end{array}$ & ECV & $\begin{array}{l}\text { Distribución } \\
\text { geográfica }\end{array}$ & $\begin{array}{l}\text { Distribución } \\
\text { estatal en } \\
\text { México }\end{array}$ & & $\begin{array}{l}\text { Ejemplar de } \\
\text { referencia }\end{array}$ \\
\hline \multicolumn{10}{|l|}{$\begin{array}{l}\text { LYCOPODIIDAE [Licófitos] } \\
\text { Lycopodiaceae }\end{array}$} \\
\hline $\begin{array}{l}\text { Huperzia dichotoma (Jacq.) } \\
\text { Trev.=Phlegmariurus dichotomus } \\
\text { (Jacq.) W.H. Wagner }\end{array}$ & $150-550$ & SAP & $E$ & A & V & $\mathrm{M}, \mathrm{CA}, \mathrm{AN}, \mathrm{SA}$ & $\begin{array}{l}\text { Chis, DF, Gro, } \\
\text { Oax, Pue, Rev, } \\
\text { SLP, Tam, Ver. }\end{array}$ & $r$ & $\begin{array}{l}\text { T. Krömer et al. } \\
\text { 1918; MEXU, UC }\end{array}$ \\
\hline $\begin{array}{l}\text { Huperzia linifolia (L.) Trevis= } \\
\text { Phlegmariurus linifolius (L.) } \\
\text { B. Øllg. }\end{array}$ & 1125 & BMM & $\mathrm{E}$ & & V & $\mathrm{M}, \mathrm{CA}, \mathrm{AN}, \mathrm{SA}$ & $\begin{array}{l}\text { Chis, Gro, Oax, } \\
\text { Pue, Tab, Ver. }\end{array}$ & $\mathrm{mr}$ & $\begin{array}{l}\text { T. Krömer \& E. Otto } \\
\text { 2959; MEXU, UC }\end{array}$ \\
\hline $\begin{array}{l}\text { Huperzia pithyoides (Schltdl. \& } \\
\text { Cham.) Holub=Phlegmariurus } \\
\text { pithyoides (Schltdl. \& Cham.) } \\
\text { B. Øllg. }\end{array}$ & 1300-1590 & $\mathrm{BMM}$ & $\mathrm{E}$ & & A & $\mathrm{M}, \mathrm{CA}, \mathrm{AN}, \mathrm{nSA}$ & $\begin{array}{l}\text { Chis, Gro, Méx, } \\
\text { Oax, Qro, SLP, } \\
\text { Tam, Ver. }\end{array}$ & $r$ & $\begin{array}{l}\text { T. Krömer \& A. } \\
\text { Acebey } 2248 ; \\
\text { MEXU, UC }\end{array}$ \\
\hline $\begin{array}{l}\text { Huperzia pringlei (Underw. \& } \\
\text { F.E. Lloyd) Holub=Phlegmariurus } \\
\text { pringlei (Underw. \& F.E. Lloyd) } \\
\text { B. Øllg. }\end{array}$ & $1500-1675$ & BMM & $E$ & & A & $\mathrm{M}, \mathrm{CA}$ & $\begin{array}{l}\text { Chis, Gro, Hgo, } \\
\text { Jal, Méx, Mich, } \\
\text { Mor, Oax, Ver. }\end{array}$ & $r$ & $\begin{array}{l}\text { T. Krömer \& A. } \\
\text { Acebey } 2259 ; \\
\text { MEXU, UC }\end{array}$ \\
\hline $\begin{array}{l}\text { Huperzia reflexa (Lam.) Trevis.= } \\
\text { Phlegmariurus reflexus (Lam.) } \\
\text { B. Øllg. }\end{array}$ & 1010 & VS & $\mathrm{T}$ & & V & $\mathrm{M}, \mathrm{CA}, \mathrm{AN}, \mathrm{SA}$ & $\begin{array}{l}\text { Chis, Gro, Hgo, } \\
\text { Jal, Méx, Oax, } \\
\text { Pue, Ver. }\end{array}$ & $\mathrm{mr}$ & R. Lira 138; UAMIZ \\
\hline $\begin{array}{l}\text { Huperzia taxifolia (Sw.) Trevis.= } \\
\text { Phlegmariurus taxifolius (Sw.) } \\
\text { Á. Löve \& D. Löve }\end{array}$ & $600-1590$ & $\begin{array}{l}\text { SAP, BMM, E } \\
\text { ECO }\end{array}$ & & V & $\mathrm{M}, \mathrm{C}$ & $\mathrm{A}, \mathrm{AN}, \mathrm{SA}$ & $\begin{array}{l}\text { Chis, DF, Gro, } \\
\text { Hgo, Jal, Méx, } \\
\text { Oax, Pue, Sin, } \\
\text { SLP, Tam, Ver. }\end{array}$ & & $\begin{array}{l}\text { T. Krömer \& A. } \\
\text { Acebey } 2263 \\
\text { MEXU, UC }\end{array}$ \\
\hline $\begin{array}{l}\text { Lycopodiella cernua (L.) Pic. } \\
\text { Serm.=Palhinhaea cernua (L.) } \\
\text { Vasc. \& Franco }\end{array}$ & $100-1200$ & SAP, BMM & $\mathrm{T}$ & & $\mathrm{S}$ & Cos & $\begin{array}{l}\text { Chis, Gro, Hgo, } \\
\text { Jal, Méx, Mich, } \\
\text { Nay, Oax, Pue, } \\
\text { Tab, Ver. }\end{array}$ & $r$ & $\begin{array}{l}\text { J.I. Calzada } \\
\text { 11235; MEXU }\end{array}$ \\
\hline $\begin{array}{l}\text { Selaginellaceae } \\
\text { Selaginella extensa Underw. }\end{array}$ & 200 & SAP & T & & A & M (endémica) & $\begin{array}{l}\text { Hgo, Jal, Oax, } \\
\text { Qro, SLP, Tam, } \\
\text { Ver. }\end{array}$ & $\mathrm{mr}$ & $\begin{array}{l}\text { F. Ramírez } \\
1143 ; \mathrm{XAL}\end{array}$ \\
\hline
\end{tabular}


Apéndice 1. Continuación

\begin{tabular}{|c|c|c|c|c|c|c|c|c|c|}
\hline Familia/Especie & $\begin{array}{l}\text { Altitud } \\
(\mathrm{m})\end{array}$ & TV & FC & $\begin{array}{l}\mathrm{EC} \\
\mathrm{NOM}\end{array}$ & ECV & $\begin{array}{l}\text { Distribución } \\
\text { geográfica }\end{array}$ & $\begin{array}{l}\text { Distribución } \\
\text { estatal en } \\
\text { México }\end{array}$ & Observ. & $\begin{array}{l}\text { Ejemplar de } \\
\text { referencia }\end{array}$ \\
\hline Selaginella flexuosa Spring & $\begin{array}{l}\text { arriba de } \\
1200\end{array}$ & BMM & $\mathrm{T}$ & & A & $\mathrm{M}, \mathrm{CA}, \mathrm{SA}$ & Oax, Pue, Ver. & $\mathrm{mr}$ & R. Lira 196; ENCB \\
\hline Selaginella guatemalensis Baker & 510 & VS & $\mathrm{T}, \mathrm{R}$ & & A & $\mathrm{M}, \mathrm{CA}$ & Chis, Oax, Ver. & $\mathrm{NV}, \mathrm{mr}$ & $\begin{array}{l}\text { T. Krömer \& A. } \\
\text { Acebey } 2277 ; \\
\text { MEXU, UC }\end{array}$ \\
\hline Selaginella hoffmannii Hieron. & $28-450$ & SAP & $\mathrm{T}$ & & $\mathrm{S}$ & $\mathrm{M}, \mathrm{CA}$ & $\begin{array}{l}\text { Chis, Col, Gro, } \\
\text { Méx, Mich, Nay, } \\
\text { Oax, Sin, Ver. }\end{array}$ & r & $\begin{array}{l}\text { J.I. Calzada 51; } \\
\text { MEXU }\end{array}$ \\
\hline Selaginella martensii Spring & $750-1450$ & $\begin{array}{l}\mathrm{ECO} \\
\mathrm{BMM}\end{array}$ & $\mathrm{T}$ & & S & $\mathrm{M}, \mathrm{CA}$ & $\begin{array}{l}\text { Chis, Méx, Oax, } \\
\text { Qro, SLP, Ver. }\end{array}$ & $\mathrm{mr}$ & $\begin{array}{l}\text { T. Krömer \& E. Otto } \\
\text { 3002; MEXU, UC }\end{array}$ \\
\hline Selaginella mickelii Valdespino & $150-450$ & SAP, VA & $\mathrm{T}$ & & A & M (endémica) & $\begin{array}{l}\text { Chis, Oax, } \\
\text { Tab, Ver }\end{array}$ & r & $\begin{array}{l}\text { T. Krömer \& A. } \\
\text { Pérez-Peña 2781; } \\
\text { MEXU, UC }\end{array}$ \\
\hline Selaginella oaxacana Spring & $750-1350$ & $\begin{array}{l}\text { SAP, BMM, } \\
\text { ECO }\end{array}$ & $\mathrm{T}$ & & A & $\mathrm{M}, \mathrm{CA}, \mathrm{nSA}$ & Chis, Oax, Ver. & & $\begin{array}{l}\text { T. Krömer \& E. Otto } \\
\text { 3006; MEXU, UC }\end{array}$ \\
\hline Selaginella reflexa Underw. & 300 & SAP & $\mathrm{T}$ & & A & M, Guat & $\begin{array}{l}\text { Dgo, Gro, Hgo, } \\
\text { Jal, NL, Qro, } \\
\text { SLP, Ver. }\end{array}$ & $\mathrm{mr}$ & $\begin{array}{l}\text { R. Riba et al. } 1222 \\
\text { B; MEXU }\end{array}$ \\
\hline Selaginella schizobasis Baker & $45-600$ & $\begin{array}{l}\text { SAP, VA, } \\
\text { VS, SMP }\end{array}$ & $\mathrm{T}$ & & V & $\mathrm{M}, \mathrm{CA}$ & $\begin{array}{l}\text { Chis, Oax, Tab, } \\
\text { Ver. }\end{array}$ & & $\begin{array}{l}\text { T. Krömer et al. } \\
\text { 2596; MEXU, UC }\end{array}$ \\
\hline Selaginella silvestris Asplund & $100-240$ & VS & $\mathrm{T}$ & & S & $\mathrm{M}, \mathrm{CA}, \mathrm{SA}$ & $\begin{array}{l}\text { Chis, Hgo, Méx, } \\
\text { Oax, Ver. }\end{array}$ & $\mathrm{mr}$ & $\begin{array}{l}\text { T. Krömer \& A. } \\
\text { Pérez-Peña 2801; } \\
\text { MEXU, UC }\end{array}$ \\
\hline Selaginella stellata Spring & $\begin{array}{l}200-450 \\
(1200 ? \text { ver } \\
\text { CIB) }\end{array}$ & SAP, BMM & $\mathrm{T}$ & & $\mathrm{S}$ & $\mathrm{M}, \mathrm{CA}$ & $\begin{array}{l}\text { Chis, Gro, Hgo, } \\
\text { Jal, Mich, Nay, } \\
\text { Oax, Pue, Ver. }\end{array}$ & r & $\begin{array}{l}\text { S. Sinaca C. 1148; } \\
\text { MEXU, EBT, }\end{array}$ \\
\hline \multicolumn{10}{|l|}{$\begin{array}{l}\text { POLYPODIIDAE [Helechos] } \\
\text { Anemiaceae }\end{array}$} \\
\hline Anemia hirsuta (L.) Sw. & $350-600$ & SAP, VS & $\mathrm{T}$ & & V & $\mathrm{M}, \mathrm{CA}, \mathrm{AN}, \mathrm{SA}$ & $\begin{array}{l}\text { Chis, Col, Gro, } \\
\text { Jal, Méx, Mich, } \\
\text { Mor, Nay, Oax, } \\
\text { Pue, Tam, Ver }\end{array}$ & r & $\begin{array}{l}\text { R. Riba } 1579 ; \\
\text { MEXU, UAMIZ }\end{array}$ \\
\hline Anemia muenchii Christ & 450 & SAP & $\mathrm{T}$ & & $P$ & M (endémica) & Chis, Oax, Ver & $\mathrm{mr}$ & $\begin{array}{l}\text { J.H. Beaman 5237; } \\
\text { MEXU }\end{array}$ \\
\hline $\begin{array}{l}\text { Anemia pastinacaria Moritz } \\
\text { ex Prantl }\end{array}$ & 490 & BQ-BP & $\mathrm{T}$ & & V & $\mathrm{M}, \mathrm{CA}, \mathrm{AN}, \mathrm{SA}$ & $\begin{array}{l}\text { Chis, Gro, Jal, } \\
\text { Nay, Oax, Ver }\end{array}$ & $\mathrm{mr}$ & $\begin{array}{l}\text { J.I. Calzada 12369; } \\
\text { MEXU }\end{array}$ \\
\hline Anemia phyllitidis (L.) Sw. & $350-450$ & $\begin{array}{l}\text { SAP, BQ, } \\
\text { VS }\end{array}$ & $\mathrm{T}$ & & S & $\mathrm{M}, \mathrm{CA}, \mathrm{AN}, \mathrm{SA}$ & $\begin{array}{l}\text { Chis, Col, Gro, } \\
\text { Hgo, Jal, Méx, } \\
\text { Mich, Nay, Oax, } \\
\text { Qro, SLP, Tam, Ve }\end{array}$ & & $\begin{array}{l}\text { R. Cedillo T. 3707; } \\
\text { MEXU }\end{array}$ \\
\hline \multicolumn{10}{|l|}{ Aspleniaceae } \\
\hline Asplenium abscissum L. & $490-1420$ & $\begin{array}{l}\text { SAP, BMM, } \\
\text { ECO }\end{array}$ & $\mathrm{T}, \mathrm{R}$ & & V & $\mathrm{M}, \mathrm{CA}, \mathrm{AN}, \mathrm{SA}$ & $\begin{array}{l}\text { Chis, Hgo, Jal, } \\
\text { Mor, Nay, Oax, } \\
\text { Tab, Ver }\end{array}$ & & $\begin{array}{l}\text { T. Krömer \& A. } \\
\text { Acebey } 2548 ; \\
\text { MEXU, UC, EBT }\end{array}$ \\
\hline $\begin{array}{l}\text { Asplenium achilleifolium } \\
\text { (M. Martens \& Galeotti) Liebm. }\end{array}$ & $1000-1250$ & BMM & $\mathrm{T}$ & & V & M, CA, Perú & $\begin{array}{l}\text { Chis, Col, Gro, } \\
\text { Jal, Oax, } \\
\text { Pue, Ver }\end{array}$ & $\begin{array}{l}\mathrm{NT}, \\
\mathrm{mr}\end{array}$ & $\begin{array}{l}\text { T. Krömer \& A. } \\
\text { Acebey; MEXU, } \\
\text { UC, EBT }\end{array}$ \\
\hline
\end{tabular}


Apéndice 1. Continuación

\begin{tabular}{|c|c|c|c|c|c|c|c|c|c|}
\hline Familia/Especie & $\begin{array}{l}\text { Altitud } \\
(\mathrm{m})\end{array}$ & TV & FC & $\begin{array}{l}\text { EC } \\
\text { NOM }\end{array}$ & ECV & $\begin{array}{l}\text { Distribución } \\
\text { geográfica }\end{array}$ & $\begin{array}{l}\text { Distribución } \\
\text { estatal en } \\
\text { México }\end{array}$ & Obse & $\begin{array}{l}\text { v. Ejemplar de } \\
\text { referencia }\end{array}$ \\
\hline Asplenium auriculatum Sw. & $350-1440$ & $\begin{array}{l}\mathrm{BMM} \\
\mathrm{ECO}\end{array}$ & $\mathrm{E}$ & & V & $\mathrm{M}, \mathrm{CA}, \mathrm{AN}, \mathrm{SA}$ & \multicolumn{2}{|l|}{$\begin{array}{l}\text { Chis, Gro, Hgo, } \\
\text { Jal, Méx, Mich, } \\
\text { Oax, Pue, Qro, } \\
\text { Tam, Ver }\end{array}$} & $\begin{array}{l}\text { T. Krömer et al. } \\
\text { 2709, MEXU, } \\
\text { UC, EBT }\end{array}$ \\
\hline Asplenium cristatum Lam. & $100-350$ & SAP & $\mathrm{T}, \mathrm{R}$ & & $\mathrm{S}$ & $\begin{array}{l}\text { USA (Fla), M, } \\
\text { CA, AN, SA }\end{array}$ & \multicolumn{2}{|l|}{$\begin{array}{l}\text { Chis, Oax, Pue, } \\
\text { Qro, SLP, Tab, } \\
\text { Tam, Ver }\end{array}$} & $\begin{array}{l}\text { S. Sinaca 904; } \\
\text { MEXU, MO, EBT }\end{array}$ \\
\hline Asplenium cuspidatum Lam. & $450-1350$ & $\begin{array}{l}\text { SAP, } \\
\text { BMM, } \\
\text { ECO,VS }\end{array}$ & $\begin{array}{l}\mathrm{T}, \mathrm{E}, \\
\mathrm{R}\end{array}$ & & $\mathrm{V}$ & $\mathrm{M}, \mathrm{CA}, \mathrm{AN}, \mathrm{SA}$ & \multicolumn{2}{|l|}{$\begin{array}{l}\text { Chis, Hgo, Jal, } \\
\text { Mich, Mor, Oax, } \\
\text { Pue, Qro, SLP, } \\
\text { Tam, Ver }\end{array}$} & $\begin{array}{l}\text { T. Krömer et al. } \\
2709 ; \text { MEXU, } \\
\text { UC, EBT }\end{array}$ \\
\hline Asplenium feei Kunze ex Fée & 1300 & SAP, BMM & $\mathrm{E}$ & & A & $\mathrm{M}, \mathrm{CA}, \mathrm{AN}, \mathrm{SA}$ & Chis, Ver & $\mathrm{mr}$ & $\begin{array}{l}\text { R. Lira 16; MEXU, } \\
\text { UAMIZ }\end{array}$ \\
\hline Asplenium flabellulatum Kunze & 1120 & BMM & $\mathrm{T}, \mathrm{R}$ & & A & $\mathrm{M}, \mathrm{CA}, \mathrm{AN}, \mathrm{SA}$ & $\begin{array}{l}\text { Chis, Oax, } \\
\text { Pue, Ver }\end{array}$ & $\begin{array}{l}\mathrm{NT}, \\
\mathrm{mr}\end{array}$ & $\begin{array}{l}\text { T. Krömer et al. 2400; } \\
\text { MEXU, UC, XAL }\end{array}$ \\
\hline Asplenium formosum Willd. & $50-600$ & SAP & $\mathrm{T}, \mathrm{R}$ & & V & Cos & \multicolumn{2}{|l|}{$\begin{array}{l}\text { Chis, Col, DF, } \\
\text { Dgo, Gro, Jal, } \\
\text { Méx, Mich, Mor, } \\
\text { Nay, Oax, Pue, } \\
\text { Rev, Tab, Ver }\end{array}$} & $\begin{array}{l}\text { S. Sinaca 903; } \\
\text { MEXU, MO, EBT }\end{array}$ \\
\hline Asplenium fragrans Sw. & 1590 & BMM & $\mathrm{T}, \mathrm{E}$ & & A & $\mathrm{M}, \mathrm{CA}, \mathrm{AN}, \mathrm{SA}$ & $\begin{array}{l}\text { Chis, Dgo, Gro, } \\
\text { Jal, Méx, Mich, } \\
\text { Mor, Nay, Oax, } \\
\text { Pue, Sin, Ver }\end{array}$ & $\begin{array}{l}\mathrm{NT} \\
\mathrm{mr}\end{array}$ & $\begin{array}{l}\text { T. Krömer \& A. } \\
\text { Acebey } 2434 ; \\
\text { MEXU, UC }\end{array}$ \\
\hline $\begin{array}{l}\text { Asplenium minimum M. } \\
\text { Martens \& Galeotti }\end{array}$ & 350 & SAP & $\mathrm{T}, \mathrm{R}$ & & $\mathrm{V}$ & $\mathrm{M}, \mathrm{CA}, \mathrm{nSA}$ & $\begin{array}{l}\text { Chis, Mor, Oax, } \\
\text { Qro, SLP, Tab, } \\
\text { Tam, Ver }\end{array}$ & $\begin{array}{l}\mathrm{NT} \\
\mathrm{mr}\end{array}$ & $\begin{array}{l}\text { J.I. Calzada 8113; } \\
\text { XAL }\end{array}$ \\
\hline Asplenium miradorense Liebm. & $740-1400$ & $\begin{array}{l}\mathrm{ECO} \\
\mathrm{BMM}\end{array}$ & $\mathrm{T}, \mathrm{R}$ & & V & $\mathrm{M}, \mathrm{CA}, \mathrm{nSA}$ & $\begin{array}{l}\text { Chis, Gro, Oax, } \\
\text { Pue, Ver }\end{array}$ & $\begin{array}{l}\text { NT, } \\
r\end{array}$ & $\begin{array}{l}\text { T. Krömer \& A. } \\
\text { Acebey 2246; MEXU, } \\
\text { UC, EBT }\end{array}$ \\
\hline Asplenium monanthes L. & 1590 & BMM & $\mathrm{T}$ & & V & $\begin{array}{l}\text { sUSA, M, CA, } \\
\text { AN, SA }\end{array}$ & $\begin{array}{l}\text { BCS, Chih, Chis, } \\
\text { Coah, Col, DF, } \\
\text { Dgo, Gro, Gto, } \\
\text { Hgo, Jal, Méx, } \\
\text { Mich, Mor, Nay, } \\
\text { NL, Oax, Pue, Qr } \\
\text { Sin, SLP, Son, Tam } \\
\text { Tlax, Ver, Zac }\end{array}$ & $\begin{array}{l}\text { NT, } \\
\mathrm{mr} \\
\\
\mathrm{mo} \\
\mathrm{m},\end{array}$ & $\begin{array}{l}\text { T. Krömer \& A. } \\
\text { Acebey 2258; } \\
\text { MEXU, UC, EBT }\end{array}$ \\
\hline Asplenium monodon Liebm. & $600-850$ & SMP, ECO & $\mathrm{T}, \mathrm{E}$ & & V & Cos & $\begin{array}{l}\text { Chis, Oax, } \\
\text { Pue, Ver }\end{array}$ & $\mathrm{mr}$ & $\begin{array}{l}\text { R. Riba et al. 1144; } \\
\text { MEXU, UAMIZ }\end{array}$ \\
\hline Asplenium pteropus Kaulf. & $980-1300$ & BMM & $\mathrm{E}$ & & A & $\mathrm{M}, \mathrm{CA}, \mathrm{AN}, \mathrm{SA}$ & $\begin{array}{l}\text { Chis, Oax, } \\
\text { Pue, Ver }\end{array}$ & & $\begin{array}{l}\text { T. Krömer \& A. } \\
\text { Acebey 2503; MEXU, } \\
\text { UC, EBT }\end{array}$ \\
\hline Asplenium pulchellum Raddi & $250-350$ & SAP & $\mathrm{R}$ & & A & $\mathrm{M}, \mathrm{CA}, \mathrm{SA}$ & Chis, Oax, Ver & $\mathrm{mr}$ & $\begin{array}{l}\text { G. Ibarra M. \& S. } \\
\text { Sinaca C. 2470; } \\
\text { MEXU, ENCB, EBT }\end{array}$ \\
\hline
\end{tabular}


Apéndice 1. Continuación

\begin{tabular}{|c|c|c|c|c|c|c|c|c|c|}
\hline Familia/Especie & $\begin{array}{l}\text { Altitud } \\
(\mathrm{m})\end{array}$ & TV & FC & $\begin{array}{l}\mathrm{EC} \\
\mathrm{NOM}\end{array}$ & ECV & $\begin{array}{l}\text { Distribución } \\
\text { geográfica }\end{array}$ & $\begin{array}{l}\text { Distribución } \\
\text { estatal en } \\
\text { México }\end{array}$ & Obse & $\begin{array}{l}\text { Ejemplar de } \\
\text { referencia }\end{array}$ \\
\hline Asplenium pumilum Sw. & $300-400$ & SAP & $\mathrm{T}$ & & S & $\operatorname{Cos}$ & $\begin{array}{l}\text { BCS, Camp, } \\
\text { Chis, Col, Gro, } \\
\text { Jal, Méx, Mich, } \\
\text { Mor, Nay, NL, } \\
\text { Oax, Qro, QR, } \\
\text { SLP, Sin, Son, } \\
\text { Tab, Ver, Yuc. }\end{array}$ & r & $\begin{array}{l}\text { Dressler, } R . \text { y Jones, } \\
\text { Q. 73; MEXU, UC }\end{array}$ \\
\hline Asplenium riparium Liebm. & $600-1250$ & $\begin{array}{l}\text { SAP, } \\
\text { ECO, } \\
\text { BMM }\end{array}$ & $\mathrm{T}$ & & V & $\mathrm{M}, \mathrm{CA}, \mathrm{nSA}$ & $\begin{array}{l}\text { Chis, Oax, } \\
\text { Pue, Ver }\end{array}$ & $\begin{array}{l}\text { NT, } \\
r\end{array}$ & $\begin{array}{l}\text { T. Krömer \& A. } \\
\text { Acebey 2555, MEXU, } \\
\text { UC, EBT }\end{array}$ \\
\hline $\begin{array}{l}\text { Asplenium rutaceum } \\
\text { (Willd.) Mett. }\end{array}$ & $750-1300$ & $\begin{array}{l}\mathrm{ECO} \\
\mathrm{BMM}\end{array}$ & $\mathrm{T}, \mathrm{E}$ & & A & $\mathrm{M}, \mathrm{CA}, \mathrm{AN}, \mathrm{SA}$ & Chis, Oax, Ver. & r & $\begin{array}{l}\text { R. Lira 217; ENCB, } \\
\text { UAMIZ }\end{array}$ \\
\hline Asplenium serratum L. & $50-300$ & SAP & $\mathrm{E}$ & A & V & $\begin{array}{l}\text { USA (Fla), M, } \\
\text { CA, AN, SA }\end{array}$ & $\begin{array}{l}\text { Chis, Oax, } \\
\text { Tab, Ver. }\end{array}$ & r & $\begin{array}{l}\text { R. Riba et al. 1217; } \\
\text { ENCB, EBT, MEXU, } \\
\text { XAL }\end{array}$ \\
\hline Asplenium uniseriale Raddi & $550-600$ & SAP, SMP & $\mathrm{T}$ & & A & $\mathrm{M}, \mathrm{CA}, \mathrm{AN}, \mathrm{SA}$ & Chis, Oax, Ver. & $\mathrm{mr}$ & $\begin{array}{l}\text { M. Vazquez T. et al. } \\
\text { 3827; CIB }\end{array}$ \\
\hline Asplenium venturae A.R. Sm. & 1350 & BMM & $\mathrm{T}$ & & $P$ & $\begin{array}{l}M \text { (endémica, } \\
\text { Ver) }\end{array}$ & Ver & $\begin{array}{l}\mathrm{NT} \\
\mathrm{mr}\end{array}$ & $\begin{array}{l}\text { T.Krömer \& E. Otto } \\
\text { 3005; MEXU, MEXU, } \\
\text { UC, EBT }\end{array}$ \\
\hline \multicolumn{10}{|l|}{ Blechnaceae } \\
\hline $\begin{array}{l}\text { Blechnum appendiculatum } \\
\text { Willd. }\end{array}$ & $740-1590$ & $\begin{array}{l}\text { ECO, } \\
\text { BMM, VA }\end{array}$ & $\mathrm{T}$ & & V & $\mathrm{M}, \mathrm{CA}, \mathrm{AN}, \mathrm{SA}$ & $\begin{array}{l}\text { Chis, Col, DF, } \\
\text { Gro, Hgo, Jal, } \\
\text { Méx, Mich, Mor, } \\
\text { Nay, Oax, Pue, } \\
\text { Qro, SLP, Tam, } \\
\text { Tlax, Ver. }\end{array}$ & r & $\begin{array}{l}\text { T. Krömer \& A. } \\
\text { Acebey 2260; MEXU, } \\
\text { UC, EBT }\end{array}$ \\
\hline $\begin{array}{l}\text { Blechnum ensiforme (Liebm.) } \\
\text { C. Chr. }\end{array}$ & $960-1300$ & $\begin{array}{l}\text { BMM, } \\
\text { ECO }\end{array}$ & $\mathrm{He}$ & & V & $\mathrm{M}, \mathrm{CA}, \mathrm{SA}$ & $\begin{array}{l}\text { Chis, Gro, } \\
\text { Oax, Ver. }\end{array}$ & r & $\begin{array}{l}\text { T. Krömer \& E. } \\
\text { Otto 2966; MEXU, } \\
\text { UC }\end{array}$ \\
\hline $\begin{array}{l}\text { Blechnum fragile (Liebm.) } \\
\text { C.V. Morton \& Lellinger }\end{array}$ & $1070-1400$ & BMM & $\mathrm{He}$ & & V & $\mathrm{M}, \mathrm{CA}, \mathrm{AN}, \mathrm{SA}$ & $\begin{array}{l}\text { Chis, Oax, } \\
\text { Pue, Ver. }\end{array}$ & $\mathrm{mr}$ & $\begin{array}{l}\text { T. Krömer et al. } \\
\text { 2592; MEXU, UC }\end{array}$ \\
\hline Blechnum gracile Kaulf. & (0) $300-575$ & $\begin{array}{l}\text { SAP, BP, } \\
\text { BQ-BP }\end{array}$ & $\mathrm{T}$ & & V & $\mathrm{M}, \mathrm{CA}, \mathrm{AN}, \mathrm{SA}$ & $\begin{array}{l}\text { Chis, Gro, Jal, } \\
\text { Nay, Oax, Tab, Ve }\end{array}$ & & $\begin{array}{l}\text { R. Riba et al. } \\
\text { 1219; MEXU, UAMIZ }\end{array}$ \\
\hline Blechnum occidentale L. & $850-890$ & $\begin{array}{l}\text { SAP, ECO, } \\
\text { BMM, VR }\end{array}$ & $\mathrm{T}, \mathrm{R}$ & & S & $\mathrm{M}, \mathrm{CA}, \mathrm{AN}, \mathrm{SA}$ & $\begin{array}{l}\text { Chis, Gro, Mich, } \\
\text { Nay, Oax, Pue, } \\
\text { SLP, Tab, Ver. }\end{array}$ & & $\begin{array}{l}\text { T. Krömer et al. } \\
\text { 2571; MEXU, UC }\end{array}$ \\
\hline Blechnum polypodioides Raddi & $490-575$ & $\begin{array}{l}\mathrm{BP}, \\
\mathrm{BQ}-\mathrm{BP}\end{array}$ & $\mathrm{T}$ & & V & $\mathrm{M}, \mathrm{CA}, \mathrm{AN}, \mathrm{SA}$ & $\begin{array}{l}\text { Chis, Gro, Jal, } \\
\text { Méx, Nay, Oax, } \\
\text { Pue, Sin, Ver. }\end{array}$ & $\begin{array}{l}\mathrm{NT} \\
\mathrm{mr}\end{array}$ & $\begin{array}{l}\text { G. Castillo-Campos } \\
\text { 13626; XAL }\end{array}$ \\
\hline $\begin{array}{l}\text { Blechnum schiedeanum } \\
\text { (Schltdl. ex C. Presl) Hieron. }\end{array}$ & $700-1570$ & $\begin{array}{l}\mathrm{ECO} \\
\mathrm{BMM}\end{array}$ & $\mathrm{T}$ & & V & $\mathrm{M}, \mathrm{CA}$ & $\begin{array}{l}\text { Chis, Gro, Hgo, } \\
\text { Méx, Oax, } \\
\text { Pue, Ver. }\end{array}$ & r & $\begin{array}{l}\text { T. Krömer \& E. Otto } \\
\text { 2831; MEXU, UC }\end{array}$ \\
\hline $\begin{array}{l}\text { Woodwardia spinulosa } \\
\text { M. Martens \& Galeotti }\end{array}$ & $1590-1650$ & BMM & $\mathrm{T}$ & & V & $\mathrm{M}, \mathrm{CA}$ & $\begin{array}{l}\text { Chih, Chis, DF, } \\
\text { Dgo, Gro, Gto, } \\
\text { Hgo, Jal, Méx, } \\
\text { Mich, Mor, Nay, } \\
\text { NL, Oax, Pue, } \\
\text { SLP, Sin, Ver. }\end{array}$ & $\mathrm{mr}$ & $\begin{array}{l}\text { T. Krömer \& A. } \\
\text { Acebey } 2264 ; \\
\text { MEXU, UC }\end{array}$ \\
\hline
\end{tabular}


Apéndice 1. Continuación

\begin{tabular}{|c|c|c|c|c|c|c|c|c|c|}
\hline Familia/Especie & $\begin{array}{l}\text { Altitud } \\
(\mathrm{m})\end{array}$ & TV & $\mathrm{FC}$ & $\begin{array}{l}\text { EC } \\
\text { NOM }\end{array}$ & ECV & $\begin{array}{l}\text { Distribución } \\
\text { geográfica }\end{array}$ & $\begin{array}{l}\text { Distribución } \\
\text { estatal en } \\
\text { México }\end{array}$ & Obse & $\begin{array}{l}\text { Ejemplar de } \\
\text { referencia }\end{array}$ \\
\hline $\begin{array}{l}\text { Cyatheaceae } \\
\text { Alsophila firma (Baker) } \\
\text { D.S. Conant }\end{array}$ & $740-1200$ & $\begin{array}{l}\text { ECO, } \\
\text { BMM, vS }\end{array}$ & $\begin{array}{l}\mathrm{T} \\
(\mathrm{A})\end{array}$ & $\mathrm{P}, \mathrm{Pr}$ & V & $\mathrm{M}, \mathrm{CA}, \mathrm{nSA}$ & $\begin{array}{l}\text { Chis, Hgo, Méx, } \\
\text { Oax, Pue, Qro, } \\
\text { SLP, Ver. }\end{array}$ & & $\begin{array}{l}\text { T. Krömer \& A. } \\
\text { Acebey 2528; } \\
\text { MEXU, UC, EBT }\end{array}$ \\
\hline Alsophila salvinii Hook. & $1000-1700$ & $\begin{array}{l}\text { BMM, } \\
\text { ECO }\end{array}$ & $\begin{array}{l}\mathrm{T} \\
(\mathrm{A})\end{array}$ & $\operatorname{Pr}$ & $\mathrm{P}$ & $\mathrm{M}, \mathrm{CA}, \mathrm{SA}$ & Chis, Oax, Ver. & & $\begin{array}{l}\text { M. Palacios-Ríos 28; } \\
\text { MEXU, UAMIZ }\end{array}$ \\
\hline $\begin{array}{l}\text { Alsophila tryoniana (Gastony) } \\
\text { D.S. Conant }\end{array}$ & $940-1250$ & $\begin{array}{l}\text { ECO, } \\
\text { BMM, vS }\end{array}$ & $\begin{array}{l}\mathrm{T} \\
(\mathrm{A})\end{array}$ & & A & $\mathrm{M}, \mathrm{CA}$ & Ver & & $\begin{array}{l}\text { T. Krömer \& A. } \\
\text { Acebey 2491; MEXU, } \\
\text { UC, EBT }\end{array}$ \\
\hline $\begin{array}{l}\text { Cnemidaria apiculata (Hook.) } \\
\text { Stolze=Cyathea aristata Domin }\end{array}$ & $1200-1700$ & BMM & $\begin{array}{l}\mathrm{T} \\
(\mathrm{A})\end{array}$ & $\operatorname{Pr}$ & A & M (endémica) & Ver, Oax & & $\begin{array}{l}\text { R. Lira 30; MEXU, } \\
\text { UAMIZ, XAL }\end{array}$ \\
\hline $\begin{array}{l}\text { Cnemidaria decurrens (Liebm.) } \\
\text { R.M. Tryon=Cyathea } \\
\text { decurrentiloba Domin }\end{array}$ & $500-1100$ & $\begin{array}{l}\text { SAP, BMM, } \\
\text { ECO, } \\
\text { VS, VR }\end{array}$ & $\begin{array}{l}\mathrm{T} \\
(\mathrm{A})\end{array}$ & $\operatorname{Pr}$ & A & $\mathrm{M}, \mathrm{CA}$ & Chis, Oax, Ver & & $\begin{array}{l}\text { M. Nee et al. } \\
\text { 24995; F, MEXU }\end{array}$ \\
\hline Cyathea bicrenata Liebm. & $200-960$ & $\begin{array}{l}\text { SAP, BMM, } \\
\text { ECO, VS }\end{array}$ & $\begin{array}{l}\mathrm{T} \\
(\mathrm{A})\end{array}$ & $\operatorname{Pr}$ & $\mathrm{S}$ & $\mathrm{M}, \mathrm{CA}$ & $\begin{array}{l}\text { Chis, Gro, Oax, } \\
\text { Pue, Ver. }\end{array}$ & & $\begin{array}{l}\text { T. Krömer et al. } \\
\text { 2149; MEXU, UC }\end{array}$ \\
\hline $\begin{array}{l}\text { Cyathea divergens Kunze var. } \\
\text { tuerckheimii (Maxon) R.M. } \\
\text { Tryonvar. tuerckheimii (Maxon) } \\
\text { R.M. Tryon }\end{array}$ & $1200-1640$ & $\mathrm{BMM}$ & $\begin{array}{l}\mathrm{T} \\
(\mathrm{A})\end{array}$ & $\operatorname{Pr}$ & V & $\mathrm{M}, \mathrm{CA}$ & $\begin{array}{l}\text { Chis, Oax, } \\
\text { Pue, Ver. }\end{array}$ & & $\begin{array}{l}\text { J.H. Beaman 5455, } \\
\text { MEXU }\end{array}$ \\
\hline $\begin{array}{l}\text { Cyathea schiedeana } \\
\text { (C. Presl) Domin }\end{array}$ & $300-1200$ & $\begin{array}{l}\text { SAP, BMM, } \\
\text { ECO, VS }\end{array}$ & $\begin{array}{l}\mathrm{T} \\
(\mathrm{A})\end{array}$ & $\operatorname{Pr}$ & $\mathrm{S}$ & $\mathrm{M}, \mathrm{CA}, \mathrm{nSA}$ & $\begin{array}{l}\text { Chis, Gro, Oax, } \\
\text { Pue, Ver. }\end{array}$ & & $\begin{array}{l}\text { R. Riba et al. 1194; } \\
\text { MEXU, UAMIZ }\end{array}$ \\
\hline $\begin{array}{l}\text { Sphaeropteris horrida } \\
\text { (Liebm.) R.M. Tryon }\end{array}$ & $500-1250$ & $\begin{array}{l}\text { SAP, BMM, } \\
\text { BQ }\end{array}$ & $\begin{array}{l}\mathrm{T} \\
(\mathrm{A})\end{array}$ & $\operatorname{Pr}$ & A & $\mathrm{M}, \mathrm{CA}$ & $\begin{array}{l}\text { Chis, Gro, } \\
\text { Oax, Ver }\end{array}$ & & $\begin{array}{l}\text { T. Krömer \& A. } \\
\text { Acebey } 2277 ; \\
\text { MEXU, UC }\end{array}$ \\
\hline $\begin{array}{l}\text { Dennstaedtiaceae } \\
\text { Dennstaedtia bipinnata } \\
\text { (Cav.) Maxon }\end{array}$ & $860-1240$ & $\begin{array}{l}\text { SAP, BMM, } \\
\text { ECO, VS, } \\
\text { VA }\end{array}$ & $\mathrm{T}$ & & V & $\begin{array}{l}\text { USA (Fla), M, } \\
\text { CA, AN, SA }\end{array}$ & $\begin{array}{l}\text { Chis, Hgo, Oax, } \\
\text { Pue, Qro, SLP, } \\
\text { Ver, Yuc. }\end{array}$ & & $\begin{array}{l}\text { T. Krömer \& A. } \\
\text { Acebey } 2065 ; \\
\text { MEXU, UC }\end{array}$ \\
\hline $\begin{array}{l}\text { Dennstaedtia cornuta } \\
\text { (Kaulf.) Mett. }\end{array}$ & $940-980$ & $\mathrm{ECO}, \mathrm{BMM}$ & $\mathrm{T}$ & & A & $\mathrm{M}, \mathrm{CA}, \mathrm{SA}$ & $\begin{array}{l}\text { Chis, Gro, } \\
\text { Oax, Ver. }\end{array}$ & $\mathrm{mr}$ & $\begin{array}{l}\text { T. Krömer et al. } \\
\text { 2581; MEXU, UC }\end{array}$ \\
\hline $\begin{array}{l}\text { Dennstaedtia globulifera } \\
\text { (Poir.) Hieron. }\end{array}$ & 750 & SAP & $\mathrm{T}$ & & V & $\mathrm{M}, \mathrm{CA}, \mathrm{SA}$ & $\begin{array}{l}\text { Chis, Gro, Hgo, } \\
\text { Jal, Mich, Mor, } \\
\text { NL, Oax, Qro, } \\
\text { SLP, Tam, Ver. }\end{array}$ & $\mathrm{mr}$ & $\begin{array}{l}\text { F. Ramírez \& F. } \\
\text { Vazquez 720; XAL }\end{array}$ \\
\hline $\begin{array}{l}\text { Hypolepis melanochlaena } \\
\text { A.R. Sm. }\end{array}$ & $950-1200$ & BMM, ECO & $\mathrm{T}$ & & & $\mathrm{M}$ (endémica) & Chis, Ver & $\mathrm{mr}$ & $\begin{array}{l}\text { A. Gómez-Pompa } \\
\text { et al. } 5460 ; \mathrm{XAL}\end{array}$ \\
\hline $\begin{array}{l}\text { Pteridium caudatum } \\
\text { (L.) Maxon }\end{array}$ & $200-1300$ & $\begin{array}{l}\text { SAP, BMM, } \\
\text { VS, VA }\end{array}$ & $\mathrm{T}$ & & $\mathrm{S}$ & $\mathrm{M}, \mathrm{CA}, \mathrm{AN}, \mathrm{SA}$ & $\begin{array}{l}\text { BCS, Camp, } \\
\text { Chis, Dgo, Gro, } \\
\text { Hgo, Jal, Mich, } \\
\text { Mor, Nay, NL, } \\
\text { Oax, Pue, Qro, } \\
\text { QR, Rev, Sin, } \\
\text { SLP, Tab, Tam, } \\
\text { Ver, Yuc. }\end{array}$ & r & $\begin{array}{l}\text { R. Riba et al. } \\
\text { 707; MEXU }\end{array}$ \\
\hline
\end{tabular}


Apéndice 1. Continuación

\begin{tabular}{|c|c|c|c|c|c|c|c|c|c|}
\hline Familia/Especie & $\begin{array}{l}\text { Altitud } \\
(\mathrm{m})\end{array}$ & TV & FC & $\begin{array}{l}\mathrm{EC} \\
\text { NOM }\end{array}$ & ECV & $\begin{array}{l}\text { Distribución } \\
\text { geográfica }\end{array}$ & $\begin{array}{l}\text { Distribución } \\
\text { estatal en } \\
\text { México }\end{array}$ & Observ. & $\begin{array}{l}\text { Ejemplar de } \\
\text { referencia }\end{array}$ \\
\hline $\begin{array}{l}\text { Dicksoniaceae } \\
\text { Lophosoria quadripinnata } \\
\text { (J.F. Gmel.) C. Chr. }\end{array}$ & $950-1200$ & BMM, ECO & $\mathrm{T}$ & & S & $\mathrm{M}, \mathrm{CA}, \mathrm{AN}, \mathrm{SA}$ & $\begin{array}{l}\text { Chis, DF, Gro, } \\
\text { Hgo, Oax, Pue, } \\
\text { Qro, Tab, Ver. }\end{array}$ & $r$ & $\begin{array}{l}\text { M. Nee et al. } \\
\text { 24944; MEXU }\end{array}$ \\
\hline $\begin{array}{l}\text { Dryopteridaceae } \\
\text { Arachniodes denticulata } \\
\text { (Sw.) Ching }\end{array}$ & $1200-1720$ & $\mathrm{BMM}$ & $\mathrm{T}$ & & S & $\mathrm{M}, \mathrm{CA}, \mathrm{AN}, \mathrm{SA}$ & $\begin{array}{l}\text { Chis, Gro, Hgo, } \\
\text { Oax, Pue, Ver }\end{array}$ & & $\begin{array}{l}\text { T. Krömer \& A. } \\
\text { Acebey 2550; MEXU, } \\
\text { UC, EBT }\end{array}$ \\
\hline $\begin{array}{l}\text { Bolbitis bernoullii (Kuhn ex } \\
\text { Christ) Ching=Mickelia } \\
\text { bernoullii (Kuhn ex Christ) } \\
\text { R.C. Moran, Labiak \& Sundue }\end{array}$ & $250-450$ & SAP, ECO & $\mathrm{He}$ & & S & $\mathrm{M}, \mathrm{CA}, \mathrm{nSA}$ & Chis, Oax, Ver. & & $\begin{array}{l}\text { T. Krömer et al. } \\
\text { 1917; MEXU, } \\
\text { UC, EBT }\end{array}$ \\
\hline $\begin{array}{l}\text { Bolbitis hastata (E. Fourn.) } \\
\text { Hennipman }\end{array}$ & $450-1220$ & $\begin{array}{l}\text { SAP, ECO, } \\
\text { BMM }\end{array}$ & $\mathrm{T}$ & & V & $\mathrm{M}, \mathrm{CA}$ & Chis, Oax, Ver. & $r$ & $\begin{array}{l}\text { R. Lira 191; MEXU, } \\
\text { UAMIZ }\end{array}$ \\
\hline $\begin{array}{l}\text { Bolbitis hemiotis (Maxon) } \\
\text { Ching=Mickelia hemiotis } \\
\text { (Maxon) R.C. Moran, Labiak } \\
\text { \& Sundue }\end{array}$ & $450-950$ & $\begin{array}{l}\text { SAP, ECO, } \\
\text { VS }\end{array}$ & $\mathrm{T}$ & & V & $\mathrm{M}, \mathrm{CA}, \mathrm{nSA}$ & Oax, Ver. & r & $\begin{array}{l}\text { R. Cedillo T. 3314; } \\
\text { MEXU, MO, EBT }\end{array}$ \\
\hline $\begin{array}{l}\text { Bolbitis pergamentacea } \\
\text { (Maxon) Ching= Mickelia } \\
\text { pergamentacea (Maxon) R.C. } \\
\text { Moran, Labiak \& Sundue }\end{array}$ & $80-980$ & $\begin{array}{l}\text { SAP, ECO, } \\
\text { VS }\end{array}$ & $\mathrm{T}$ & & V & $\mathrm{M}, \mathrm{CA}, \mathrm{AN}, \mathrm{nSA}$ & Chis, Oax, Ver. & r & $\begin{array}{l}\text { M. Nee et al. } \\
\text { 19883; MEXU }\end{array}$ \\
\hline $\begin{array}{l}\text { Bolbitis portoricensis } \\
\text { (Spreng.) Hennipman }\end{array}$ & $20-850$ & $\begin{array}{l}\text { SAP, SMP, } \\
\text { ECO }\end{array}$ & $\mathrm{T}$ & & V & $\mathrm{M}, \mathrm{CA}, \mathrm{AN}, \mathrm{nSA}$ & $\begin{array}{l}\text { Chis, Gro, Jal, } \\
\text { Mich, Nay, Oax, } \\
\text { Pue, Tab, Ver. }\end{array}$ & & $\begin{array}{l}\text { R. Riba et al. 1128; } \\
\text { MEXU, UAMIZ }\end{array}$ \\
\hline $\begin{array}{l}\text { Bolbitis umbrosa (Liebm.) } \\
\text { Ching }\end{array}$ & $150-600$ & SAP & $\mathrm{T}$ & & A & $\mathrm{M}, \mathrm{CA}$ & Chis, Ver. & $\mathrm{NT}, \mathrm{mr}$ & $\begin{array}{l}\text { B. Pérez-García et al. } \\
\text { 1132; MEXU, UAMIZ }\end{array}$ \\
\hline Ctenitis excelsa (Desv.) Proctor & $250-640$ & SAP & $\mathrm{T}$ & & V & $\mathrm{M}, \mathrm{CA}, \mathrm{AN}$ & $\begin{array}{l}\text { Chis, Gro, } \\
\text { Oax, Ver. }\end{array}$ & $\mathrm{mr}$ & $\begin{array}{l}\text { T. Krömer et al. } \\
\text { 2181; MEXU, UC }\end{array}$ \\
\hline $\begin{array}{l}\text { Ctenitis interjecta (C. Chr.) } \\
\text { Ching }\end{array}$ & 130 & SAP & $\mathrm{T}$ & & A & $\mathrm{M}, \mathrm{CA}$ & Chis, Oax, Ver & $\mathrm{mr}$ & $\begin{array}{l}\text { Nee \& Calzada } \\
22752 ; \mathrm{F}, \mathrm{NY}\end{array}$ \\
\hline $\begin{array}{l}\text { Ctenitis melanosticta } \\
\text { (Kunze) Copel. }\end{array}$ & $350-1300$ & $\begin{array}{l}\text { SAP, BMM, } \\
\text { ECO, VA }\end{array}$ & $\mathrm{T}$ & & S & $\mathrm{M}, \mathrm{CA}$ & $\begin{array}{l}\text { Chis, Hgo, Oax, } \\
\text { Pue, Qro, SLP, } \\
\text { Tab, Tam, Ver. }\end{array}$ & & $\begin{array}{l}\text { T. Krömer \& A. } \\
\text { Acebey } 2721 ; \\
\text { MEXU, UC }\end{array}$ \\
\hline Ctenitis mexicana A.R. Sm. & 1250 & BMM & $\mathrm{T}$ & & A & M (endémica) & Pue, Qro, Ver & NT, mr & $\begin{array}{l}\text { T. Krömer \& A. } \\
\text { Acebey } 2557 ; \\
\text { MEXU, UC }\end{array}$ \\
\hline $\begin{array}{l}\text { Didymochlaena trunculata } \\
\text { (Sw.) J. Sm. }\end{array}$ & $480-840$ & $\begin{array}{l}\text { SAP, ECO, } \\
\text { VS }\end{array}$ & $\mathrm{T}$ & & V & $\operatorname{Cos}$ & $\begin{array}{l}\text { Chis, Oax, } \\
\text { Pue, Ver. }\end{array}$ & & $\begin{array}{l}\text { T. Krömer y A. } \\
\text { Pérez-Peña 2747; } \\
\text { MEXU, UC }\end{array}$ \\
\hline $\begin{array}{l}\text { Elaphoglossum auricomum } \\
\text { (Kunze) T. Moore }\end{array}$ & $180-1300$ & SAP, BMM & E & & A & $\mathrm{M}, \mathrm{CA}, \mathrm{AN}, \mathrm{SA}$ & Chis, Oax, Ver. & $\mathrm{mr}$ & $\begin{array}{l}\text { R. Hernández 1385; } \\
\text { MEXU }\end{array}$ \\
\hline $\begin{array}{l}\text { Elaphoglossum erinaceum } \\
\text { var. erinaceum (Fée) T. Moore }\end{array}$ & $740-1590$ & BMM, ECO & $\mathrm{E}, \mathrm{R}$ & & S & $\mathrm{M}, \mathrm{CA}, \mathrm{AN}, \mathrm{SA}$ & $\begin{array}{l}\text { Chis, Hgo, Oax, } \\
\text { Pue, Ver. }\end{array}$ & & $\begin{array}{l}\text { T. Krömer \& A. } \\
\text { Acebey } 2257 ; \\
\text { MEXU, UC }\end{array}$ \\
\hline
\end{tabular}


Apéndice 1. Continuación

\begin{tabular}{|c|c|c|c|c|c|c|c|c|c|}
\hline Familia/Especie & $\begin{array}{l}\text { Altitud } \\
(\mathrm{m})\end{array}$ & TV & FC & $\begin{array}{l}\mathrm{EC} \\
\text { NOM }\end{array}$ & ECV & $\begin{array}{l}\text { Distribución } \\
\text { geográfica }\end{array}$ & $\begin{array}{l}\text { Distribución } \\
\text { estatal en } \\
\text { México }\end{array}$ & Observ. & $\begin{array}{l}\text { Ejemplar de } \\
\text { referencia }\end{array}$ \\
\hline Elaphoglossum glabellum J. Sm. & 850 & BQ-BP & $E$ & & & M (endémica) & Oax, Ver & \multicolumn{2}{|c|}{$\begin{array}{c}\mathrm{NV}, \mathrm{mr} \text { T. Krömer \& E. Otto } \\
\text { 2850; MEXU, UC }\end{array}$} \\
\hline $\begin{array}{l}\text { Elaphoglossum guatemalense } \\
\text { (Klotzsch) T. Moore }\end{array}$ & $500-1675$ & $\begin{array}{l}\text { SAP, BMM, } \\
\text { BP-BQ, } \\
\text { ECO }\end{array}$ & E & & V & $\mathrm{M}, \mathrm{CA}$ & \multicolumn{2}{|l|}{$\begin{array}{l}\text { Chis, Hgo, Oax, } \\
\text { Pue, Qro, Ver. }\end{array}$} & $\begin{array}{l}\text { T. Krömer \& A. } \\
\text { Acebey 2506; } \\
\text { MEXU, UC }\end{array}$ \\
\hline $\begin{array}{l}\text { Elaphoglossum muscosum } \\
\text { (Sw.) T. Moore }\end{array}$ & 1590 & BMM & $\mathrm{E}$ & & A & $\mathrm{M}, \mathrm{CA}, \mathrm{AN}, \mathrm{SA}$ & Chis, Oax, Ver. & $\mathrm{mr}$ & $\begin{array}{l}\text { T. Krömer \& A. } \\
\text { Acebey } 2430 ; \\
\text { MEXU, UC }\end{array}$ \\
\hline $\begin{array}{l}\text { Elaphoglossum peltatum } \\
\text { (Sw.) Urb. }\end{array}$ & $720-1720$ & $\begin{array}{l}\text { SAP, BMM, } \\
\text { ECO }\end{array}$ & $\mathrm{E}$ & & $\mathrm{S}$ & $\mathrm{M}, \mathrm{CA}, \mathrm{AN}, \mathrm{SA}$ & $\begin{array}{l}\text { Chis, Gro, Hgo, } \\
\text { Jal, Oax, } \\
\text { Pue, Ver. }\end{array}$ & & $\begin{array}{l}\text { T. Krömer \& A. } \\
\text { Acebey 1986; } \\
\text { MEXU, UC }\end{array}$ \\
\hline $\begin{array}{l}\text { Elaphoglossum petiolatum } \\
\text { (Sw.) Urb. }\end{array}$ & $740-1550$ & BMM, ECO & $\mathrm{E}$ & & V & $\mathrm{M}, \mathrm{CA}, \mathrm{AN}, \mathrm{SA}$ & $\begin{array}{l}\text { Chis, Col, DF, } \\
\text { Gro, Gto, Hgo, } \\
\text { Jal, Méx, Mich, } \\
\text { Mor, Nay, Oax, } \\
\text { Pue, Qro, Sin, } \\
\text { Tlax, Ver, Zac. }\end{array}$ & NT & $\begin{array}{l}\text { T. Krömer \& A. } \\
\text { Acebey } 2498 ; \\
\text { MEXU, UC }\end{array}$ \\
\hline $\begin{array}{l}\text { Elaphoglossum pringlei } \\
\text { (Davenp.) C. Chr. }\end{array}$ & 850 & BQ-BP & $\mathrm{E}$ & & & $\begin{array}{l}\text { M (endémica, } \\
\text { Ver) }\end{array}$ & Oax, Ver & $\mathrm{NV}, \mathrm{mr}$ & $\begin{array}{l}\text { T. Krömer \& E. Otto } \\
\text { 2872; MEXU, UC }\end{array}$ \\
\hline $\begin{array}{l}\text { Elaphoglossum revolutum } \\
\text { (Liebm.) T. Moore }\end{array}$ & 850 & BQ-BP & $\mathrm{E}, \mathrm{R}$ & & A & $\mathrm{M}, \mathrm{CA}, \mathrm{AN}, \mathrm{SA}$ & $\begin{array}{l}\text { Chis, Gro, } \\
\text { Oax, Ver. }\end{array}$ & $\mathrm{NT}, \mathrm{mr}$ & $\begin{array}{l}\text { T. Krömer \& E. Otto } \\
\text { 2873; MEXU, UC }\end{array}$ \\
\hline $\begin{array}{l}\text { Elaphoglossum sartorii } \\
\text { (Liebm.) Mickel }\end{array}$ & $640-1590$ & $\begin{array}{l}\text { SAP, BMM, } \\
\text { ECO, } \\
\text { BP-BQ }\end{array}$ & $\mathrm{E}$ & & V & M (endémica) & $\begin{array}{l}\text { Chis, Dgo, Gro, } \\
\text { Hgo, Jal, Méx, } \\
\text { Mich, Mor, Nay, } \\
\text { Oax, Pue, Sin, Ver }\end{array}$ & & $\begin{array}{l}\text { T. Krömer \& A. } \\
\text { Acebey } 2198 ; \\
\text { MEXU, UC }\end{array}$ \\
\hline $\begin{array}{l}\text { Elaphoglossum vestitum } \\
\text { (Schltdl. \& Cham.) T. Moore }\end{array}$ & $740-1720$ & $\mathrm{ECO}, \mathrm{BMM}$ & $\mathrm{E}$ & & A & M (endémica) & $\begin{array}{l}\text { Chis, Hgo, Oax, } \\
\text { Pue, Qro, Ver. }\end{array}$ & & $\begin{array}{l}\text { T. Krömer \& A. } \\
\text { Acebey 1987; } \\
\text { MEXU, UC }\end{array}$ \\
\hline $\begin{array}{l}\text { Elaphoglossum viride } \\
\text { (E. Fourn.) C. Chr. }\end{array}$ & $900-1660$ & $\mathrm{ECO}, \mathrm{BMM}$ & $\mathrm{T}, \mathrm{E}$ & & $P$ & M (endémica) & Oax, Ver & & $\begin{array}{l}\text { T. Krömer \& A. } \\
\text { Acebey } 2426 ; \\
\text { MEXU, UC }\end{array}$ \\
\hline $\begin{array}{l}\text { Lastreopsis effusa subsp. } \\
\text { dilatata Tindale }\end{array}$ & $\begin{array}{l}50-950 \\
(-1300)\end{array}$ & SAP, BMM & $\mathrm{T}$ & & V & $\mathrm{M}, \mathrm{CA}, \mathrm{An}, \mathrm{nSA}$ & $\begin{array}{l}\text { Chis, Gro, Hgo, } \\
\text { Oax, SLP, Ver. }\end{array}$ & r & $\begin{array}{l}\text { R. Riba et al. 1224; } \\
\text { MEXU, UAMIZ, XAL }\end{array}$ \\
\hline $\begin{array}{l}\text { Megalastrum atrogriseum } \\
\text { (C. Chr.) A.R. Sm. \& } \\
\text { R.C. Moran }\end{array}$ & $510-700$ & SAP, VS & $\mathrm{T}$ & & A & $\mathrm{M}, \mathrm{CA}$ & Oax, Ver. & $\mathrm{mr}$ & $\begin{array}{l}\text { T. Krömer \& A. } \\
\text { Acebey } 2278 ; \\
\text { MEXU, UC }\end{array}$ \\
\hline $\begin{array}{l}\text { Megalastrum subincisum } \\
\text { (Willd.) Ching }\end{array}$ & $960-1450$ & BMM & $\mathrm{T}$ & & V & $\mathrm{M}, \mathrm{CA}, \mathrm{AN}, \mathrm{SA}$ & $\begin{array}{l}\text { Chis, Gro, } \\
\text { Oax, Ver. }\end{array}$ & $r$ & R. Riba 1185; MEXU \\
\hline Olfersia cervina (L.) Kunze & $170-400$ & SAP & $\mathrm{T}, \mathrm{R}$ & & A & $\mathrm{M}, \mathrm{CA}, \mathrm{AN}, \mathrm{SA}$ & Chis, Oax, Ver. & r & $\begin{array}{l}\text { S. Sinaca \& F. Chigo } \\
\text { S. } 562 ; \text { MEXU, EBT }\end{array}$ \\
\hline $\begin{array}{l}\text { Phanerophlebia remotispora } \\
\text { E. Fourn. }\end{array}$ & - & BMM & $\mathrm{T}$ & & V & M, Guat & $\begin{array}{l}\text { Chis, Hgo, Méx, } \\
\text { Oax, Pue, Qro, } \\
\text { SLP, Ver }\end{array}$ & $\mathrm{NT}, \mathrm{mr}$ & $\begin{array}{l}\text { J.I. Calzada } \\
\text { 11920; XAL }\end{array}$ \\
\hline $\begin{array}{l}\text { Polystichum mickelii } \\
\text { A. R. Sm. }\end{array}$ & $1030-1360$ & BMM & $\mathrm{T}$ & & A & M, Guat, Hon & Chis, Oax, Ver. & $N T, r$ & $\begin{array}{l}\text { T. Krömer \& A. } \\
\text { Acebey 2556; } \\
\text { MEXU, UC }\end{array}$ \\
\hline
\end{tabular}


Apéndice 1. Continuación

\begin{tabular}{|c|c|c|c|c|c|c|c|c|c|}
\hline Familia/Especie & $\begin{array}{l}\text { Altitud } \\
(\mathrm{m})\end{array}$ & TV & FC & $\begin{array}{l}\mathrm{EC} \\
\mathrm{NOM}\end{array}$ & ECV & $\begin{array}{l}\text { Distribución } \\
\text { geográfica }\end{array}$ & $\begin{array}{l}\text { Distribución } \\
\text { estatal en } \\
\text { México }\end{array}$ & Observ. & $\begin{array}{l}\text { Ejemplar de } \\
\text { referencia }\end{array}$ \\
\hline $\begin{array}{l}\text { Stigmatopteris longicaudata } \\
\text { (Liebm.) C. Chr. }\end{array}$ & $800-1100$ & BMM, ECO & $\mathrm{T}$ & & V & $\mathrm{M}, \mathrm{CA}, \mathrm{AN}, \mathrm{SA}$ & $\begin{array}{l}\text { Chis, Oax, } \\
\text { Pue, Ver. }\end{array}$ & r & $\begin{array}{l}\text { R. Riba et al. } \\
\text { 1093; MEXU }\end{array}$ \\
\hline $\begin{array}{l}\text { Stigmatopteris sordida } \\
\text { (Maxon) C. Chr. }\end{array}$ & 1010 & VS & $\mathrm{T}$ & & A & M, CA, SA & Chis, Oax, Ver. & $\mathrm{mr}$ & R. Lira 163; MEXU \\
\hline $\begin{array}{l}\text { Gleicheniaceae } \\
\text { Diplopterygium bancroftii } \\
\text { (Hook.) A.R. Sm. }\end{array}$ & 1420 & BMM & $\mathrm{T}$ & & S & $\mathrm{M}, \mathrm{CA}, \mathrm{AN}, \mathrm{SA}$ & $\begin{array}{l}\text { Chis, Gro, Oax, } \\
\text { Pue, Ver. }\end{array}$ & $\mathrm{mr}$ & $\begin{array}{l}\text { J.H. Beaman 5441; } \\
\text { MEXU }\end{array}$ \\
\hline $\begin{array}{l}\text { Gleichenella pectinata } \\
\text { (Willd.) Ching }\end{array}$ & 850 & BP-BQ & $\mathrm{T}$ & & V & $\mathrm{M}, \mathrm{CA}, \mathrm{AN}, \mathrm{SA}$ & $\begin{array}{l}\text { Chis, Gro, Hgo, } \\
\text { Jal, Méx, Oax, } \\
\text { Pue, Tab, Ver. }\end{array}$ & $\mathrm{mr}$ & $\begin{array}{l}\text { T. Krömer \& E. Otto } \\
\text { 2883; MEXU, UC }\end{array}$ \\
\hline $\begin{array}{l}\text { Sticherus bifidus (Willd.) } \\
\text { Ching }\end{array}$ & $100-1010$ & SAP, VS & $\mathrm{T}$ & & $\mathrm{S}$ & $\mathrm{M}, \mathrm{CA}, \mathrm{AN}, \mathrm{SA}$ & $\begin{array}{l}\text { Chis, Gro, Jal, } \\
\text { Méx, Oax, Pue, } \\
\text { Tab, Ver. }\end{array}$ & r & R. Lira 129; MEXU \\
\hline $\begin{array}{l}\text { Sticherus palmatus (W. } \\
\text { Schaffn. ex E. Fourn.) Copel. }\end{array}$ & $830-1720$ & $\mathrm{ECO}, \mathrm{BMM}$ & $\mathrm{T}$ & & $S$ & $\mathrm{M}, \mathrm{CA}, \mathrm{AN}$ & $\begin{array}{l}\text { Chis, Gro, Hgo, } \\
\text { Oax, Pue, Ver. }\end{array}$ & r & $\begin{array}{l}\text { T. Krömer \& E. Otto } \\
\text { 2834; MEXU, UC }\end{array}$ \\
\hline $\begin{array}{l}\text { Hymenophyllaceae } \\
\text { Hymenophyllum asplenioides } \\
\text { (Sw.) Sw. }\end{array}$ & 1700 & BMM & $E$ & & V & $\mathrm{M}, \mathrm{CA}, \mathrm{AN}, \mathrm{nSA}$ & $\begin{array}{l}\text { Chis, Oax, } \\
\text { Pue, Ver. }\end{array}$ & $\mathrm{mr}$ & R. Lira 39; MEXU \\
\hline $\begin{array}{l}\text { Hymenophyllum fucoides } \\
\text { (Sw.) Sw. }\end{array}$ & $1500-1590$ & $\mathrm{BMM}$ & $\mathrm{E}$ & & V & $\mathrm{M}, \mathrm{CA}, \mathrm{AN}, \mathrm{SA}$ & $\begin{array}{l}\text { Chis, Gro, } \\
\text { Oax, Ver. }\end{array}$ & NT, mr & $\begin{array}{l}\text { T. Krömer \& A. } \\
\text { Acebey } 2197 ; \\
\text { MEXU, UC }\end{array}$ \\
\hline $\begin{array}{l}\text { Hymenophyllum hirsutum } \\
\text { (L.) Sw. }\end{array}$ & 440 & SMP & $E$ & & & $\mathrm{M}, \mathrm{CA}, \mathrm{AN}, \mathrm{SA}$ & $\begin{array}{l}\text { Chis, Gro, Oax, } \\
\text { Pue, Ver }\end{array}$ & $\mathrm{NT}, \mathrm{mr}$ & $\begin{array}{l}\text { T. Krömer et al. } \\
\text { 4095; CITRO }\end{array}$ \\
\hline Hymenophyllum lanatum Fée & $740-1010$ & $\mathrm{BMM}, \mathrm{ECO}$ & $\mathrm{E}$ & & $A$ & $\mathrm{M}, \mathrm{CA}, \mathrm{AN}, \mathrm{nSA}$ & $\begin{array}{l}\text { Chis, Gro, } \\
\text { Oax, Ver }\end{array}$ & $\mathrm{NV}, \mathrm{r}$ & $\begin{array}{l}\text { T. Krömer \& A. } \\
\text { Acebey } 2588 ; \\
\text { MEXU, UC }\end{array}$ \\
\hline $\begin{array}{l}\text { Hymenophyllum maxonii } \\
\text { Christ ex C.V. Morton }\end{array}$ & $1100-1640$ & BMM & $\mathrm{E}$ & & $A$ & M, Guat & $\begin{array}{l}\text { Chis, Oax, } \\
\text { Pue, Ver. }\end{array}$ & r & $\begin{array}{l}\text { T. Krömer \& A. } \\
\text { Acebey } 2422 ; \\
\text { MEXU, UC }\end{array}$ \\
\hline $\begin{array}{l}\text { Hymenophyllum } \\
\text { myriocarpum Hook. }\end{array}$ & 1570 & BMM & $E$ & & V & $\mathrm{M}, \mathrm{CA}, \mathrm{AN}, \mathrm{SA}$ & $\begin{array}{l}\text { Chis, Gro, Jal, } \\
\text { Oax, Pue, Ver. }\end{array}$ & $\mathrm{NT}, \mathrm{mr}$ & $\begin{array}{l}\text { T. Krömer \& E. Otto } \\
\text { 2889; MEXU, UC }\end{array}$ \\
\hline $\begin{array}{l}\text { Hymenophyllum polyanthos } \\
\text { (Sw.) Sw. }\end{array}$ & $650-1590$ & $\begin{array}{l}\text { SAP, BMM, } \\
\text { ECO }\end{array}$ & $E$ & & S & $\operatorname{Cos}$ & $\begin{array}{l}\text { Chis, Gro, Hgo, } \\
\text { Oax, Pue, Ver }\end{array}$ & & $\begin{array}{l}\text { T. Krömer \& A. } \\
\text { Acebey } 2423 ; \\
\text { MEXU, UC }\end{array}$ \\
\hline $\begin{array}{l}\text { Hymenophyllum pulchellum } \\
\text { Schltdl. \& Cham. }\end{array}$ & $870-1100$ & BMM, ECO & E & & V & $\mathrm{M}, \mathrm{CA}, \mathrm{SA}$ & Chis, Oax, Ver. & NT, mr & $\begin{array}{l}\text { T. Krömer \& A. } \\
\text { Acebey } 2587 ; \\
\text { MEXU, UC }\end{array}$ \\
\hline $\begin{array}{l}\text { Hymenophyllum } \\
\text { trapezoidale Liebm. }\end{array}$ & $1570-1720$ & BMM & $\mathrm{E}$ & & $S$ & $\mathrm{M}, \mathrm{CA}, \mathrm{nSA}$ & $\begin{array}{l}\text { Chis, Gro, Méx, } \\
\text { Mor, Oax, Pue, } \\
\text { Ver. }\end{array}$ & r & $\begin{array}{l}\text { T. Krömer \& E. Otto } \\
\text { 2890; MEXU, UC }\end{array}$ \\
\hline $\begin{array}{l}\text { Hymenophyllum } \\
\text { tunbrigense (L.) Sm. }\end{array}$ & 1675 & BMM & $\mathrm{E}$ & & A & $\operatorname{Cos}$ & $\begin{array}{l}\text { Chih, Chis, Hgo, } \\
\text { Oax, Pue, Qro, } \\
\text { Ver. }\end{array}$ & $\mathrm{NT}, \mathrm{mr}$ & $\begin{array}{l}\text { T. Krömer \& A. } \\
\text { Acebey 2520; } \\
\text { MEXU, UC }\end{array}$ \\
\hline
\end{tabular}


Apéndice 1. Continuación

\begin{tabular}{|c|c|c|c|c|c|c|c|c|c|}
\hline Familia/Especie & $\begin{array}{l}\text { Altitud } \\
(\mathrm{m})\end{array}$ & TV & FC & $\begin{array}{l}\text { EC } \\
\text { NOM }\end{array}$ & ECV & $\begin{array}{l}\text { Distribución } \\
\text { geográfica }\end{array}$ & $\begin{array}{l}\text { Distribución } \\
\text { estatal en } \\
\text { México }\end{array}$ & Observ & $\begin{array}{l}\text { Ejemplar de } \\
\text { referencia }\end{array}$ \\
\hline $\begin{array}{l}\text { Trichomanes capillaceum } \\
\text { L.=Polyphlebium capillaceum } \\
\text { (L.) Ebihara \& Dubuisson }\end{array}$ & $1010-1450$ & BMM, VS & $E$ & & S & $\mathrm{M}, \mathrm{CA}, \mathrm{AN}, \mathrm{SA}$ & $\begin{array}{l}\text { Chis, Gro, Méx, } \\
\text { Mor, Oax, Pue, } \\
\text { Tab, Ver. }\end{array}$ & & $\begin{array}{l}\text { T. Krömer \& A. } \\
\text { Acebey 2553; } \\
\text { MEXU, UC }\end{array}$ \\
\hline $\begin{array}{l}\text { Trichomanes collariatum } \\
\text { Bosch=Vandenboschia } \\
\text { collariata (Bosch) Ebihara } \\
\text { \& K. Iwats. }\end{array}$ & $150-1000$ & SAP, ECO & $\mathrm{E}$ & & V & $\mathrm{M}, \mathrm{CA}, \mathrm{SA}$ & $\begin{array}{l}\text { Chis, Oax, } \\
\text { Tab, Ver. }\end{array}$ & & $\begin{array}{l}\text { T. Krömer \& A. } \\
\text { Acebey } 2740 ; \\
\text { MEXU, UC }\end{array}$ \\
\hline $\begin{array}{l}\text { Trichomanes galeottii } \\
\text { E. Fourn. }\end{array}$ & 1125 & BMM & $E$ & & $A$ & $\mathrm{M}, \mathrm{CA}, \mathrm{nSA}$ & Chis, Oax, Ver. & $\mathrm{mr}$ & $\begin{array}{l}\text { T. Krömer \& E. Otto } \\
\text { 2962; MEXU, } \\
\text { UC, XAL }\end{array}$ \\
\hline $\begin{array}{l}\text { Trichomanes hymenoides } \\
\text { Hedw.=Didymoglossum } \\
\text { hymenoides (Hedw.) Copel. }\end{array}$ & 1350 & BMM & $E$ & & A & $\mathrm{M}, \mathrm{CA}, \mathrm{AN}, \mathrm{SA}$ & Chis, Oax, Ver. & $\mathrm{mr}$ & $\begin{array}{l}\text { T. Krömer \& E. Otto } \\
\text { 2932; MEXU, } \\
\text { UC, XAL }\end{array}$ \\
\hline $\begin{array}{l}\text { Trichomanes hymenophylloides } \\
\text { Bosch= Polyphlebium } \\
\text { hymenophylloides (Bosch) } \\
\text { Ebihara \& Dubuisson }\end{array}$ & 1675 & BMM & $E$ & & A & $\mathrm{M}, \mathrm{CA}, \mathrm{AN}, \mathrm{SA}$ & $\begin{array}{l}\text { Chis, Hgo, Méx, } \\
\text { Mor, Oax, Ver. }\end{array}$ & $\mathrm{mr}$ & $\begin{array}{l}\text { T. Krömer \& A. } \\
\text { Acebey } 2521 ; \\
\text { MEXU, UC }\end{array}$ \\
\hline $\begin{array}{l}\text { Trichomanes krausii Hook. \& } \\
\text { Grev.=Didymoglossum krausii } \\
\text { (Hook. \& Grev.) C. Presl }\end{array}$ & 900 & ECO & $E$ & & $\mathrm{~S}$ & $\begin{array}{l}\text { USA (Fla), M, } \\
\text { CA, AN, SA }\end{array}$ & $\begin{array}{l}\text { Chis, Oax, Pue, } \\
\text { SLP, Tam, Ver. }\end{array}$ & $\mathrm{mr}$ & $\begin{array}{l}\text { Den Held, J. \& Van } \\
\text { Rhiin, F. 4; MEXU }\end{array}$ \\
\hline $\begin{array}{l}\text { Trichomanes membranaceum } \\
\text { L.=Didymoglossum } \\
\text { membranaceum (L.) Vareschi }\end{array}$ & 600 & SAP & $\mathrm{E}, \mathrm{R}$ & & A & $\mathrm{M}, \mathrm{CA}, \mathrm{AN}, \mathrm{SA}$ & Chis, Tab, Ver. & $\mathrm{mr}$ & $\begin{array}{l}\text { Van Rooden, J. } \\
\text { 762; MEXU }\end{array}$ \\
\hline $\begin{array}{l}\text { Trichomanes ovale (E. Fourn.) } \\
\text { Wess. Boer= Didymoglossum } \\
\text { ovale E. Fourn. }\end{array}$ & 200 & SAP & $E$ & & $A$ & $\mathrm{M}, \mathrm{CA}, \mathrm{AN}, \mathrm{SA}$ & $\begin{array}{l}\text { Chis, Oax, } \\
\text { Tab, Ver. }\end{array}$ & $\mathrm{NV}, \mathrm{mr}$ & $\begin{array}{l}\text { T. Krömer \& A. } \\
\text { Acebey } 2736 \text {; } \\
\text { MEXU, UC }\end{array}$ \\
\hline Trichomanes polypodioides L. & 1300 & BMM & $\mathrm{E}$ & & V & $\mathrm{M}, \mathrm{CA}, \mathrm{AN}, \mathrm{SA}$ & $\begin{array}{l}\text { Chis, Gro, } \\
\text { Oax, Ver. }\end{array}$ & $\mathrm{mr}$ & $\begin{array}{l}\text { R. Lira 10; ENCB, } \\
\text { MEXU, XAL }\end{array}$ \\
\hline $\begin{array}{l}\text { Trichomanes radicans Sw.= } \\
\text { Vandenboschia radicans } \\
\text { (Sw.) Copel. }\end{array}$ & $920-1280$ & $\begin{array}{l}\text { BMM, } \\
\text { BP-BQ, } \\
\text { ECO, VS }\end{array}$ & $\mathrm{E}$ & & $\mathrm{S}$ & $\operatorname{Cos}$ & \multicolumn{2}{|c|}{$\begin{array}{l}\text { Chih, Chis, Dgo, } \\
\text { Gro, Hgo, Jal, Méx, } \\
\text { Mich, Mor, Oax, } \\
\text { Pue, Qro, SLP, Ver. }\end{array}$} & $\begin{array}{l}\text { T. Krömer \& A. } \\
\text { Acebey } 2064 ; \\
\text { MEXU, UC }\end{array}$ \\
\hline $\begin{array}{l}\text { Trichomanes reptans Sw.= } \\
\text { Didymoglossum reptans } \\
\text { (Sw.) C. Presl }\end{array}$ & $740-1400$ & BMM, ECO & $\mathrm{E}, \mathrm{R}$ & & V & $\mathrm{M}, \mathrm{CA}, \mathrm{AN}, \mathrm{SA}$ & $\begin{array}{l}\text { Chis, Gro, Hgo, } \\
\text { Jal, Oax, Pue, } \\
\text { Ver. }\end{array}$ & & $\begin{array}{l}\text { R. Lira 199; ENCB, } \\
\text { MEXU }\end{array}$ \\
\hline $\begin{array}{l}\text { Trichomanes rigidum Sw.= } \\
\text { Abrodictyum rigidum (Sw.) } \\
\text { Ebihara \& Dubuisson }\end{array}$ & $900-1125$ & BMM, ECO & $\mathrm{T}$ & & $A$ & $\operatorname{Cos}$ & Chis, Oax, Ver. & $N T, r$ & $\begin{array}{l}\text { T. Krömer \& E. Otto } \\
\text { 2973; MEXU, UC }\end{array}$ \\
\hline $\begin{array}{l}\text { Lindsaeaceae } \\
\text { Lindsaea Klotzschiana } \\
\text { Moritz ex Ettingsh. }\end{array}$ & $750-980$ & $\mathrm{ECO}, \mathrm{BMM}$ & $\mathrm{T}$ & & A & $\mathrm{M}, \mathrm{CA}, \mathrm{nSA}$ & Ver. & $\mathrm{mr}$ & $\begin{array}{l}\text { M. Nee \& I. Calzada } \\
\text { 22710; NY, XAL }\end{array}$ \\
\hline Lonchitis hirsutus L. & $190-600$ & SAP & $\mathrm{T}$ & & S & $\mathrm{M}, \mathrm{CA}, \mathrm{AN}, \mathrm{SA}$ & $\begin{array}{l}\text { Chis, Oax, } \\
\text { Pue, Ver. }\end{array}$ & r & $\begin{array}{l}\text { R. Riba et al. 1233; } \\
\text { MEXU }\end{array}$ \\
\hline $\begin{array}{l}\text { Odontosoria schlechtendalii } \\
\text { (C. Presl.) C. Chr. }\end{array}$ & $800-1480$ & $\begin{array}{l}\text { ECO, SMP, } \\
\text { BMM }\end{array}$ & $\mathrm{T}$ & & V & $\mathrm{M}, \mathrm{CA}$ & $\begin{array}{l}\text { Chis, Gro, Oax, } \\
\text { Pue, Ver. }\end{array}$ & & $\begin{array}{l}\text { T. Krömer \& E. Otto } \\
\text { 2852; MEXU, UC }\end{array}$ \\
\hline
\end{tabular}


Apéndice 1. Continuación

\begin{tabular}{|c|c|c|c|c|c|c|c|c|c|}
\hline Familia/Especie & $\begin{array}{l}\text { Altitud } \\
(\mathrm{m})\end{array}$ & TV & FC & $\begin{array}{l}\mathrm{EC} \\
\mathrm{NOM}\end{array}$ & ECV & $\begin{array}{l}\text { Distribución } \\
\text { geográfica }\end{array}$ & $\begin{array}{l}\text { Distribución } \\
\text { estatal en } \\
\text { México }\end{array}$ & Observ. & $\begin{array}{l}\text { Ejemplar de } \\
\text { referencia }\end{array}$ \\
\hline $\begin{array}{l}\text { Lomariopsidaceae } \\
\text { Lomariopsis mexicana } \\
\text { Holttum }\end{array}$ & $150-700$ & SAP & $\mathrm{He}$ & & A & M (endémica) & $\begin{array}{l}\text { Chis, Hgo, Oax, n } \\
\text { Tab, Ver. }\end{array}$ & $\mathrm{mr}$ & $\begin{array}{l}\text { S.H. Sohmer 9460; } \\
\text { MEXU }\end{array}$ \\
\hline Lomariopsis recurvata Fée & $400-570$ & SAP & $\mathrm{He}$ & & A & $\mathrm{M}, \mathrm{CA}$ & $\begin{array}{l}\text { Chis, Oax, } \\
\text { Tab, Ver. }\end{array}$ & r & $\begin{array}{l}\text { T. Krömer \& A. } \\
\text { Acebey } 2275 ; \\
\text { MEXU, UC }\end{array}$ \\
\hline $\begin{array}{l}\text { Nephrolepis brownii (Desv.) } \\
\text { Hovenkamp \& Miyam. }\end{array}$ & $45-1220$ & $\begin{array}{l}\text { SAP, BMM, } \\
\text { VS, VA, VA }\end{array}$ & $\mathrm{T}$ & & V & $\operatorname{Cos}$ & $\begin{array}{l}\text { Chis, Oax, QR, } \\
\text { Tab, Ver, Yuc }\end{array}$ & & $\begin{array}{l}\text { Thorsten Krömer \& } \\
\text { Adam Pérez Peña } \\
\text { 2804; MEXU, UC }\end{array}$ \\
\hline $\begin{array}{l}\text { Nephrolepis pectinata } \\
\text { (Willd.) Schott }\end{array}$ & $1450-1500$ & BMM & $\mathrm{T}$ & & V & $\mathrm{M}, \mathrm{CA}, \mathrm{AN}, \mathrm{SA}$ & $\begin{array}{l}\text { Chis, Oax, } \\
\text { Pue, Ver. }\end{array}$ & $\mathrm{mr}$ & $\begin{array}{l}\text { T. Krömer \& A. } \\
\text { Acebey } 2240 ; \\
\text { MEXU, UC }\end{array}$ \\
\hline $\begin{array}{l}\text { Lygodiaceae } \\
\text { Lygodium heterodoxum } \\
\text { Kunze }\end{array}$ & $50-530$ & $\begin{array}{l}\text { SAP, VS, } \\
\text { VA }\end{array}$ & $\mathrm{T}$ & & S & $\mathrm{M}, \mathrm{CA}$ & \multicolumn{2}{|l|}{$\begin{array}{l}\text { Chis, Oax, Pue, } \\
\text { Tab, Ver }\end{array}$} & $\begin{array}{l}\text { T. Krömer et al. 1975; } \\
\text { MEXU, UC }\end{array}$ \\
\hline Lygodium venustum Sw. & $100-850$ & $\begin{array}{l}\text { SAP, } \\
\text { BP-BQ, } \\
\text { DNC, VR, } \\
\text { VS }\end{array}$ & $\mathrm{T}$ & & S & $\mathrm{M}, \mathrm{CA}, \mathrm{AN}, \mathrm{SA}$ & \multicolumn{2}{|l|}{$\begin{array}{l}\text { Ags, Camp, Chis, } \\
\text { Col, Gro, Hgo, } \\
\text { Jal, Méx, Mich, } \\
\text { Nay, Oax, Pue, QR, } \\
\text { Qro, Sin, SLP, Tab, } \\
\text { Tam, Ver, Yuc. }\end{array}$} & $\begin{array}{l}\text { T. Krömer \& E. Otto } \\
\text { 2877; MEXU, UC }\end{array}$ \\
\hline $\begin{array}{l}\text { Marattiaceae } \\
\text { Danaea cuspidata Liebm. }\end{array}$ & 1010 & VS & $\mathrm{T}$ & & A & $\mathrm{M}, \mathrm{CA}$ & Chis, Oax, Ver. & $\mathrm{mr}$ & $\begin{array}{l}\text { R. Lira 162; MEXU, } \\
\text { UAMIZ, XAL }\end{array}$ \\
\hline Danaea geniculata Raddi & 410 & SMP & $\mathrm{T}$ & & A & $\mathrm{M}, \mathrm{CA}, \mathrm{AN}, \mathrm{SA}$ & Chis, Oax, Ver. & NT, mr & $\begin{array}{l}\text { G. Castillo-Campos } \\
\text { et al. 12598; XAL }\end{array}$ \\
\hline Danaea nodosa (L.) Sm. & $150-300$ & SAP & $\mathrm{T}$ & & V & $\mathrm{M}, \mathrm{CA}, \mathrm{AN}, \mathrm{SA}$ & Chis, Oax, Ver. & r & $\begin{array}{l}\text { S. Sinaca C. 1028; } \\
\text { MEXU, MO, EBT }\end{array}$ \\
\hline $\begin{array}{l}\text { Marattia weinmanniifolia } \\
\text { Liebm. }\end{array}$ & ca. 900 & VS & $\mathrm{T}$ & & V & $\mathrm{M}, \mathrm{CA}$ & $\begin{array}{l}\text { Chis, Gro, Hgo, n } \\
\text { Jal, Oax, Pue, } \\
\text { Qro, Ver }\end{array}$ & $\mathrm{mr}$ & $\begin{array}{l}\text { F. Ramírez R. 693; } \\
\text { XAL }\end{array}$ \\
\hline $\begin{array}{l}\text { Polypodiaceae } \\
\text { Campyloneurum amphostenon } \\
\text { (Kunze ex Klotzsch) Fée }\end{array}$ & 600 & SAP & $E$ & & V & $\mathrm{M}, \mathrm{CA}, \mathrm{AN}, \mathrm{SA}$ & $\begin{array}{l}\text { Chis, DF, Gro, } \\
\text { Hgo, Jal, Méx, } \\
\text { Mor, Oax, Pue, } \\
\text { SLP, Ver. }\end{array}$ & $\mathrm{mr}$ & $\begin{array}{l}\text { E. Garibay V. y R. } \\
\text { Acosta P. } 55 ; \text { CIB }\end{array}$ \\
\hline $\begin{array}{l}\text { Campyloneurum } \\
\text { angustifolium (Sw.) Fée }\end{array}$ & $35-1350$ & $\begin{array}{l}\text { SAP, SMP, } \\
\text { BMM, } \\
\text { ECO, VA }\end{array}$ & $\mathrm{E}$ & & S & $\begin{array}{l}\text { USA (Fla), M, } \\
\text { CA, AN, SA }\end{array}$ & $\begin{array}{l}\text { Chis, Gro, Hgo, } \\
\text { Jal, NL, Oax, } \\
\text { Pue, Qro, SLP, } \\
\text { Tab, Tam, Ver }\end{array}$ & & $\begin{array}{l}\text { T. Krömer et al. } \\
\text { 2465; MEXU, UC }\end{array}$ \\
\hline $\begin{array}{l}\text { Campyloneurum phyllitidis } \\
\text { (L.) C. Presl }\end{array}$ & $60-600$ & $\begin{array}{l}\text { SAP, VA, } \\
\text { VS }\end{array}$ & $\mathrm{E}$ & A & $S$ & $\begin{array}{l}\text { USA (Fla), M, } \\
\text { CA,AN, SA }\end{array}$ & $\begin{array}{l}\text { Camp, Chis, Gro, } \\
\text { Hgo, Jal, Mich, } \\
\text { Oax, Pue, Qro, } \\
\text { QR, SLP, Tab, } \\
\text { Ver, Yuc }\end{array}$ & & $\begin{array}{l}\text { T. Krömer et al. } \\
\text { 2599; MEXU, UC }\end{array}$ \\
\hline
\end{tabular}


Apéndice 1. Continuación

\begin{tabular}{|c|c|c|c|c|c|c|c|c|c|}
\hline Familia/Especie & $\begin{array}{l}\text { Altitud } \\
(\mathrm{m})\end{array}$ & TV & FC & $\begin{array}{l}\mathrm{EC} \\
\text { NOM }\end{array}$ & ECV & $\begin{array}{l}\text { Distribución } \\
\text { geográfica }\end{array}$ & $\begin{array}{l}\text { Distribución } \\
\text { estatal en } \\
\text { México }\end{array}$ & Obser & $\begin{array}{l}\text { v. Ejemplar de } \\
\text { referencia }\end{array}$ \\
\hline $\begin{array}{l}\text { Campyloneurum serpentinum } \\
\text { (Christ) Ching }\end{array}$ & 440 & SMP & $E$ & & & M, CA, SA & $\begin{array}{l}\text { Chis, Gro, Oax, } \\
\text { Tab, ver. }\end{array}$ & $\mathrm{mr}$ & $\begin{array}{l}\text { T. Krömer et al. } \\
\text { 4100; CITRO }\end{array}$ \\
\hline $\begin{array}{l}\text { Campyloneurum } \\
\text { xalapense Fée }\end{array}$ & $650-1600$ & $\begin{array}{l}\text { SAP, BMM, } \\
\text { VS, ECO }\end{array}$ & $\mathrm{E}$ & & S & $\mathrm{M}, \mathrm{CA}$ & $\begin{array}{l}\text { Chis, Gro, Hgo, } \\
\text { Nay, Oax, Pue, } \\
\text { Qro, SLP, Tab, Ver }\end{array}$ & & $\begin{array}{l}\text { T. Krömer \& A. } \\
\text { Acebey } 2474 ; \\
\text { MEXU, UC }\end{array}$ \\
\hline $\begin{array}{l}\text { Cochlidium linearifolium } \\
\text { (Desv.) Maxon ex C. Chr. }\end{array}$ & $500-1720$ & $\begin{array}{l}\text { SAP, BMM, } \\
\text { ECO }\end{array}$ & $\mathrm{E}$ & & V & $\mathrm{M}, \mathrm{CA}, \mathrm{AN}, \mathrm{SA}$ & $\begin{array}{l}\text { Chis, Gro, } \\
\text { Oax, Ver. }\end{array}$ & & $\begin{array}{l}\text { T. Krömer \& A. } \\
\text { Acebey 2077; EBT, } \\
\text { MEXU, SEL, UC, XAL }\end{array}$ \\
\hline $\begin{array}{l}\text { Cochlidium serrulatum (Sw.) } \\
\text { L.E. Bishop }\end{array}$ & $950-1480$ & BMM, ECO & $E$ & & V & $\operatorname{Cos}$ & $\begin{array}{l}\text { Chis, Oax, } \\
\text { Pue, Ver. }\end{array}$ & & $\begin{array}{l}\text { T. Krömer \& A. } \\
\text { Acebey 2540; EBT, } \\
\text { MEXU, SEL, UC, XAL }\end{array}$ \\
\hline $\begin{array}{l}\text { Lellingeria delitescens (Maxon) } \\
\text { A.R. Sm. \& R.C. Moran= } \\
\text { Stenogrammitis delitescens } \\
\text { (Maxon) Labiak }\end{array}$ & $830-980$ & $\mathrm{ECO}, \mathrm{BMM}$ & $\mathrm{E}$ & & $P$ & M, An & Oax, Ver. & $\mathrm{mr}$ & $\begin{array}{l}\text { M. Nee et al. 25071; } \\
\text { F, XAL }\end{array}$ \\
\hline $\begin{array}{l}\text { Lellingeria limula (H. Christ) } \\
\text { A. R. Sm. \& R. C. Moran= } \\
\text { Stenogrammitis limula } \\
\text { (Christ) Labiak }\end{array}$ & 1125 & BMM & $E$ & & & $\mathrm{M}, \mathrm{CA}, \mathrm{nSA}$ & Chis, Ver. & $\mathrm{NV}, \mathrm{m}$ & $\begin{array}{l}\text { T. Krömer \& E. Otto } \\
\text { 2957; MEXU, UC }\end{array}$ \\
\hline $\begin{array}{l}\text { Lellingeria prionodes (Mickel \& } \\
\text { Beitel) A.R. Sm. \& R.C. Moran= } \\
\text { Stenogrammitis prionodes } \\
\text { (Mickel \& Beitel) Labiak }\end{array}$ & $1570-1700$ & $\mathrm{BMM}$ & $E$ & & A & $\mathrm{M}, \mathrm{CA}$ & $\begin{array}{l}\text { Chis, Hgo, Oax, } \\
\text { Pue, Ver. }\end{array}$ & $\mathrm{r}$ & $\begin{array}{l}\text { T. Krömer \& A. } \\
\text { Acebey 2561; EBT, } \\
\text { MEXU, UC, XAL }\end{array}$ \\
\hline $\begin{array}{l}\text { Melpomene leptostoma (Fée) } \\
\text { A.R. Sm. \& R.C. Moran }\end{array}$ & $1050-2000$ & $\mathrm{BMM}, \mathrm{BQ}$ & $E$ & & A & M, Guat & $\begin{array}{l}\text { Chis, Hgo, Oax, } \\
\text { Pue, Ver. }\end{array}$ & $\mathrm{mr}$ & F. Ramírez 543; XAL \\
\hline $\begin{array}{l}\text { Melpomene xiphopteroides } \\
\text { (Liebm.) A.R. Sm. \& } \\
\text { R.C. Moran }\end{array}$ & $1480-1590$ & BMM & $\mathrm{E}$ & & V & $\mathrm{M}, \mathrm{CA}, \mathrm{AN}, \mathrm{SA}$ & $\begin{array}{l}\text { Chis, Gro, } \\
\text { Oax, Ver }\end{array}$ & r & $\begin{array}{l}\text { T. Krömer \& A. } \\
\text { Acebey 2433; EBT, } \\
\text { MEXU, SEL, UC, XAL }\end{array}$ \\
\hline $\begin{array}{l}\text { Microgramma nitida } \\
\text { (J. Sm.) A.R. Sm. }\end{array}$ & $0-450$ & $\begin{array}{l}\text { SAP, MGL, } \\
\text { VS, VA }\end{array}$ & E & & S & $\mathrm{M}, \mathrm{CA}, \mathrm{AN}$ & \multicolumn{2}{|l|}{$\begin{array}{l}\text { Camp, Chis, Hgo, } \\
\text { Oax, Pue, QR, } \\
\text { Qro, SLP, Tab, } \\
\text { Tam, Ver, Yuc. }\end{array}$} & $\begin{array}{l}\text { T. Krömer et al. } \\
\text { 2453; MEXU, UC }\end{array}$ \\
\hline $\begin{array}{l}\text { Micropolypodium taenifolium } \\
\text { (Jenman) A.R. Sm.= } \\
\text { Moranopteris taenifolia } \\
\text { (Jenman) R.Y. Hirai \& J. Prado }\end{array}$ & $950-1200$ & BMM & $E$ & & A & $\mathrm{M}, \mathrm{CA}, \mathrm{An}, \mathrm{nSA}$ & Chis, Oax, Ver. & $\mathrm{mr}$ & $\begin{array}{l}\text { M. Vázquez T. et al. } \\
\text { 4108; XAL, CIB }\end{array}$ \\
\hline $\begin{array}{l}\text { Micropolypodium } \\
\text { trichomanoides (Sw.) A. R. Sm.= } \\
\text { Moranopteris trichomanoides } \\
\text { (Swartz) R.Y. Hirai \& J. Prado }\end{array}$ & 1480-1570 & BMM & $\mathrm{E}$ & & A & $\mathrm{M}, \mathrm{CA}, \mathrm{An}, \mathrm{nSA}$ & Chis, Oax, Ver. & $\mathrm{mr}$ & $\begin{array}{l}\text { T. Krömer \& A. } \\
\text { Acebey } 2541 ; \text { EBT, } \\
\text { MEXU, UC }\end{array}$ \\
\hline $\begin{array}{l}\text { Niphidium crassifolium } \\
\text { (L.) Lellinger }\end{array}$ & $450-1240$ & $\begin{array}{l}\text { SAP, BMM, } \\
\text { SMP, BQ-BP, } \\
\text { VS, ECO }\end{array}$ & E, R & & V & $\mathrm{M}, \mathrm{CA}, \mathrm{AN}, \mathrm{SA}$ & $\begin{array}{l}\text { Chis, Gro, Hgo, } \\
\text { Oax, Pue, Qro, } \\
\text { Ver. }\end{array}$ & & $\begin{array}{l}\text { T. Krömer \& A. } \\
\text { Acebey } 2001 ; \\
\text { MEXU, UC }\end{array}$ \\
\hline $\begin{array}{l}\text { Pecluma atra (A.M. Evans) } \\
\text { M.G. Price }\end{array}$ & $400-910$ & $\begin{array}{l}\text { SAP, VS, } \\
\text { SMP, ECO }\end{array}$ & $\mathrm{T}$ & & V & $\mathrm{M}, \mathrm{CA}$ & $\begin{array}{l}\text { Chis, Oax, Qro, } \\
\text { Tab, Tlax, Ver. }\end{array}$ & $r$ & $\begin{array}{l}\text { R. Riba et al. } \\
\text { 1133; ENCB }\end{array}$ \\
\hline
\end{tabular}


Apéndice 1. Continuación

\begin{tabular}{|c|c|c|c|c|c|c|c|c|c|}
\hline Familia/Especie & $\begin{array}{l}\text { Altitud } \\
(\mathrm{m})\end{array}$ & TV & FC & $\begin{array}{l}\mathrm{EC} \\
\mathrm{NOM}\end{array}$ & ECV & $\begin{array}{l}\text { Distribución } \\
\text { geográfica }\end{array}$ & $\begin{array}{l}\text { Distribución } \\
\text { estatal en } \\
\text { México }\end{array}$ & Obser & $\begin{array}{l}\text { v. Ejemplar de } \\
\text { referencia }\end{array}$ \\
\hline $\begin{array}{l}\text { Pecluma consimilis (Mett.) } \\
\text { M.G. Price }\end{array}$ & $450-1550$ & $\begin{array}{l}\text { BMM, } \\
\text { BP-BQ, } \\
\text { VA, VS, } \\
\text { SMP, ECO }\end{array}$ & $\begin{array}{l}T, E \\
R\end{array}$ & & A & $\mathrm{M}, \mathrm{CA}, \mathrm{An}, \mathrm{nSA}$ & Chis, Oax, Ver. & & $\begin{array}{l}\text { T. Krömer \& A. } \\
\text { Acebey 1995; } \\
\text { MEXU, UC }\end{array}$ \\
\hline $\begin{array}{l}\text { Pecluma ptilodon (Kunze) } \\
\text { M.G. Price var. bourgeauana } \\
\text { (E. Fourn.) A.R. Sm. }\end{array}$ & ca. 300 & SAP & $\mathrm{E}$ & & V & $\mathrm{M}, \mathrm{CA}, \mathrm{AN}$ & $\begin{array}{l}\text { Chis, Hgo, Oax, } \\
\text { Pue, Qro, SLP, } \\
\text { Tam, Ver. }\end{array}$ & NT, r & $\begin{array}{l}\text { R. Villalobos S. 30; } \\
\text { ENCB }\end{array}$ \\
\hline $\begin{array}{l}\text { Pecluma sursumcurrens } \\
\text { (Copel.) M.G. Price }\end{array}$ & $920-1675$ & $\begin{array}{l}\text { BMM, } \\
\text { BP-BQ, } \\
\text { ECO }\end{array}$ & $E$ & & A & M, Guat & $\begin{array}{l}\text { Chis, Hgo, Oax, } \\
\text { Pue, Qro, SLP, } \\
\text { Tab, Ver. }\end{array}$ & NT & $\begin{array}{l}\text { T. Krömer \& A. } \\
\text { Acebey 2067; } \\
\text { MEXU, UC }\end{array}$ \\
\hline $\begin{array}{l}\text { Phlebodium pseudoaureum } \\
\text { (Cav.) Lellinger }\end{array}$ & 640-1550 & $\begin{array}{l}\text { SAP, BMM, } \\
\text { ECO, VA, } \\
\text { VS }\end{array}$ & $\mathrm{T}, \mathrm{E}$ & & V & $\begin{array}{l}\text { USA (Fla), M, } \\
\text { CA, AN, SA }\end{array}$ & $\begin{array}{l}\text { Ags, Chih, Chis, } \\
\text { Col, DF, Dgo, } \\
\text { Gro, Gto, Hgo, } \\
\text { Jal, Méx, Mich, } \\
\text { Mor, Nay, NL, } \\
\text { Oax, Pue, Qro, } \\
\text { Sin, SLP, Tam, Ver. }\end{array}$ & & $\begin{array}{l}\text { T. Krömer et al. } \\
\text { 1933; MEXU, UC }\end{array}$ \\
\hline $\begin{array}{l}\text { Pleopeltis angusta var. } \\
\text { stenoloma (Fée) Farw. }\end{array}$ & $500-1350$ & $\begin{array}{l}\text { SAP, BMM, } \\
\text { VS, ECO }\end{array}$ & E & & V & M, Guat & Chis, Oax, Ver. & & $\begin{array}{l}\text { T. Krömer \& A. } \\
\text { Acebey } 2122 ; \\
\text { MEXU, UC }\end{array}$ \\
\hline $\begin{array}{l}\text { Pleopeltis astrolepis } \\
\text { (Liebm.) E. Fourn. }\end{array}$ & $45-600$ & $\begin{array}{l}\text { SAP, SMP, } \\
\text { MGL, VS, } \\
\text { VA }\end{array}$ & $\mathrm{E}$ & & S & $\mathrm{M}, \mathrm{CA}, \mathrm{AN}, \mathrm{SA}$ & $\begin{array}{l}\text { Camp, Chis, Col, } \\
\text { Gro, Jal, Nay, } \\
\text { Oax, Tab, Ver. }\end{array}$ & & $\begin{array}{l}\text { T. Krömer et al. } \\
\text { 1928; MEXU, UC }\end{array}$ \\
\hline $\begin{array}{l}\text { Pleopeltis crassinervata } \\
\text { (Fée) T. Moore }\end{array}$ & $560-1550$ & $\begin{array}{l}\text { SAP, BMM, } \\
\text { VA, VS, } \\
\text { ECO }\end{array}$ & $\mathrm{E}$ & & S & $\mathrm{M}, \mathrm{CA}$ & $\begin{array}{l}\text { Chis, Hgo, Oax, } \\
\text { Pue, Qro, SLP, } \\
\text { Tam, Ver. }\end{array}$ & & $\begin{array}{l}\text { T. Krömer \& A. } \\
\text { Acebey 2534; } \\
\text { MEXU, UC }\end{array}$ \\
\hline $\begin{array}{l}\text { Pleopeltis fallax (Schltdl. \& } \\
\text { Cham.) Mickel \& Beitel }\end{array}$ & $160-1010$ & $\begin{array}{l}\text { SAP, BMM, } \\
\text { ECO, VA }\end{array}$ & E & & $S$ & $\mathrm{M}, \mathrm{CA}$ & $\begin{array}{l}\text { Chis, Hgo, Oax, } \\
\text { Pue, Qro, SLP, } \\
\text { Ver. }\end{array}$ & & $\begin{array}{l}\text { T. Krömer \& A. } \\
\text { Acebey 1983; } \\
\text { MEXU, UC }\end{array}$ \\
\hline Polypodium collinsii Maxon & $740-1730$ & $\begin{array}{l}\text { BMM, } \\
\text { BP-BQ, } \\
\text { ECO }\end{array}$ & $\mathrm{E}, \mathrm{R}$ & & A & M (endémica) & Chis, Oax, Ver & & $\begin{array}{l}\text { T. Krömer \& A. } \\
\text { Acebey } 2000 ; \\
\text { MEXU, UC }\end{array}$ \\
\hline Polypodium echinolepis Fée & $1010-1350$ & BMM, VS & $E$ & & S & $\mathrm{M}, \mathrm{CA}$ & $\begin{array}{l}\text { Chis, Mich, Mor, } \\
\text { Oax, Pue, Ver. }\end{array}$ & & $\begin{array}{l}\text { T. Krömer \& A. } \\
\text { Acebey } 2484 ; \\
\text { MEXU, UC }\end{array}$ \\
\hline $\begin{array}{l}\text { Polypodium fraternum } \\
\text { Schltl. \& Cham. }\end{array}$ & $800-1000$ & $\begin{array}{l}\text { BP-BQ, } \\
\text { BMM }\end{array}$ & $\mathrm{E}$ & & S & $\mathrm{M}, \mathrm{CA}$ & $\begin{array}{l}\text { Chis, Gro, Hgo, } \\
\text { Jal, Mich, Nay, } \\
\text { Oax, Pue, Qro, } \\
\text { SLP, Ver. }\end{array}$ & $\mathrm{mr}$ & $\begin{array}{l}\text { T. Krömer \& E. Otto } \\
\text { 2892; MEXU, UC }\end{array}$ \\
\hline $\begin{array}{l}\text { Polypodium furfuraceum } \\
\text { Schltdl. \& Cham. }\end{array}$ & $450-700$ & $\begin{array}{l}\text { SAP, SMP, } \\
\text { BP-BQ, } \\
\text { ECO, VS }\end{array}$ & $\mathrm{E}$ & & V & $\mathrm{M}, \mathrm{CA}, \mathrm{SA}$ & $\begin{array}{l}\text { Chis, Col, Dgo, } \\
\text { Gro, Hgo, Jal, } \\
\text { Méx, Mich, Mor, } \\
\text { Nay, Oax, Qro, } \\
\text { Sin, SLP, Ver. }\end{array}$ & r & $\begin{array}{l}\text { T. Krömer \& E. Otto } \\
\text { 2887; MEXU, UC }\end{array}$ \\
\hline $\begin{array}{l}\text { Polypodium } \\
\text { longepinnulatum E. Fourn. }\end{array}$ & $860-1600$ & $\begin{array}{l}\text { BMM, } \\
\text { BP-BQ, VS }\end{array}$ & $\mathrm{E}$ & & V & M, Guat, Hon & $\begin{array}{l}\text { Chis, Gro, Hgo, } \\
\text { Jal, Oax, Pue, } \\
\text { Qro, Ver. }\end{array}$ & & $\begin{array}{l}\text { T. Krömer \& A. } \\
\text { Acebey 2083; } \\
\text { MEXU, UC }\end{array}$ \\
\hline
\end{tabular}


Apéndice 1. Continuación

\begin{tabular}{|c|c|c|c|c|c|c|c|c|c|}
\hline Familia/Especie & $\begin{array}{l}\text { Altitud } \\
(\mathrm{m})\end{array}$ & TV & FC & $\begin{array}{l}\mathrm{EC} \\
\mathrm{NOM}\end{array}$ & ECV & $\begin{array}{l}\text { Distribución } \\
\text { geográfica }\end{array}$ & $\begin{array}{l}\text { Distribución } \\
\text { estatal en } \\
\text { México }\end{array}$ & Obser & $\begin{array}{l}\text { Ejemplar de } \\
\text { referencia }\end{array}$ \\
\hline $\begin{array}{l}\text { Polypodium plebeium } \\
\text { Schltdl. \& Cham. }\end{array}$ & $840-1600$ & $\begin{array}{l}\text { BMM, } \\
\text { ECO, vS }\end{array}$ & $E$ & & S & $\mathrm{M}, \mathrm{CA}$ & $\begin{array}{l}\text { Chis, Gto, Hgo, } \\
\text { Méx, Oax, Pue, Q } \\
\text { SLP, Tam, Ver. }\end{array}$ & Qro, & $\begin{array}{l}\text { T. Krömer \& A. } \\
\text { Acebey 2081; } \\
\text { MEXU, UC }\end{array}$ \\
\hline $\begin{array}{l}\text { Polypodium plesiosorum } \\
\text { Kunze }\end{array}$ & $600-950$ & $\mathrm{ECO}$ & $E$ & & S & $\mathrm{M}, \mathrm{CA}$ & $\begin{array}{l}\text { Chis, Coah, DF, } \\
\text { Gro, Gto, Hgo, } \\
\text { Jal, Méx, Mich, } \\
\text { Mor, Nay, NL, } \\
\text { Oax, Pue, Qro, } \\
\text { SLP, Tam, Ver. }\end{array}$ & $\mathrm{r}$ & $\begin{array}{l}\text { R. Riba 1132; } \\
\text { MEXU }\end{array}$ \\
\hline $\begin{array}{l}\text { Polypodium } \\
\text { polypodioides (L.) Watt }\end{array}$ & $30-1010$ & $\begin{array}{l}\text { SAP, BMM, } \\
\text { ECO, SMP, } \\
\text { VS, VA }\end{array}$ & $\mathrm{E}$ & & S & $\mathrm{M}, \mathrm{CA}$ & $\begin{array}{l}\text { Chis, Col, DF, } \\
\text { Dgo, Gro, Gto, } \\
\text { Hgo, Jal, Méx, } \\
\text { Mich, Mor, Nay, } \\
\text { Oax, Pue, Qro, } \\
\text { Rev, Sin, SLP, } \\
\text { Ver, Zac. }\end{array}$ & & $\begin{array}{l}\text { T. Krömer et al. } \\
\text { 1925; MEXU, UC }\end{array}$ \\
\hline $\begin{array}{l}\text { Polypodium } \\
\text { rhachipterygium Liebm. }\end{array}$ & $100-850$ & SAP, ECO & $\mathrm{T}, \mathrm{R}$ & & V & M, Guat & Chis, Oax, Ver. & & $\begin{array}{l}\text { T. Krömer \& A. } \\
\text { Acebey 1998; } \\
\text { MEXU, UC }\end{array}$ \\
\hline $\begin{array}{l}\text { Polypodium } \\
\text { rhodopleuron Kunze }\end{array}$ & $1090-1570$ & $\mathrm{BMM}$ & $E$ & & S & $\mathrm{M}, \mathrm{CA}$ & $\begin{array}{l}\text { Chis, Gro, Hgo, } \\
\text { Oax, Pue, Qro, } \\
\text { Ver. }\end{array}$ & NT, r & $\begin{array}{l}\text { T. Krömer \& A. } \\
\text { Acebey } 2196 ; \\
\text { MEXU, UC }\end{array}$ \\
\hline $\begin{array}{l}\text { Serpocaulon falcaria } \\
\text { (Kunze) A.R. Sm. }\end{array}$ & $1200-1640$ & BMM & $\mathrm{E}$ & & S & $\mathrm{M}, \mathrm{CA}$ & $\begin{array}{l}\text { Chis, Gro, Oax, } \\
\text { Pue, Ver. }\end{array}$ & r & $\begin{array}{l}\text { R. Riba \& B. } \\
\text { Pérez-García 1089; } \\
\text { MEXU }\end{array}$ \\
\hline $\begin{array}{l}\text { Serpocaulon triseriale } \\
\text { (Sw.) A. R. Sm. }\end{array}$ & $0-1300$ & $\begin{array}{l}\text { SAP, SMP, } \\
\text { BMM, } \\
\text { BP-BQ, } \\
\text { VS, VA, } \\
\text { MGL, ECO }\end{array}$ & $E$ & $A$ & S & $\mathrm{M}, \mathrm{CA}, \mathrm{AN}, \mathrm{SA}$ & $\begin{array}{l}\text { Camp, Chis, Gro, } \\
\text { Oax, Pue, Tab, } \\
\text { Ver. }\end{array}$ & & $\begin{array}{l}\text { T. Krömer et al. } \\
\text { 1927; MEXU, UC }\end{array}$ \\
\hline $\begin{array}{l}\text { Terpsichore asplenifolia } \\
\text { (L.) A.R. Sm. }\end{array}$ & 1200 & BMM & $E$ & & V & $\mathrm{M}, \mathrm{CA}, \mathrm{AN}, \mathrm{nSA}$ & $\begin{array}{l}\text { Chis, Gro, Oax, } \\
\text { Ver. }\end{array}$ & $\mathrm{mr}$ & R. Lira 231; UAMIZ \\
\hline $\begin{array}{l}\text { Terpsichore mollissima } \\
\text { (Fée) A.R. Sm.=Alansmia } \\
\text { elastica (Bory ex Willdenow) } \\
\text { Moguel \& M.Kessler }\end{array}$ & 740-1010 & BMM, ECO & $E$ & & $A$ & $\mathrm{M}, \mathrm{CA}, \mathrm{AN}, \mathrm{nSA}$ & Chis, Oax, Ver. & r & $\begin{array}{l}\text { T. Krömer \& A. } \\
\text { Acebey 2164; EBT, } \\
\text { MEXU, SEL, UC, XAL }\end{array}$ \\
\hline $\begin{array}{l}\text { Pteridaceae } \\
\text { Acrostichum aureum L. }\end{array}$ & $0-10$ & MGL, DNC & $\mathrm{T}, \mathrm{Hi}$ & & V & Cos & $\begin{array}{l}\text { Camp, Chis, Gro, } \\
\text { Nay, Oax, Tab, } \\
\text { QR, Ver, Yuc }\end{array}$ & & $\begin{array}{l}\text { R. Riba \& B. } \\
\text { Pérez-García 1190; } \\
\text { MEXU, UAMIZ }\end{array}$ \\
\hline $\begin{array}{l}\text { Acrostichum danaeifolium } \\
\text { Langsd. \& Fisch. }\end{array}$ & 150 & VS & $\mathrm{T}, \mathrm{Hi}$ & & S & $\mathrm{M}, \mathrm{CA}, \mathrm{AN}, \mathrm{SA}$ & $\begin{array}{l}\text { Camp, Chis, Col, } \\
\text { Gro, Jal, Mich, } \\
\text { Nay, Oax, QR, } \\
\text { SLP, Tab, Tam, } \\
\text { Ver, Yuc }\end{array}$ & $\mathrm{mr}$ & $\begin{array}{l}\text { G. Martinez 3020; } \\
\text { XAL }\end{array}$ \\
\hline Adiantopsis radiata (L.) Fée & $650-850$ & $\begin{array}{l}\text { SAP, SMP, } \\
\text { ECO }\end{array}$ & $\mathrm{T}, \mathrm{R}$ & & V & $\mathrm{M}, \mathrm{CA}, \mathrm{AN}, \mathrm{SA}$ & $\begin{array}{l}\text { Chis, Col, Gro, } \\
\text { Oax, Pue, Rev, } \\
\text { SLP, Tab, Tam, Ver }\end{array}$ & r & $\begin{array}{l}\text { S. Sinaca C. et al. } \\
\text { 958; MEXU, EBT }\end{array}$ \\
\hline
\end{tabular}


Apéndice 1. Continuación

\begin{tabular}{|c|c|c|c|c|c|c|c|c|c|}
\hline Familia/Especie & $\begin{array}{l}\text { Altitud } \\
(\mathrm{m})\end{array}$ & TV & FC & $\begin{array}{l}\mathrm{EC} \\
\mathrm{NOM}\end{array}$ & ECV & $\begin{array}{l}\text { Distribución } \\
\text { geográfica }\end{array}$ & $\begin{array}{l}\text { Distribución } \\
\text { estatal en } \\
\text { México }\end{array}$ & Observ & $\begin{array}{l}\text { v. Ejemplar de } \\
\text { referencia }\end{array}$ \\
\hline Adiantum amplum C. Presl & $150-600$ & SAP, VS & $\mathrm{T}$ & & V & $\mathrm{M}, \mathrm{CA}, \mathrm{nSA}$ & $\begin{array}{l}\text { Chis, Col, Gro, } \\
\text { Jal, Mich, Nay, } \\
\text { Oax, Sin, Tab, Ver }\end{array}$ & & M. Nee 23628; XAL \\
\hline $\begin{array}{l}\text { Adiantum concinnum Humb. } \\
\text { \& Bonpl. ex Willd. }\end{array}$ & $400-800$ & $\begin{array}{l}\text { SMP, VA, } \\
\text { VS }\end{array}$ & $\mathrm{T}, \mathrm{R}$ & & $\mathrm{S}$ & $\mathrm{M}, \mathrm{CA}, \mathrm{AN}, \mathrm{SA}$ & $\begin{array}{l}\text { BCS, Chis, Col, } \\
\text { DF, Dgo, Gro, } \\
\text { Jal, Méx, Mich, } \\
\text { Mor, Nay, Oax, } \\
\text { Pue, Qro, SLP, } \\
\text { Sin, Son, Tam, Ver }\end{array}$ & & $\begin{array}{l}\text { T. Krömer \& E. Otto } \\
\text { 2943; MEXU, UC }\end{array}$ \\
\hline Adiantum latifolium Lam. & 60 & VA & $\mathrm{T}$ & & V & $\mathrm{M}, \mathrm{CA}, \mathrm{AN}, \mathrm{SA}$ & $\begin{array}{l}\text { Chis, Oax, Tab, } \\
\text { Ver }\end{array}$ & $\mathrm{mr}$ & $\begin{array}{l}\text { T. Krömer et al. } \\
\text { 2459; MEXU, UC }\end{array}$ \\
\hline Adiantum macrophyllum Sw. & 520 & SAP & $\mathrm{T}$ & & V & $\mathrm{M}, \mathrm{CA}, \mathrm{AN}, \mathrm{SA}$ & $\begin{array}{l}\text { Chis, Gro, Oax, } \\
\text { Pue, Ver }\end{array}$ & $\mathrm{NT}, \mathrm{mr}$ & H. Bravo 101; MEXU \\
\hline Adiantum petiolatum Desv. & $150-600$ & SAP & $\mathrm{T}$ & & V & $\mathrm{M}, \mathrm{CA}, \mathrm{AN}, \mathrm{SA}$ & $\begin{array}{l}\text { Chis, Oax, Tab, } \\
\text { Ver }\end{array}$ & $\mathrm{mr}$ & R. Riba 1940; MEXU \\
\hline Adiantum pulverulentum L. & $35-600$ & $\begin{array}{l}\text { SAP, ECO, } \\
\text { BP, VS, VA }\end{array}$ & $\mathrm{T}$ & & V & $\mathrm{M}, \mathrm{CA}, \mathrm{AN}, \mathrm{SA}$ & $\begin{array}{l}\text { Chis, Gro, Oax, } \\
\text { QR, SLP, Tab, } \\
\text { Ver. }\end{array}$ & & $\begin{array}{l}\text { T. Krömer et al. } \\
\text { 2463; MEXU, UC }\end{array}$ \\
\hline $\begin{array}{l}\text { Adiantum tetraphyllum } \\
\text { Humb. \& Bonpl. ex Willd. }\end{array}$ & $100-530$ & SAP & $\mathrm{T}$ & & V & $\mathrm{M}, \mathrm{CA}, \mathrm{AN}, \mathrm{SA}$ & Chis, Oax, Ver & & $\begin{array}{l}\text { G. Martinez C. } \\
\text { 2292; MEXU }\end{array}$ \\
\hline Adiantum trapeziforme L. & $100-450$ & $\begin{array}{l}\text { SAP, VS, } \\
\text { VR }\end{array}$ & $\mathrm{T}$ & & V & $\mathrm{M}, \mathrm{CA}, \mathrm{AN}, \mathrm{SA}$ & $\begin{array}{l}\text { Chis, Gro, Hgo, } \\
\text { Jal, Méx, Mich, } \\
\text { Nay, NL, Oax, } \\
\text { Pue, Qro, SLP, } \\
\text { Tam, Ver. }\end{array}$ & & $\begin{array}{l}\text { T. Krömer et al. } \\
2470 ; \text { MEXU }\end{array}$ \\
\hline Adiantum wilesianum Hook. & 450 & SAP & $\mathrm{T}$ & & V & $\mathrm{M}, \mathrm{CA}$ & $\begin{array}{l}\text { Chis, Hgo, Oax, } \\
\text { SLP, Tab, Ver. }\end{array}$ & $r$ & $\begin{array}{l}\text { R. Riba et al. } 711 \text {; } \\
\text { MEXU, UAMIZ }\end{array}$ \\
\hline $\begin{array}{l}\text { Ananthacorus angustifolius } \\
\text { (Sw.) Underw. \& Maxon }\end{array}$ & 600 & SMS & $\mathrm{E}$ & & V & $\mathrm{M}, \mathrm{CA}, \mathrm{AN}, \mathrm{SA}$ & $\begin{array}{l}\text { Chis, Col, Gro, } \\
\text { Jal, Nay, Oax, } \\
\text { Ver }\end{array}$ & $\mathrm{mr}$ & $\begin{array}{l}\text { R. Riba et al. 1141; } \\
\text { MEXU, UAMIZ }\end{array}$ \\
\hline Hemionitis palmata L. & $45-600$ & $\begin{array}{l}\text { SAP, VS, } \\
\text { VA, VR }\end{array}$ & $\mathrm{T}$ & & $S$ & $\mathrm{M}, \mathrm{CA}, \mathrm{AN}, \mathrm{SA}$ & $\begin{array}{l}\text { Chis, Col, Gro, } \\
\text { Oax, Pue, Qro, } \\
\text { Sin, SLP, Tab, } \\
\text { Tam, Ver, Yuc. }\end{array}$ & & $\begin{array}{l}\text { T. Krömer \& A. } \\
\text { Acebey 2308; } \\
\text { MEXU, UC }\end{array}$ \\
\hline $\begin{array}{l}\text { Mildella intramarginalis } \\
\text { (Kaulf. ex Link) Trevis. }\end{array}$ & $900-1450$ & VS & $\mathrm{T}$ & & V & $\mathrm{M}, \mathrm{CA}$ & $\begin{array}{l}\text { Chis, Gro, Hgo, } \\
\text { Mich, Mor, Oax, } \\
\text { Pue, Qro, Sin, } \\
\text { SLP, Tam, Ver. }\end{array}$ & r & $\begin{array}{l}\text { T. Krömer \& A. } \\
\text { Acebey 2240; MEXU }\end{array}$ \\
\hline Pellaea ternifolia (Cav.) Link & - & VA & $\mathrm{T}$ & & $\begin{array}{l}\text { Vó } \\
\text { A }\end{array}$ & $\begin{array}{l}\text { swUSA, M, } \\
\text { CA, SA }\end{array}$ & $\begin{array}{l}\text { Ags, BCN, Chih, } \\
\text { Chis, Coah, DF, } \\
\text { Dgo, Gto, Hgo, } \\
\text { Jal, Méx, Mich, } \\
\text { Mor, NL, Oax, } \\
\text { Pue, Qro, SLP, } \\
\text { Son, Tlax, Ver, Zac }\end{array}$ & $\begin{array}{l}\mathrm{mr} \\
\mathrm{ac}\end{array}$ & $\begin{array}{l}\text { J.I. Calzada 555; } \\
\text { MEXU, XAL }\end{array}$ \\
\hline
\end{tabular}


Apéndice 1. Continuación

\begin{tabular}{|c|c|c|c|c|c|c|c|c|c|}
\hline Familia/Especie & $\begin{array}{l}\text { Altitud } \\
(\mathrm{m})\end{array}$ & TV & FC & $\begin{array}{l}\text { EC } \\
\text { NOM }\end{array}$ & ECV & $\begin{array}{l}\text { Distribución } \\
\text { geográfica }\end{array}$ & $\begin{array}{l}\text { Distribución } \\
\text { estatal en } \\
\text { México }\end{array}$ & Obse & $\begin{array}{l}\text { v. Ejemplar de } \\
\text { referencia }\end{array}$ \\
\hline $\begin{array}{l}\text { Pityrogramma calomelanos } \\
\text { (L.) Link }\end{array}$ & $0-950$ & $\begin{array}{l}\text { SAP, MGL, } \\
\text { VA, VS, } \\
\text { ECO }\end{array}$ & $\mathrm{T}$ & & S & Cos & $\begin{array}{l}\text { Chis, Col, Gro, } \\
\text { Hgo, Jal, Méx, } \\
\text { Mich, Nay, Oax, } \\
\text { Qro, QR, Sin, SLP, } \\
\text { Tab, Tam, Ver. }\end{array}$ & & $\begin{array}{l}\text { T. Krömer \& A. } \\
\text { Acebey } 2310 ; \\
\text { MEXU, UC }\end{array}$ \\
\hline $\begin{array}{l}\text { Pityrogramma ebenea } \\
\text { (L.) Proctor }\end{array}$ & $960-1730$ & BMM, VS & $\mathrm{T}$ & & $\mathrm{S}$ & $\mathrm{M}, \mathrm{CA}, \mathrm{AN}, \mathrm{SA}$ & $\begin{array}{l}\text { Chis, Col, DF, } \\
\text { Dgo, Gro, Gto, } \\
\text { Hgo, Jal, Méx, } \\
\text { Mich, Mor, Nay, } \\
\text { Oax, Pue, Qro, } \\
\text { Rev, Sin, SLP, Ver. }\end{array}$ & $r$ & $\begin{array}{l}\text { T. Krömer \& A. } \\
\text { Acebey } 2241 ; \\
\text { MEXU, UC }\end{array}$ \\
\hline $\begin{array}{l}\text { Polytaenium feei } \\
\text { (W. Schaffn. ex Fée) Maxon }\end{array}$ & $300-1100$ & $\begin{array}{l}\text { SAP, BMM, } \\
\text { ECO }\end{array}$ & $\mathrm{E}$ & & A & $\mathrm{M}, \mathrm{CA}, \mathrm{AN}, \mathrm{SA}$ & Chis, Oax, Ver. & & $\begin{array}{l}\text { T. Krömer \& A. } \\
\text { Acebey 1993; } \\
\text { MEXU, UC }\end{array}$ \\
\hline $\begin{array}{l}\text { Polytaenium lineatum } \\
\text { (Sw.) J. Sm. }\end{array}$ & 1120 & BMM & $\mathrm{E}$ & & $\mathrm{P}$ & $\mathrm{M}, \mathrm{CA}, \mathrm{AN}, \mathrm{SA}$ & $\begin{array}{l}\text { Chis, Gro, Oax, } \\
\text { Ver. }\end{array}$ & $\begin{array}{l}\mathrm{NT} \\
\mathrm{mr}\end{array}$ & $\begin{array}{l}\text { T. Krömer \& A. } \\
\text { Acebey 2368; } \\
\text { MEXU, UC }\end{array}$ \\
\hline Pteris altissima Poir. & $100-800$ & SAP, ECO & $\mathrm{T}$ & & $\mathrm{S}$ & $\mathrm{M}, \mathrm{CA}, \mathrm{AN}, \mathrm{SA}$ & \multicolumn{2}{|l|}{$\begin{array}{l}\text { Chis, Hgo, Oax, } \\
\text { Pue, SLP, Tab, Ver. }\end{array}$} & $\begin{array}{l}\text { T. Krömer et al. } \\
\text { 1968; MEXU, UC }\end{array}$ \\
\hline Pteris grandifolia L. & 400 & SAP & $\mathrm{T}$ & & $\mathrm{S}$ & $\mathrm{M}, \mathrm{CA}, \mathrm{AN}, \mathrm{SA}$ & $\begin{array}{l}\text { Chis, Gro, Hgo, } \\
\text { Mich, Oax, Pue, } \\
\text { QR, Qro, SLP, } \\
\text { Tab, Ver. }\end{array}$ & $\mathrm{mr}$ & $\begin{array}{l}\text { I.I. Calzada 10720; } \\
\text { MEXU }\end{array}$ \\
\hline Pteris longifolia L. & $350-450$ & VS & $\mathrm{T}$ & & S & $\mathrm{M}, \mathrm{CA}, \mathrm{An}, \mathrm{nSA}$ & $\begin{array}{l}\text { Chis, Col, Gro, } \\
\text { Méx, Mich, Mor, } \\
\text { Nay, Oax, Pue, } \\
\text { QR, Qro, Sin, } \\
\text { SLP, Tab, Islas } \\
\text { Tres Marias, Ver. }\end{array}$ & $\mathrm{mr}$ & $\begin{array}{l}\text { R. Cedillo T. y J.I. } \\
\text { Calzada 81; MEXU }\end{array}$ \\
\hline $\begin{array}{l}\text { Pteris orizabae M. Martens } \\
\& \text { Galeotti }\end{array}$ & $100-1525$ & $\begin{array}{l}\text { BMM, } \\
\text { BP-BQ, } \\
\text { VA }\end{array}$ & $\mathrm{T}$ & & V & $\mathrm{M}, \mathrm{CA}$ & $\begin{array}{l}\text { Chis, DF, Gro, } \\
\text { Hgo, Jal, Méx, } \\
\text { Mich, Mor, Oax, } \\
\text { Pue, Qro, Ver. }\end{array}$ & r & $\begin{array}{l}\text { T. Krömer \& A. } \\
\text { Acebey } 2505 ; \\
\text { MEXU, UC }\end{array}$ \\
\hline Pteris podophylla Sw. & 960 & ECO & $\mathrm{T}$ & & V & $\mathrm{M}, \mathrm{CA}, \mathrm{AN}, \mathrm{SA}$ & $\begin{array}{l}\text { Chis, Gro, Jal, } \\
\text { Oax, Pue, Ver. }\end{array}$ & r & $\begin{array}{l}\text { R. Ortega et al. } \\
1161 ; \text { XAL }\end{array}$ \\
\hline Pteris pulchra Schltdl. \& Cham. & $350-1010$ & $\begin{array}{l}\text { SAP, ECO, } \\
\text { VA, VS }\end{array}$ & $\mathrm{T}$ & & $\mathrm{S}$ & $\mathrm{M}, \mathrm{CA}, \mathrm{nSA}$ & $\begin{array}{l}\text { Chis, Gro, Hgo, } \\
\text { Oax, Pue, Qro, } \\
\text { SLP, Ver. }\end{array}$ & r & $\begin{array}{l}\text { T. Krömer \& A. } \\
\text { Acebey 2153; } \\
\text { MEXU, UC }\end{array}$ \\
\hline Pteris quadriaurita Retz. & $550-940$ & SAP, ECO & $\mathrm{T}$ & & $\mathrm{S}$ & $\operatorname{Cos}$ & $\begin{array}{l}\text { Chis, Col, Gro, } \\
\text { Hgo, Jal, Méx, } \\
\text { Mich, Mor, Nay, } \\
\text { Oax, Qro, SLP, } \\
\text { Tam, Ver. }\end{array}$ & $\mathrm{mr}$ & $\begin{array}{l}\text { T. Krömer \& A. } \\
\text { Acebey } 2145 ; \\
\text { MEXU, UC }\end{array}$ \\
\hline $\begin{array}{l}\text { Scoliosorus ensiformis } \\
\text { (Hook.) T. Moore }\end{array}$ & $\begin{array}{l}200(740- \\
1600)\end{array}$ & $\begin{array}{l}\text { SMP, ECO, } \\
\text { BMM }\end{array}$ & E & & V & $\mathrm{M}, \mathrm{CA}$ & $\begin{array}{l}\text { Chis, Gro, Oax, } \\
\text { Pue, SLP, Ver. }\end{array}$ & & $\begin{array}{l}\text { T. Krömer \& A. } \\
\text { Acebey 1994; } \\
\text { MEXU, UC }\end{array}$ \\
\hline
\end{tabular}


Apéndice 1. Continuación

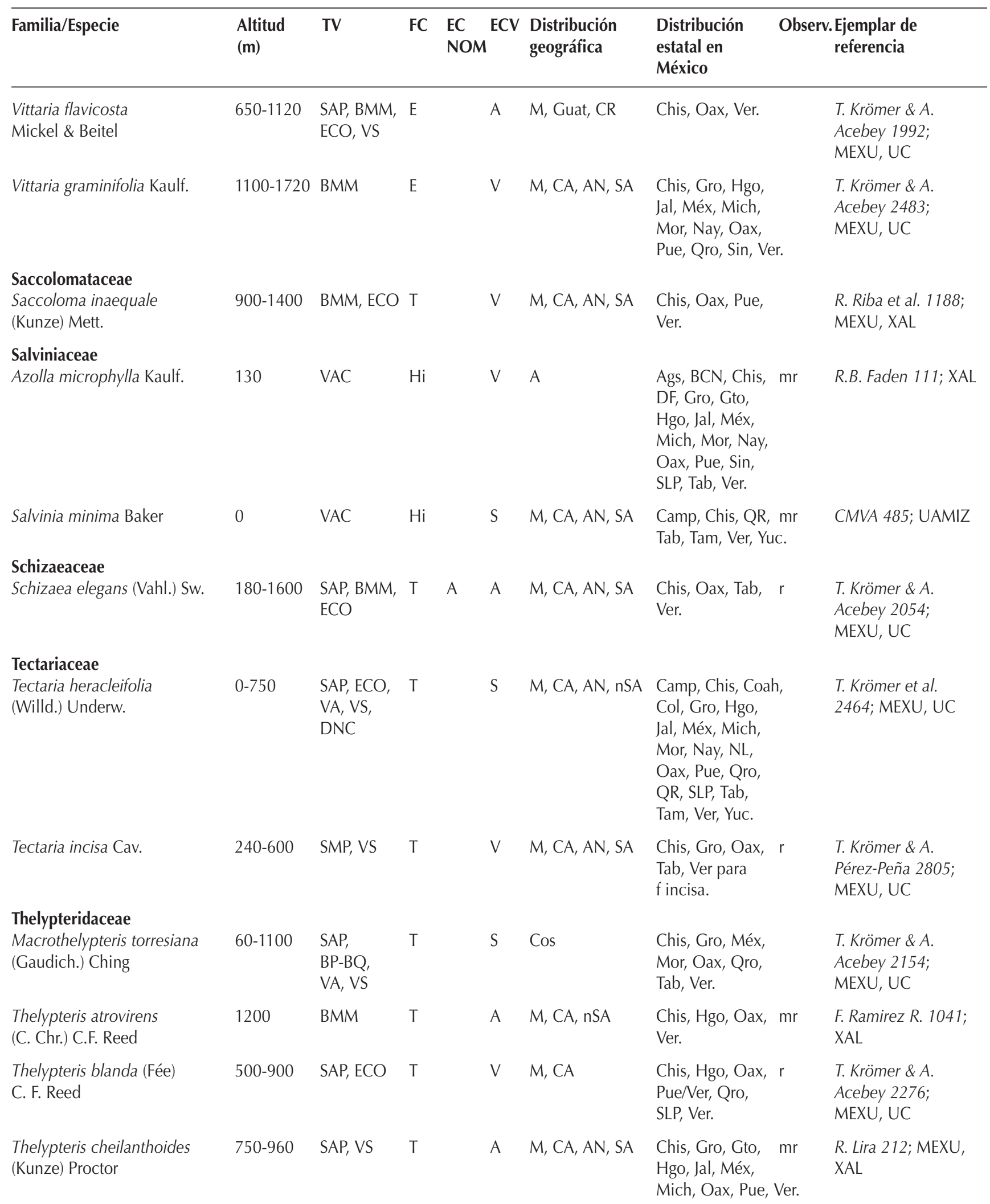


Apéndice 1. Continuación

\begin{tabular}{|c|c|c|c|c|c|c|c|c|c|}
\hline Familia/Especie & $\begin{array}{l}\text { Altitud } \\
(\mathrm{m})\end{array}$ & TV & FC & $\begin{array}{l}\mathrm{EC} \\
\text { NOM }\end{array}$ & ECV & $\begin{array}{l}\text { Distribución } \\
\text { geográfica }\end{array}$ & $\begin{array}{l}\text { Distribución } \\
\text { estatal en } \\
\text { México }\end{array}$ & Obse & $\begin{array}{l}\text { Ejemplar de } \\
\text { referencia }\end{array}$ \\
\hline $\begin{array}{l}\text { Thelypteris dentata (Forssk.) } \\
\text { E. P. St. John }\end{array}$ & $60-1240$ & BMM, VA & $\mathrm{T}$ & & V & $\operatorname{Cos}$ & \multicolumn{2}{|l|}{$\begin{array}{l}\text { Camp, Chis, Col, } \\
\text { Gro, Mor, Oax, } \\
\text { Pue, Qro, QR, } \\
\text { Tab, Ver, Yuc. }\end{array}$} & $\begin{array}{l}\text { T. Krömer \& A. } \\
\text { Acebey } 2157 ; \\
\text { MEXU, UC }\end{array}$ \\
\hline Thelypteris hatchii A.R. Sm. & $700-920$ & SAP, ECO & $\mathrm{T}$ & & A & $\mathrm{M}, \mathrm{CA}$ & Chis, Oax, Ver. & $\mathrm{mr}$ & $\begin{array}{l}\text { A. Gómez-Pompa } \\
\text { et al. 5456; XAL }\end{array}$ \\
\hline $\begin{array}{l}\text { Thelypteris hispidula } \\
\text { (Decne.) C.F. Reed }\end{array}$ & 150 & VS & $\mathrm{T}$ & & V & $\operatorname{Cos}$ & $\begin{array}{l}\text { Chis, Col, Jal, } \\
\text { Mich, Nay, Oax, } \\
\text { Sin, SLP, Son, } \\
\text { Tab, Tam, Ver. }\end{array}$ & $\mathrm{mr}$ & $\begin{array}{l}\text { G. Martínez C. 2182; } \\
\text { MEXU, MO, XAL }\end{array}$ \\
\hline $\begin{array}{l}\text { Thelypteris imbricata } \\
\text { (Liebm.) C. F. Reed }\end{array}$ & $190-250$ & SAP, VS & $\mathrm{T}$ & & V & $\mathrm{M}, \mathrm{CA}$ & $\begin{array}{l}\text { Chis, Col, Gro, } \\
\text { Jal, Nay, Oax, } \\
\text { Tab, Ver. }\end{array}$ & $\mathrm{mr}$ & $\begin{array}{l}\text { T. Krömer et al. } \\
\text { 2449; MEXU, UC }\end{array}$ \\
\hline $\begin{array}{l}\text { Thelypteris meniscioides } \\
\text { (Liebm.) C. F. Reed }\end{array}$ & $100-900$ & $\begin{array}{l}\text { SAP, BMM, } \\
\text { BP-BQ, BP, } \\
\text { ECO, VR, } \\
\text { SMP }\end{array}$ & $\mathrm{T}$ & & A & M, Guat & $\begin{array}{l}\text { Chis, Oax, Tab, } \\
\text { Ver. }\end{array}$ & & $\begin{array}{l}\text { T. Krömer \& E. Otto } \\
\text { 2834; MEXU, UC }\end{array}$ \\
\hline Thelypteris patens (Sw.) Small & $140-150$ & SAP & $\mathrm{T}$ & & A & $\mathrm{M}, \mathrm{CA}, \mathrm{AN}, \mathrm{SA}$ & $\begin{array}{l}\text { Camp, Chis, Gro, } \\
\text { Hgo, Mich, Oax, } \\
\text { Qro, QR, Tab, Ver }\end{array}$ & & $\begin{array}{l}\text { F. Vázquez B. 761; } \\
\text { XAL }\end{array}$ \\
\hline $\begin{array}{l}\text { Thelypteris paucipinnata } \\
\text { (Donn. Sm.) C.F. Reed }\end{array}$ & $740-1400$ & $\begin{array}{l}\mathrm{ECO}, \\
\mathrm{BP}-\mathrm{BQ}, \\
\mathrm{BMM}\end{array}$ & $\mathrm{T}$ & & A & M, Guat, Bel & Chis, Oax, Ver. & r & $\begin{array}{l}\text { T. Krömer \& A. } \\
\text { Acebey 2004; } \\
\text { MEXU, UC }\end{array}$ \\
\hline $\begin{array}{l}\text { Thelypteris pilosohispida } \\
\text { (Hook.) Alston }\end{array}$ & 1250 & BMM & $\mathrm{T}$ & & A & $\mathrm{M}, \mathrm{CA}, \mathrm{AN}, \mathrm{SA}$ & $\begin{array}{l}\text { Chis, Oax, Pue, } \\
\text { Ver. }\end{array}$ & $\mathrm{mr}$ & $\begin{array}{l}\text { R. Lira 18; MEXU, } \\
\text { UAMIZ, XAL }\end{array}$ \\
\hline $\begin{array}{l}\text { Thelypteris resiliens } \\
\text { (Maxon) A. R. Sm. }\end{array}$ & $450-650$ & SAP & $\mathrm{T}$ & & $P$ & $\begin{array}{l}\text { M, Guat, Bel, } \\
\text { Hon }\end{array}$ & $\begin{array}{l}\text { Chis, Oax, Tab, } \\
\text { Ver. }\end{array}$ & r & $\begin{array}{l}\text { T. Krömer \& A. } \\
\text { Acebey } 2274 ; \\
\text { MEXU, UC }\end{array}$ \\
\hline $\begin{array}{l}\text { Thelypteris resinifera } \\
\text { (Desv.) Proctor }\end{array}$ & $150-950$ & $\begin{array}{l}\text { ECO, VA, } \\
\text { VR }\end{array}$ & $\mathrm{T}$ & & S & $\begin{array}{l}\text { USA (Fla), M, } \\
\text { CA, AN, nSA }\end{array}$ & $\begin{array}{l}\text { Chis, Col, Gro, } \\
\text { Jal, Méx, Mich, } \\
\text { Mor, Oax, Pue, } \\
\text { Qro, Tab, Ver. }\end{array}$ & r & $\begin{array}{l}\text { T. Krömer \& A. } \\
\text { Pérez-Peña 2782; } \\
\text { MEXU }\end{array}$ \\
\hline $\begin{array}{l}\text { Thelypteris rhachiflexuosa } \\
\text { Riba }\end{array}$ & $180-400$ & $\begin{array}{l}\text { SAP, VA, } \\
\text { VS, }\end{array}$ & $\mathrm{T}$ & & A & M (endémica) & Chis, Ver & & $\begin{array}{l}\text { T. Krömer \& A. } \\
\text { Acebey 2309; } \\
\text { MEXU, UC }\end{array}$ \\
\hline $\begin{array}{l}\text { Thelypteris schaffneri (Fée) } \\
\text { C. F. Reed }\end{array}$ & са. 700 & $\mathrm{ECO}$ & $\mathrm{T}$ & & A & M (endémica) & $\begin{array}{l}\text { Qro, SLP, Tam, } \\
\text { Ver }\end{array}$ & $\mathrm{mr}$ & $\begin{array}{l}\text { L. Scheinvar et al. } \\
678 ; \text { MEXU }\end{array}$ \\
\hline $\begin{array}{l}\text { Thelypteris serrata } \\
\text { (Cav.) Alston }\end{array}$ & $50-770$ & SAP, VA & $\mathrm{T}$ & & V & $\mathrm{M}, \mathrm{CA}, \mathrm{AN}, \mathrm{SA}$ & $\begin{array}{l}\text { Chis, Gro, Nay, } \\
\text { Oax, Pue, QR, } \\
\text { Ver, Tab. }\end{array}$ & r & $\begin{array}{l}\text { R. Acosta P. et al. } \\
3173 ; \mathrm{CIB}\end{array}$ \\
\hline $\begin{array}{l}\text { Thelypteris tetragona } \\
\text { (Sw.) Small }\end{array}$ & 180 & VA & $\mathrm{T}$ & & V & $\mathrm{M}, \mathrm{CA}, \mathrm{AN}, \mathrm{SA}$ & $\begin{array}{l}\text { Camp, Chis, Col, } \\
\text { Gro, Hgo, Mich, } \\
\text { Nay, Oax, Pue, } \\
\text { Qro, QR, SLP, } \\
\text { Sin, Tab, Tam, } \\
\text { Ver, Yuc. }\end{array}$ & & $\begin{array}{l}\text { T. Krömer \& A. } \\
\text { Acebey 2311; } \\
\text { MEXU, UC }\end{array}$ \\
\hline
\end{tabular}


Apéndice 1. Continuación

\begin{tabular}{|c|c|c|c|c|c|c|c|c|c|}
\hline Familia/Especie & $\begin{array}{l}\text { Altitud } \\
(\mathrm{m})\end{array}$ & TV & FC & $\begin{array}{l}\text { EC } \\
\text { NOM }\end{array}$ & ECV & $\begin{array}{l}\text { Distribución } \\
\text { geográfica }\end{array}$ & $\begin{array}{l}\text { Distribución } \\
\text { estatal en } \\
\text { México }\end{array}$ & Obser & $\begin{array}{l}\text { v. Ejemplar de } \\
\text { referencia }\end{array}$ \\
\hline $\begin{array}{l}\text { Thelypteris tuxtlensis T. } \\
\text { Krömer, Acebey \& A.R. Sm. }\end{array}$ & $920-1100$ & BMM, ECO & $\mathrm{T}$ & & $\mathrm{P}$ & M (endémica) & Ver & & $\begin{array}{l}\text { T. Krömer \& A. } \\
\text { Acebey } 2475 ; \\
\text { MEXU, UC, XAL }\end{array}$ \\
\hline $\begin{array}{l}\text { Woodsiaceae } \\
\text { Diplazium donnell-smithii } \\
\text { Christ }\end{array}$ & $180-480$ & SAP, VS & $\mathrm{T}$ & & A & $\mathrm{M}, \mathrm{CA}$ & Oax, Ver & $\mathrm{mr}$ & $\begin{array}{l}\text { T. Krömer \& A. } \\
\text { Pérez-Peña 2743; } \\
\text { MEXU, UC }\end{array}$ \\
\hline $\begin{array}{l}\text { Diplazium drepanolobium } \\
\text { A.R. Sm. }\end{array}$ & $150-520$ & SAP & $\mathrm{T}$ & & A & $\mathrm{M}, \mathrm{CA}$ & $\begin{array}{l}\text { Chis, Oax, Tab, } \\
\text { Ver }\end{array}$ & & $\begin{array}{l}\text { T. Krömer \& A. } \\
\text { Acebey } 2719 ; \\
\text { MEXU, UC }\end{array}$ \\
\hline Diplazium franconis Liebm. & $450-1250$ & SAP, BMM & $\mathrm{T}$ & & V & $\mathrm{M}, \mathrm{CA}$ & $\begin{array}{l}\text { Chis, Gro, Hgo, } \\
\text { Méx, Mich, Mor, } \\
\text { Oax, Pue, Qro, } \\
\text { SLP, Ver }\end{array}$ & NT, r & $\begin{array}{l}\text { T. Krömer \& A. } \\
\text { Acebey 2560; } \\
\text { MEXU, UC }\end{array}$ \\
\hline $\begin{array}{l}\text { Diplazium lonchophyllum } \\
\text { Kunze }\end{array}$ & $50-370$ & $\begin{array}{l}\text { SAP, VA, } \\
\text { VS }\end{array}$ & $\mathrm{T}$ & & S & $\mathrm{M}, \mathrm{CA}, \mathrm{nSA}$ & $\begin{array}{l}\text { Chis, Col, Gro, } \\
\text { Hgo, Jal, Méx, } \\
\text { Mich, Mor, Nay, } \\
\text { NL, Oax, Qro, } \\
\text { Tab, Ver }\end{array}$ & & $\begin{array}{l}\text { T. Krömer \& A. } \\
\text { Acebey } 2720 ; \\
\text { MEXU, UC }\end{array}$ \\
\hline $\begin{array}{l}\text { Diplazium plantaginifolium } \\
\text { (L.) Urb }\end{array}$ & $450-700$ & SAP & $\mathrm{T}$ & & V & $\mathrm{M}, \mathrm{CA}, \mathrm{AN}, \mathrm{SA}$ & $\begin{array}{l}\text { Chis, Oax, Pue, } \\
\text { Ver }\end{array}$ & $\mathrm{mr}$ & $\begin{array}{l}\text { F. Ramírez R. } \\
\text { 1098; XAL }\end{array}$ \\
\hline $\begin{array}{l}\text { Diplazium striatastrum } \\
\text { Lellinger }\end{array}$ & $970-1190$ & BMM, ECO & $\mathrm{T}$ & & A & $\mathrm{M}, \mathrm{CA}, \mathrm{nSA}$ & $\begin{array}{l}\text { Chis, Hgo, Oax, } \\
\text { Qro, Ver }\end{array}$ & NT, r & $\begin{array}{l}\text { T. Krömer \& A. } \\
\text { Acebey } 2514 ; \\
\text { MEXU, UC }\end{array}$ \\
\hline $\begin{array}{l}\text { Diplazium striatum (L.) } \\
\text { C. Presl }\end{array}$ & 980 & BMM & $\mathrm{T}$ & & V & $\mathrm{M}, \mathrm{CA}, \mathrm{AN}, \mathrm{SA}$ & $\begin{array}{l}\text { Chis, Gro, Oax, } \\
\text { Pue, Tab, Ver }\end{array}$ & $\mathrm{mr}$ & $\begin{array}{l}\text { T. Krömer et al. } \\
\text { 2582; MEXU, UC }\end{array}$ \\
\hline Diplazium ternatum Liebm. & $850-1440$ & $\mathrm{ECO}, \mathrm{BMM}$ & $\mathrm{T}$ & & V & $\mathrm{M}, \mathrm{CA}$ & $\begin{array}{l}\text { Chis, Gro, Hgo, } \\
\text { Oax, Pue, Ver }\end{array}$ & & $\begin{array}{l}\text { R. Riba 1160; } \\
\text { MEXU, UAMIZ }\end{array}$ \\
\hline Diplazium urticifolium Christ & $850-1300$ & BMM, ECO & $\mathrm{T}$ & & V & $\mathrm{M}, \mathrm{CA}$ & $\begin{array}{l}\text { Chis, Oax, Pue, } \\
\text { Ver. }\end{array}$ & r & $\begin{array}{l}\text { T. Krömer \& A. } \\
\text { Acebey } 2485 ; \\
\text { MEXU, UC }\end{array}$ \\
\hline
\end{tabular}


Apéndice 2. Listado de especies citadas para la región de Los Tuxtlas (Lira y Riba, 1984; Riba y Pérez-García, 1997, Ramírez, 1999, Tejero-Diéz et al., 2011) excluídas por este trabajo.

\begin{tabular}{|c|c|c|}
\hline Determinaciones erróneas & $\begin{array}{l}\text { Lista de especies dudosas } \\
\text { no confirmadas }\end{array}$ & $\begin{array}{l}\text { Lista de especies fuera } \\
\text { de los límites de la RBLT }\end{array}$ \\
\hline Adiantum tenerum Sw. & Anemia adiantifolia (L.) Sw. & Adiantum villosum $\mathrm{L}$. \\
\hline Asplenium auritum Sw. & Anemia oblongifolia (Cav.) Sw. & Camplyoneurum costatum (Kunze) C.Presl \\
\hline Asplenium hoffmannii Hieron. & Asplenium laetum Sw. & Ceratopteris pteridoides (Hook.) Hieron. \\
\hline Asplenium otites Link & Blechnum caudatum Cav. & Dicranopteris flexuosa (Schrad.) Underw. \\
\hline Blechnum falciforme (Liebm.) C.Chr. & Cibotium schiedei Schltdl. \& Cham. & Elaphoglossum tejeroanum A.Rojas \\
\hline Bolbitis aliena (Sw.) Alston & $\begin{array}{l}\text { Cyathea fulva (M.Martens \& } \\
\text { Galeotti) Fée }\end{array}$ & Lindsaea arcuata Kunze \\
\hline Bolbitis nicotianifolia (Sw.) Alston & Cyathea microdonta (Desv.) Domin & Lindsaea stricta (Sw.) Dryand var. stricta \\
\hline $\begin{array}{l}\text { Cochlidium rostratum (Hook.) Maxon } \\
\text { ex C.Chr. }\end{array}$ & Cyathea myosuroides (Liebm.) Domin & Lindsaea lancea (L.) Bedd. \\
\hline $\begin{array}{l}\text { Ctenitis subincisum (Willd.) A.R.Sm. } \\
\text { \& R.C.Moran (nombre mal escrito por } \\
\text { Megalastrum subincisum (Willd.) } \\
\text { A.R.Sm. \& R.C.Moran }\end{array}$ & $\begin{array}{l}\text { Elaphoglossum obscurum } \\
\text { (E.Fourn.) C.Chr. }\end{array}$ & Loxogramme mexicana (Fée) C.Chr. \\
\hline Danaea elliptica Sm. & $\begin{array}{l}\text { Elaphoglossum eximium } \\
\text { (Mett.) Christ }\end{array}$ & Lycopodium clavatum L. \\
\hline $\begin{array}{l}\text { Dennstaedtia obtusifolia (Humb. } \\
\text { \& Bonpl. ex Willd.) T.Moore }\end{array}$ & $\begin{array}{l}\text { Hemidictyum marginatum } \\
\text { (L.) C.PresI }\end{array}$ & Lygodium volubile Sw. \\
\hline Diplazium cristatum (Desr.) Alston & $\begin{array}{l}\text { Hymenophyllum tegularis } \\
\text { (Desv.) Proctor \& Lourteig }\end{array}$ & $\begin{array}{l}\text { Osmunda regalis L. var. spectabilis } \\
\text { (Willd.) A.Gray }\end{array}$ \\
\hline Elaphoglossum latifolium (Sw.) J.Sm. & Phanerophlebia gastonyi Yatsk. & Plagiogyria pectinata (Liebm.) Lellinger \\
\hline Grammitis basiattenuata (Jenman) Proctor & $\begin{array}{l}\text { Polybotrya polybotryoides } \\
\text { (Baker) Christ. }\end{array}$ & Polypodium remotum Desv. \\
\hline $\begin{array}{l}\text { Huperzia orizabae (Underw. \& F.E. } \\
\text { Lloyd) Holub }\end{array}$ & Polypodium cryptocarpon Fée & Pteris propinqua J.Agardh \\
\hline $\begin{array}{l}\text { Hymenophyllum hirsitum (L.) Sw. = } \\
\text { Hymenophyllum hirsutum (L.) Sw. }\end{array}$ & Psilotum complanatum Sw. & Pteris pungens Willd. \\
\hline Hypolepis repens (L.) C. Presl & $\begin{array}{l}\text { Pteridium aquilinum var. feei (W. } \\
\text { Schaffn. Ex Fée) Maxon ex Yunck. }\end{array}$ & Saccoloma elegans Kaulf. \\
\hline Hypolepis nigrescens Hook. & $\begin{array}{l}\text { Pteridium arachnoideum } \\
\text { (Kaulf.) Maxon }\end{array}$ & Selaginella sellowii Hieron. \\
\hline $\begin{array}{l}\text { Megalastrum atrogriseum (C.Chr.) } \\
\text { A.R.Sm. \& R.C.Moran }\end{array}$ & $\begin{array}{l}\text { Selaginella delicatissima Linden } \\
\text { ex A.Braun }\end{array}$ & Thelypteris angustifolia (Willd.) Proctor \\
\hline $\begin{array}{l}\text { Megalastrum subincisum (Willd.) } \\
\text { A.R.Sm. \& R.C.Moran }\end{array}$ & Selaginella porphyrospora A. Braun & Thelypteris falcata (Liebm.) R.M.Tryon \\
\hline Marattia alata Sw. & Selaginella schiedeana A.Braun & Trichomanes pinnatum Hedw. \\
\hline Nephrolepis exaltata (L.) Schott & Selaginella sertata Spring & \\
\hline N. biserrata (Sw.) Schott & Selaginella tenella (P.Beauv.) Spring & \\
\hline N. rivularis (Vahl) Mett. ex Krug & Thelypteris balbisii (Spreng.) Ching & \\
\hline $\begin{array}{l}\text { Pecluma plumula (Humb. \& Bonpl. } \\
\text { ex Willd.) M.G.Price }\end{array}$ & Thelypteris rudis (Kunze) Proctor & \\
\hline Phlebodium aureum (L.) J.Sm. & & \\
\hline Phlebodium decumanum (Willd.) J.Sm. & & \\
\hline Polypodium aureum L. & & \\
\hline Polypodium dissimile L. & & \\
\hline Polypodium loriceum L. & & \\
\hline Polypodium rzedowskianum Mickel & & \\
\hline Selaginella mollis A.Braun & & \\
\hline $\begin{array}{l}\text { Selaginella pulcherrima Liebm. ex E.Fourn. } \\
\text { Vittaria lineata (L.) Sm. }\end{array}$ & & \\
\hline
\end{tabular}


Apéndice 3. Listado de sinónimos de especies incluídas en este trabajo que formaron parte de listados anteriores (Lira y Riba, 1984; Riba y Pérez-García, 1997, Ramírez, 1999).

\section{Sinónimos}

Adiantum princeps T.Moore $=$ Adiantum amplum C.Pres

Anthrophyum ensiforme Hook. in Bentham = Scoliosorus ensiformis (Hook.) T.Moore

Antrophyum lanceolatum (L.) Kaulf. = Polytaenium feei (W.Schaffn. ex Fée) Maxon

Asplenium lacerum Schltdl. \& Cham $=$ Asplenium cuspidatum Lam.

Asplenium pyramidatum Liebm. $=$ Asplenium cuspidatum Lam.

Asplenium conquisitum Underw. \& Maxon ex Christ = Asplenium rutaceum (Willd.) Mett.

Asplenium repandulum Kunze $=$ Hymenasplenium riparium (Liebm.) L.Regalado \& Prada

Blechnum fraxineum auct. non Willd. = Blechnum gracile Kaulf.

Blechnum varians (E. Fourn.) C.Chr. = Blechnum schiedeanum (Schltdl. ex C.Presl) Hieron.

Grammitis xiphopteroides (Liebm.) A.R.Sm. = Melpomene xiphopteroides (Liebm.) A.R.Sm. \& R.C.Moran

Nephrolepis multiflora (Roxb.) F.M.Jarrett ex C.V.Morton = Nephrolepis brownii (Desv.) Hovenkamp \& Miyam.

Pleopeltis revoluta (Spreng. ex Willd.) A.R.Sm. = Pleopeltis astrolepis (Liebm.) E.Fourn.

Polypodium consimile Mett. $=$ Pecluma consimilis (Mett.) M.G.Price

Polypodium polypodioides (L.) Watt = Pleopeltis polypodioides (L.) E.G. Andrews \& Windham

Pteris mexicana (Fée) E.Fourn. = Pteris pulchra Schltdl. \& Cham.

Selaginella galeottii Spring = Selaginella stellata Spring

Vittaria costata Kunze = Ananthacorus angustifolius (Sw.) Underw. \& Maxon in Maxon

Vittaria dimorpha Müll. Berol. = Vittaria graminifolia Kaulf. 